\title{
SELF-SENSING CEMENTITIOUS COMPOSITES WITH GRAPHENE NANOPLATELETS
}

\author{
A Thesis \\ by \\ ZHANGFAN JIANG \\ Submitted to School of Engineering and Applied Science of \\ University of Virginia \\ In partial fulfillment of the requirements of the degree of \\ MASTER OF SCIENCE \\ in \\ Civil Engineering
}

April 2017 


\title{
SELF-SENSING CEMENTITIOUS COMPOSITES WITH GRAPHENE NANOPLATELETS
}

\author{
A Thesis \\ by \\ ZHANGFAN JIANG \\ Submitted to School of Engineering and Applied Science of \\ University of Virginia \\ In partial fulfillment of the requirements of the degree of \\ MASTER OF SCIENCE \\ in \\ Civil Engineering
}

Approved by:

Chair of Committee,

Devin K. Harris

Committee Members,

Osman E. Ozbulut

Jose Gomez

Chair of Department, Brian Smith

April 2017 


\section{ABSTRACT}

Traditional strategies in structural health monitoring of civil infrastructure systems involve a limited number of distributed sensors over a relatively large area. The high cost, low durability, and weak compatibility with host structure are among the challenges for conventional sensors. Cement-based self-sensing composites with intrinsic strain- and damage-sensing capabilities can be a more practical and sustainable alternative to monitor the health of concrete structures. Numerous research studies have been conducted to explore behavior of self-sensing cementitious composites with different functional fillers. Most of previous studies investigated the use of fillers such as carbon fiber (CF), carbon nanofiber (CNF), and carbon nanotubes (CNTs) in cement composites as a method to develop multifunctionality in the base material. More recently, graphene nanoplatelets (GNPs), which have very thin (several layer thickness of graphene sheet) but wide aspect ratio, are gaining traction in the graphene market due to their advantages such as ease of processing and excellent material properties at a very low cost. However, the understanding of behavior of cementitious composites with GNPs is still in its infancy. In addition, although a large number of efforts have been made to develop intrinsically self-sensing cementitious materials with different nano fillers, fewer efforts have been made to find simple, repeatable, and large-scale fabrication procedures of these multifunctional composites. Therefore, there is a need for further research on the practical and scalable fabrication methods for the development of cement-based self-sensing composites using GNPs.

The objective of this study is to explore the development of self-sensing cementitious composites with GNPs using a simple fabrication method and investigate the piezoelectric characteristics of the developed composites. Systematic studies were conducted to determine the influence of GNP concentration ratio and mixing method on the electrical conductivity of GNPbased self-sensing cementitious composites. In particular, two fabrication methods that do not require any special treating procedure such as ultrasonication and covalent treatment were considered. For the detection of percolation threshold, which roughly represents the optimal quantity of the GNPs required achieving satisfactory self-sensing, the specimens with various GNP concentration were prepared. For measuring the electrical resistivity, four copper meshes were used as electrodes and embedded into the specimens immediately after casting. Cyclic compression tests were conducted to explore piezoresistive behavior of the specimens with 
different GNP concentrations. To better assess the GNP dispersion at the specimens prepared using different mixing method, scanning electron microscopy images of the tested specimens were taken. Results revealed that the GNP-reinforced cementitious composites exhibit good piezoresistive behavior with high gage factors up to 125 under cyclic compressive loads when the GNP ratio exceeds $5 \%$ by weight of cement. Recommendations for further investigations to fully characterize both mechanical and piezoresistive behavior of GNP-reinforced cement composites were provided. 


\section{DEDICATION}

To my parents, Guoping Jiang and Huijun Zhang, and my best friend, Li Ding, for their endless support and company. 


\section{ACKNOWLEDGEMENTS}

I would like to thank the faculty and staff of the Department of Civil Engineering of University of Virginia, the Virginia Transportation Research Council. In particular, I would like to express my most sincere gratitude to my advisor, Dr. Osman Ozbulut, for his guidance and support throughout my thesis work. In addition, I would also like to thank Dr. Devin Harris and Dr. Gomez for serving on my thesis defense committee.

I am grateful to Dr. Richard White and Mr. Joe Thompson for their technical support on ultrasonicator and SEM test. I would also like to thank Mr. Arthur W. Ordel for guiding me on the operation of MTS machine. I would like to express my deepest appreciation to my laboratory mates, Mr. Muhammad M. Sherif, Mr. Sherif Daghash, Ms. Radhika Pavgi, for their support on my research. In the end, I would like to thank to my family for their ceaseless support. 


\section{NOMENCLATURE}

$\begin{array}{ll}\text { SHM } & \text { Structure health monitoring } \\ \text { GNP } & \text { Graphene Nanoplatelets } \\ \text { CNT } & \text { Carbon Nanotubes } \\ \text { CF } & \text { Carbon Fiber } \\ \text { CNF } & \text { Carbon Nanofiber } \\ \text { MWCNT } & \text { Multi wall Carbon Nanotube } \\ \text { DC } & \text { Direct Current } \\ \text { AC } & \text { Alternating Current } \\ \text { FCR } & \text { Fractional change in resistivity }\end{array}$




\section{TABLE OF CONTENTS}

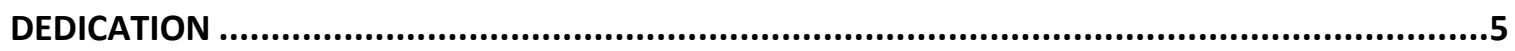

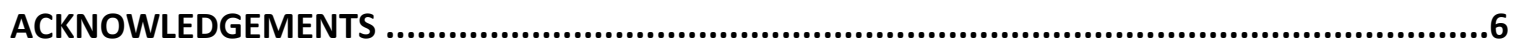

NOMENCLATURE

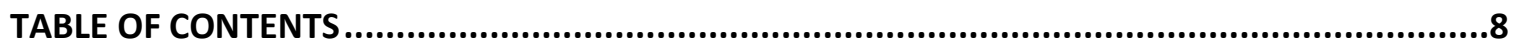

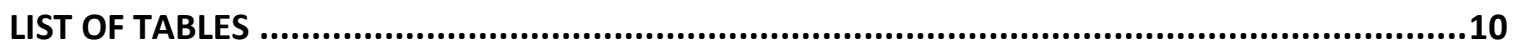

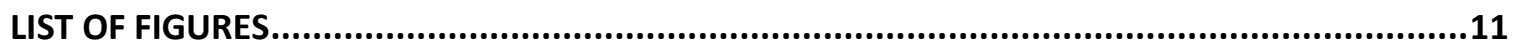

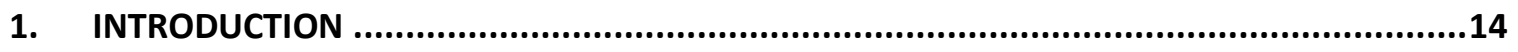

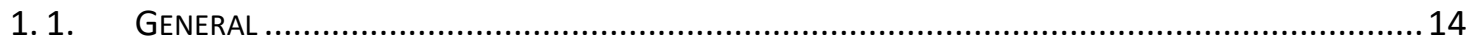

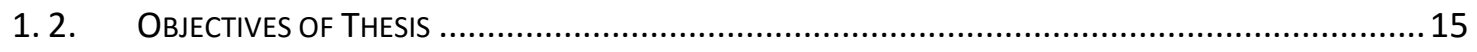

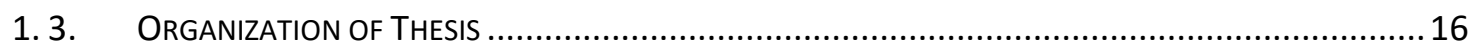

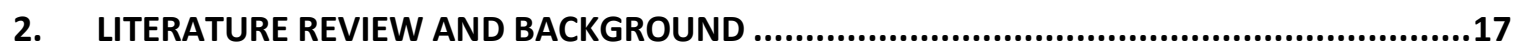

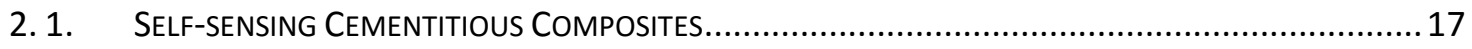

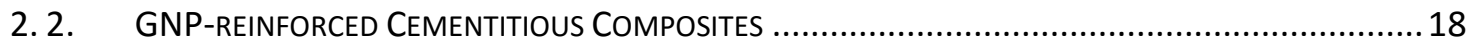

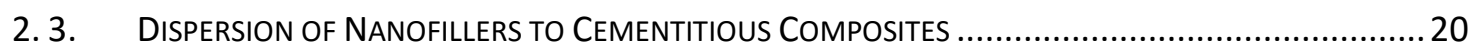

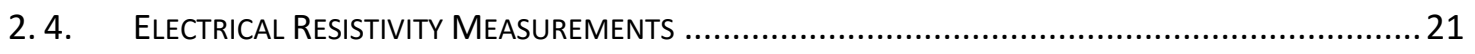

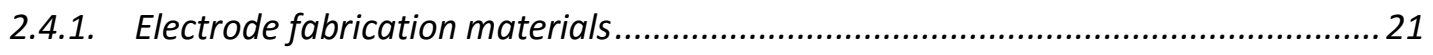

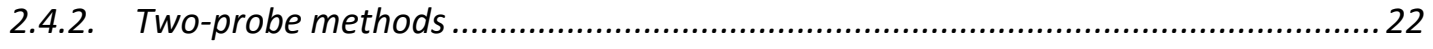

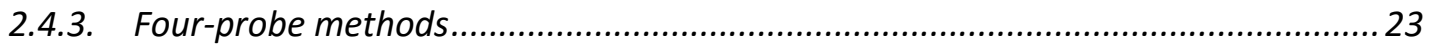

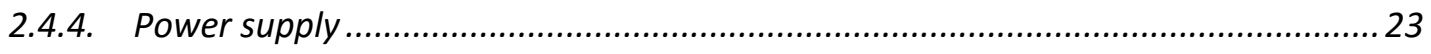

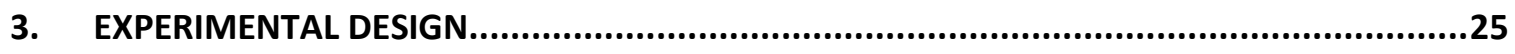

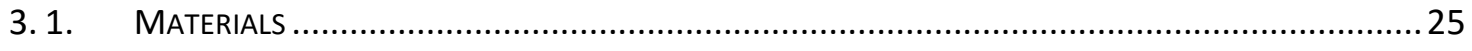

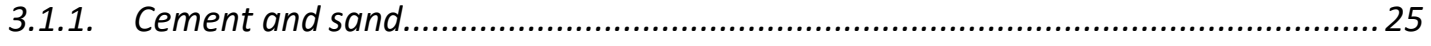

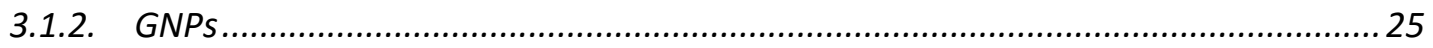

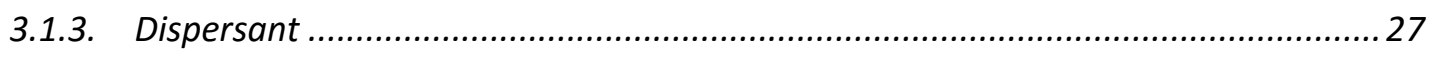

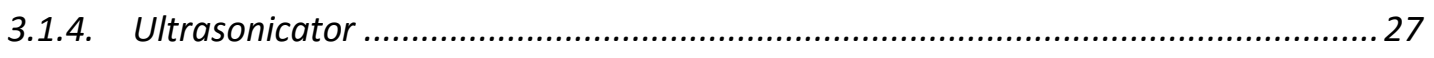

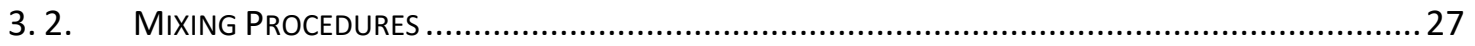

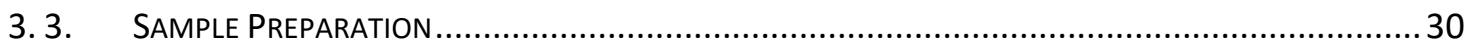

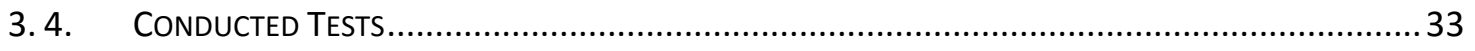




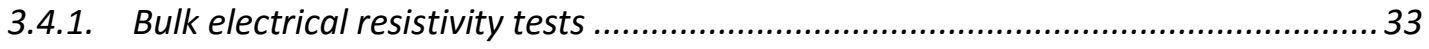

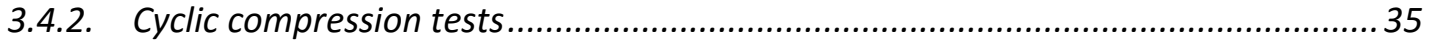

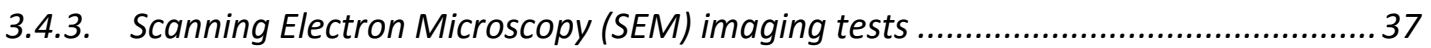

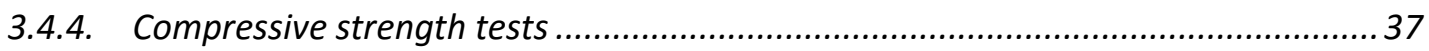

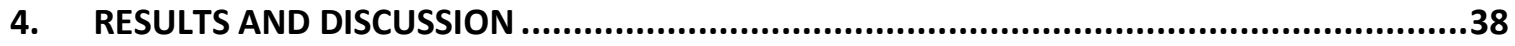

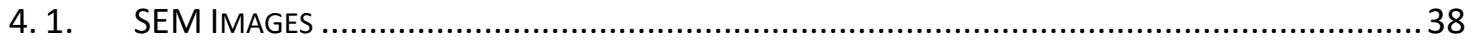

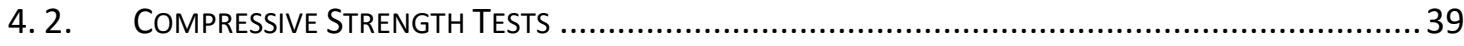

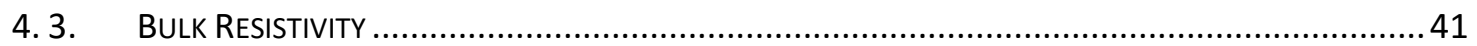

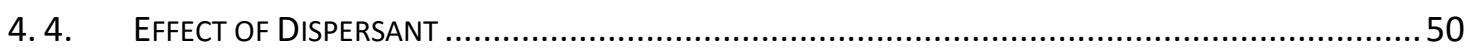

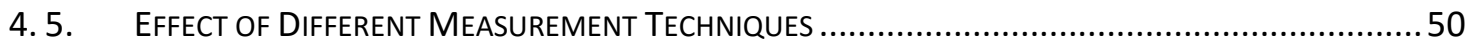

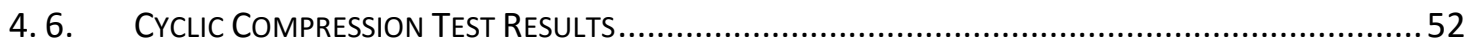

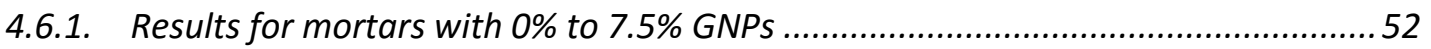

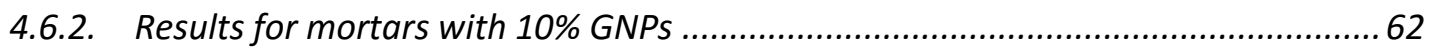

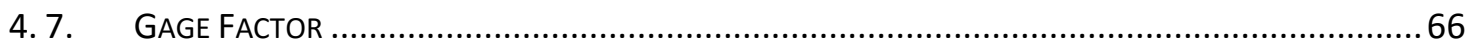

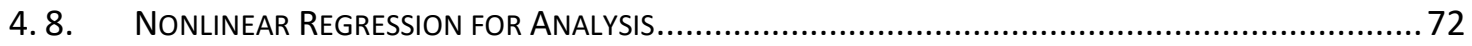

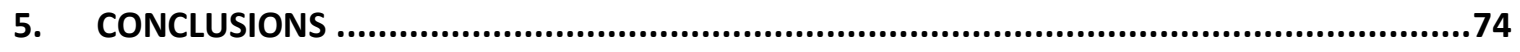

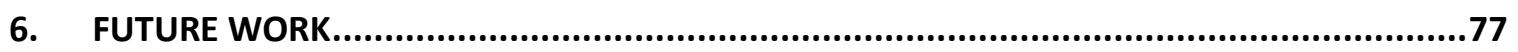

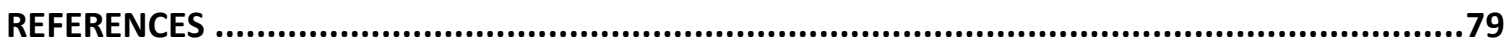




\section{LIST OF TABLES}

Table 1. Calculations of percolation thresholds for different types of GNPs .......................... 26

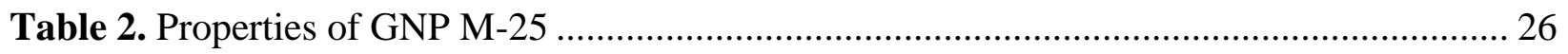

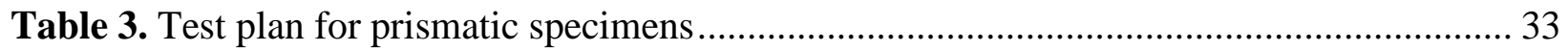

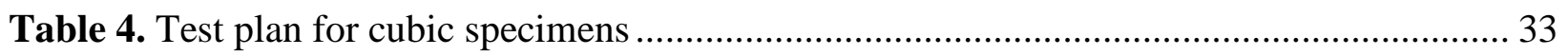

Table 5. Compressive strength of cubic specimens with varying GNP proportions cast using

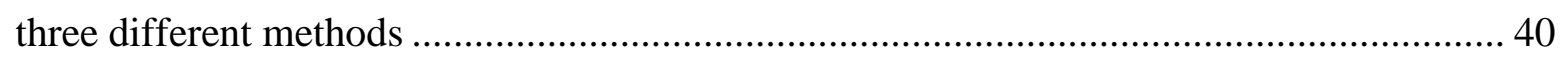

Table 6. Resistivity measurements with different methods at 28 days of specimens cast using Method I; Method II and Method III ........................................................................... 51

Table 7. Gage factor of specimens with different concentrations prepared by different mixing

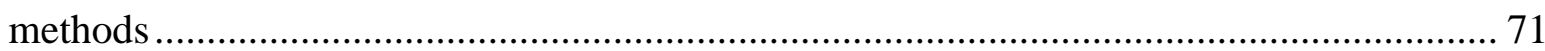




\section{LIST OF FIGURES}

Figure 1.Schematic representations of (a) Graphene, (b) single-walled CNT, (c) multi-walled CNT, and (d) GNP. 18

Figure 2. Commonly used electrode configurations for measuring specimens resistivity [3]..... 22

Figure 3. (a) two-probe method; (b) four-probe method. 23

Figure 4. Fabrication Procedures. 29

Figure 5. GNP solutions before and after dispersion via ultrasonication or high-speed shear mixing. 30

Figure 6. Prismatic specimens with (a) copper mesh and (b) copper tape .............................. 32

Figure 7. Real specimens embedded with (a) copper mesh and (b) copper tape..................... 32

Figure 8. (a) Digital multimeters; (b) Programmable power supply; (c) Resistivity meter measurements; (d) Bulk resistivity measurements with four-probe method. ...................... 34

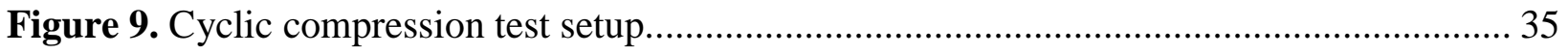

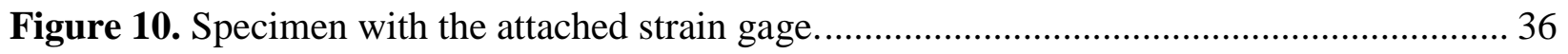

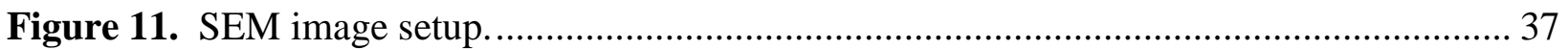

Figure 12. SEM images of specimens cast using (a) Method I; (b) Method II; (c) Method III and (d) Method III with fly ash. 39

Figure 13. Electrical resistivity of specimens cast using Method I. ....................................... 42

Figure 14. Electrical resistivity of specimens cast using Method II. .................................... 43

Figure 15. Electrical resistivity of specimens cast using Method III..................................... 44

Figure 16. Electrical resistivity of specimens cast using Method III with Fly Ash.................. 45

Figure 17. Electrical resistivity of mortar specimens with different GNP concentrations cast using (a) Method I; (b) Method II; (c) Method III and (d) Method III with Fly Ash. 47 
Figure 18. Electrical resistivity of mortar specimens with (a) 5\%; (b) $7.5 \%$ and (c) 10\% GNPs at different curing age.

Figure 19. Electrical resistivity of specimens with 2.5 GNPs dispersed with surfactant or superplasticizer using (a) Method I and (b) Method II. 50

Figure 20. Comparison of results measured using Wenner Probe and Copper meshes. 52

Figure 21. Cyclic compression response of specimens cast using Method I with (a) 0\% GNPs; (b) $0.1 \%$ GNPs; (c) $1 \%$ GNPs. 54

Figure 22. Cyclic compression response of specimens cast using Method I with (a) 2.5\% GNPs; (b) $5 \%$ GNPs; (c) $7.5 \%$ GNPs. 55

Figure 23. Cyclic compression response of specimens cast using Method II with (a) 0\% GNPs; (b) $0.1 \%$ GNPs; (c) $1 \%$ GNPs. 56

Figure 24. Cyclic compression response of specimens cast using Method II with (a) $2.5 \%$ GNPs; (b) $5 \%$ GNPs; (c) $7.5 \%$ GNPs. 57

Figure 25. Cyclic compression response of specimens cast using Method III with (a) 0\% GNPs; (b) $0.1 \%$ GNPs; (c) $1 \%$ GNPs. 58

Figure 26. Cyclic compression response of specimens cast using Method III with (a) 2.5\% GNPs; (b) 5\% GNPs; (c) 7.5\% GNPs. 59

Figure 27. Cyclic compression response of specimens cast using Method III with Fly Ash with (a) $0 \%$ GNPs; (b) $0.1 \%$ GNPs; (c) $1 \%$ GNPs. 60

Figure 28. Cyclic compression response of specimens cast using Method III with Fly Ash with (a) $2.5 \%$ GNPs; (b) $5 \%$ GNPs; (c) $7.5 \%$ GNPs. 61

Figure 29. Fractional change in resistivity of specimens in 4 hours cast using (a) Method I; (b) Method II; (c) Method III; (d) Method III with fly ash. 63

Figure 30.Cyclic compression response of specimens with $10 \%$ GNPs cast using (a) Method I; (b) Method II; (c) Method III and (d) Method III with Fly Ash. 65 
Figure 31. Strain and fractional change in resistivity of specimens with 7.5\% GNPs cast using

(a) Method I; (b) Method II; (c) Method III; (d) Method III with fly ash. 67

Figure 32. Fractional change in resistivity vs. strain of the specimens with $7.5 \%$ GNPs cast using (a) Method I; (b) Method II; (c) Method III; (d) Method III with fly ash. 68

Figure 33. Strain and fractional change in resistivity of specimens with $10 \%$ GNPs cast using (a) Method I; (b) Method II; (c) Method III; (d) Method III with fly ash. 70

Figure 34. Fractional change in resistivity vs. strain of the specimens with $10 \%$ GNPs cast using (a) Method I; (b) Method II; (c) Method III; (d) Method III with fly ash. 71

Figure 35. Fractional change in resistivity vs. strain and FCR-strain correlation of the specimens with 7.5\% GNPs cast using (a) Method I; (b) Method II; (c) Method III; (d) Method III with fly ash.

Figure 36. Fractional change in resistivity vs. strain and FCR-strain correlation of the specimens with 10\% GNPs cast using (a) Method I; (b) Method II; (c) Method III; (d) Method III with fly ash. 73 


\section{INTRODUCTION}

\section{1. General}

Cementitious composites are the most widely used materials for the design of civil structures. However, cementitious materials are brittle and susceptible to cracking and have no electrical functional properties. Numerous factors cause damage to concrete structures over their service life [1]. Rebar corrosion is a leading cause of deterioration [2-3]. In addition, seismic events may cause significant damage and failure [4]. Furthermore, as extreme weather events such as hurricanes, tropical storms, and prolonged intense temperatures occur more frequently, they are expected to considerably impact the health of concrete structures [5]. Therefore, there is a need for innovative strategies to detect damage in concrete structures and minimize potential consequences of deterioration through timely maintenance actions.

Over the past decades, structural health monitoring (SHM) systems have been developed and implemented for continuously monitoring and evaluating the state of civil infrastructure systems [6-8]. SHM systems can obtain real-time data on the condition of structures using various sensors that measure parameters such as strain, displacement, temperature, etc. Using this information, the owners and engineers can timely detect anomalies in the structural performance and carry out the required maintenance actions, improving reliability and safety. However, traditional strategies in SHM involve a limited number of distributed sensors over a relatively large area of a structure. The high cost, low durability, and weak compatibility with the host structure are among the challenges for conventional sensors. Cement-based self-sensing composites with intrinsic strain- and damage-sensing capabilities can be a more practical and sustainable alternative to monitor the health of concrete structures [9].

The strain sensing capacity of a material can be described as the response on the volumetric electrical resistivity due to its strain state. When under compression, the electric resistance on that direction decreases. On the other hand, the electrical resistance increases when the material is under tension as the fillers to separate. Since both effects are reversible in the elastic range of the material, the electrical resistance returns to its initial value upon unloading [4]. When plastic deformations are present, irreversible changes occur in electrical resistance. While the first property can be used for strain-sensing, the latter can be used for damage-sensing. 
Self-sensing cement-based composites have various advantages over traditional strain sensors such as durability, compatibility with concrete matrix, and spatially distributed measurement capability. Since the early 1990s, numerous research studies have been conducted to explore behavior of self-sensing cementitious composites with different functional fillers [3]. Most of previous studies investigated the use of fillers such as carbon fiber (CF), carbon nanofiber (CNF), and carbon nanotubes (CNTs) in cement composites as a method to develop multifunctionality in the base material [10-11]. Since its discovery in 2004, graphene has also gained significant attention as 2D nanoscale reinforcement for composite materials. Compared to the aforementioned carbon fillers, the planar structure of graphene sheets provides more contact area with the host material because of ultra-high specific surface area. However, high cost and dispersion difficulties have been cited as drawbacks of graphene. More recently, graphene nanoplatelets (GNPs), which have very thin (several layer thickness of graphene sheet) but wide aspect ratios, are gaining traction in the graphene market due to their advantages such as ease of processing and excellent material properties at a very low cost. Graphene nanoplatelets, when compared with CNTs, offer the desired mechanical and physical characteristics at about 1/500th of the cost [12]. However, the understanding of behavior of cementitious composites with GNPs is still in its infancy.

In addition, although a large number of efforts have been made to develop intrinsically self-sensing cementitious materials with different nano fillers, fewer efforts have been made to find simple, repeatable, and large-scale fabrication procedures of these multifunctional composites [13]. There is a need for further research on the practical and scalable fabrication methods that do not require special treatment procedures such as ultrasonication for the proper dispersion of the filler material.

\section{2. Objectives of Thesis}

This thesis explores the development of self-sensing cementitious composites with GNPs using a simple fabrication method and investigates the piezoelectric characteristics of the developed composites. Systematic studies were conducted to determine the influence of GNP concentration ratio and mixing method on the electrical conductivity of GNP-based self-sensing cementitious composites. In particular, two fabrication methods that do not require any special treatment procedure such as ultrasonication and covalent treatment were considered. For the 
detection of percolation threshold, which roughly represents the optimal quantity of the GNPs required achieving satisfactory self-sensing, specimens with various GNP concentration were prepared. For measuring the electrical resistivity, four copper meshes were used as electrodes and embedded into the specimens immediately after casting. In addition, copper tape was used for the electrodes and a commercial resistivity meter was used for resistivity measurements were explored. Cyclic compression tests were conducted to explore the piezoresistive behavior of specimens with different GNP concentrations. The results were analyzed to evaluate bulk resistivity and piezoresistivity of the developed cementitious composites.

\section{3. Organization of Thesis}

This thesis is organized into the following sections:

Chapter 1 describes the motivation for the research and the scope of the research. It also gives a brief description of this thesis.

Chapter 2 presents a literature review on the self-sensing and GNP-reinforced cementitious composites. It then provides some background information on dispersion of nanofillers into cementitious composites and electrical measurement methods for self-sensing composites.

Chapter 3 explains the materials and equipment used in this research, describes the three different methods used to develop GNP-reinforced cement composites, and then discusses the experimental tests conducted in this study.

Chapter 4 discusses the experimental test results and provides a discussion on the effects of measurement method and dispersant on the resistivity of the developed composites. In addition, it provides the gage factor, which relates the applied strains to change in resistivity of the material, for the developed self-sensing composites.

Chapter 5 summarizes the findings of the current study.

Chapter 6 provides recommendations for potential further research. 


\section{LITERATURE REVIEW AND BACKGROUND}

\section{1. Self-sensing Cementitious Composites}

Self-sensing cementitious composites are fabricated by adding functional fillers into conventional cement-based composites such as cement paste, mortar or concrete. Carbon nanotubes (CNT), carbon fibers (CF), carbon nanofibers (CNF), and carbon black (CB) have commonly been used as functional fillers to increase the conductivity of cementitious composites and enable the material to sense strain and monitor the damage $[3,4,9,14,15,16]$.

Dalla et al. [16] prepared mortar specimens with CNT and CNF and investigated their strain and damage sensing potentials. CNT-based and CNF-based mortar specimens were tested in cyclic compression test and fully recoverable electrical resistivity was observed. The results showed the inverse relationship between the resistivity and applied compressive load and stress. Three-point bending test were conducted to study damage sensing capability. Their results showed that a sudden increase in the resistivity at a load level below the maximum load indicated damage in the specimens.

Konsta-Gdoutos et al. [17] added different amount of CNT and CNF into cementitious composites for real time damage assessment. The results indicated that the addition of CNT and CNF were able to reduce the resistivity of cementitious materials, while better results were observed in specimens containing CNTs. The cyclic compression testing revealed that the change in the resistivity and applied load were well correlated.

Galoa et al. [4] studied the self-sensing properties of CNF reinforced cement pastes and tested prismatic specimens with different CNF dosages under compression. Wen and Chung [5] tested small beam specimens made of cement pastes with short carbon fibers under flexural load. Chen and Liu [6] investigated the damage detection capabilities of cement pastes with micro-size carbon fibers.

Several researchers fabricated individual small-size cement sensors and embedded them

into a structure. Xiao et al. [7] monitored the strain of the concrete columns under cyclic and monotonic loading using carbon black-filled cement based embedded sensors. Saafi [8] designed and fabricated a CNT-based cement sensor. The developed sensors with one electrode at each 
end were embedded into beam specimens and a wireless communication system was used to measure the response of the CNT-cement sensors. Azhari and Banthia [9] developed two cement-based sensors, one with carbon fibers alone and the other including both carbon fibers and CNTs. Under compressive loads, the response of the cement-based sensors was found to be nonlinear and rate-dependent. They also indicated that the hybrid sensor providing a better quality signal, improved reliability and increased sensitivity over sensors carrying CF alone. D'Alessandro et al. [10] studied the comparative performance of self-sensing cementitious composites with CNT and CNF inclusions. The test results showed that CNF composite sensors have a higher level of noise and a greater influence of the polarization effect.

\section{2. GNP-reinforced Cementitious Composites}

Graphene nanoplatelets are formed by several layers of graphene, which is a single-layer $\mathrm{sp}^{2}$-bonded carbon sheet. Figure 1 illustrates schematic representations of graphene, CNTs, and GNPs. GNPs are thin with a total thickness of less than $100 \mathrm{~nm}$ but have wide aspect ratios. They are less prone to agglomeration and entanglement because of their increased thickness compared to CNTs [11]. In addition, the cost of GNPs is a fraction of that of CNTs. GNPs have unique mechanical, thermal, and electrical properties that make them an ideal nano-reinforcement for cementitious composites. Although the behavior of cementitious composites with CNTs and CNFs has been extensively studied by various researchers, limited work has been reported on the use GNPs in cementitious composites $[12,13,14]$.

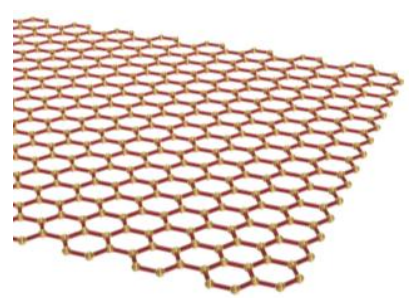

(a)

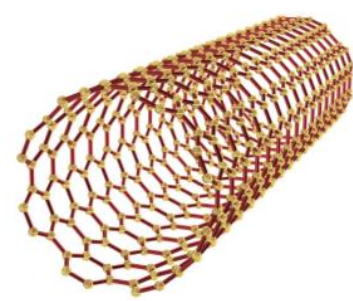

(b)

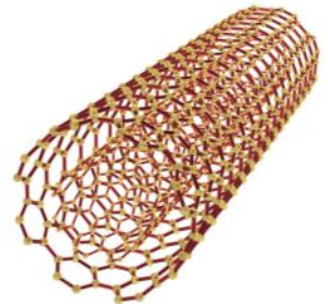

(c)

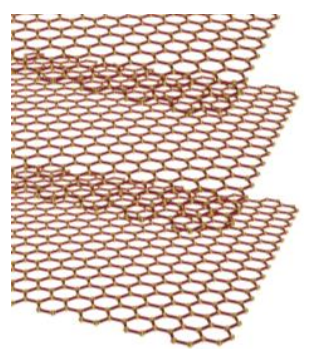

(d)

Figure 1.Schematic representations of (a) Graphene, (b) single-walled CNT, (c) multiwalled CNT, and (d) GNP.

Some researchers explored the effect of GNPs on the mechanical and transport properties of cementitious composites. Zohhadi et al. [12] investigated the use of surfactant-coated GNPs at two concentrations ( 0.05 and 0.5 by weight of the cement) in mortar cubes and cement paste 
beams. Results from compressive and flexural tests indicated that well-dispersed GNPs can improve the flexural strength of the cement paste. Wotring et al. [13] explored the effect of water reducing admixtures on GNP dispersion using scanning electron microscopy and ultravioletvisible spectroscopy. Alkhateb et al. [18] studied the behavior of cement pastes with pristine and functionalized GNPs by correlating atomic assembly of the composite to its macroscopic behavior. Du and Pang [19] examined the barrier properties of GNP reinforced mortars and reported significant decrease in water penetration depth, chloride diffusion coefficient and chloride migration for the cement mortar with GNPs as compared to plain cement mortar. Tong et al. [20] and Fan [21] investigated the effects of GNPs on the durability of cementitious composites and assessed the freeze-thaw performance and corrosion resistance of GNPreinforced cement composites. Khushnood [22] studied the effect GNPs on the compressive strength of cementitious composite.

More recently, a few researchers have studied the electrical properties of GNP-reinforced cementitious composites. Research reported in Pang et al. [17] and Le et al. [14] considered the addition of GNPs to ordinary cement mortars to enhance their electrical conductivity. The GNPs used in these studies had a diameter of 2.6 microns and a thickness of 2.6 nanometers, which yields an aspect ratio of 1000. The GNPs were mixed in water with a high range water reducer and ultrasonicated for 2 hours before adding the aqueous solution to a cement and sand mixture. The four-probe method was used to measure electrical resistivity of mortar specimens during compression and tension tests, and flexural testing on beam specimens with artificial notches were performed to assess damage sensing ability of the GNP reinforced mortars. The results of these studies indicated good strain-sensing and damage-sensing capabilities for the GNP reinforced mortars.

Huang [23] investigated the feasibility of using GNPs in the development of multifunctional cementitious composites and studied the conductivity of GNP-reinforced cement and mortar composites. They reported that a conductive mechanism in GNP-cement composites could be achieved in three different ways: (i) the ionic conduction through the free vaporable water in cement matrix; (ii) the electronic conduction and hole conduction through GNP and cement matrix by tunneling effect; and (iii) the electronic conduction and hole conduction 
through a conductive network formed by GNP particles. They found that the third path dominates if the GNP ratio exceeds the percolation threshold.

Du et al. [24] prepared mortar specimens with $0 \%, 1.2 \%, 2.4 \%, 3.6 \%$ and $4.8 \%$ GNPs by volume of the mixture and investigated strain-sensing of the developed composites considering the effect of moisture. When the GNP content was below the percolation threshold, the electrical resistivity was highly sensitive to the moisture content of the environment, which negatively affects the strain-sensing ability. However, when then amount of the GNP exceeded the percolation threshold, which was between $2.4 \%$ and $3.6 \%$ in this case, the effect of moisture on the electrical properties was not significant.

The above-mentioned studies on the GNP-reinforced self-sensing cement mortars used a naphthalene sulphonate-based superplasticizer as dispersant, which operates according to the mechanism of electrostatic repulsion. However, it has been shown that polycarboxylate-based superplasticizers, which disperse the cement particles through steric hindrance, are more effective in dispersing CNTs compared to naphthalene sulphonate-based superplasticizers [25]. Therefore, there is a need for further research to evaluate the effect of superplasticizer type as dispersing agent in GNP-reinforced cementitious composites. Furthermore, to facilitate the realworld implementations of intrinsically self-sensing cementitious materials, simple, repeatable, and large-scale fabrication procedures of these multifunctional composites should be developed. This research will investigate practical and scalable fabrication methods that do not require special treating procedures such as ultrasonication for the proper dispersion of the GNPs in cementitious composites.

\section{3. Dispersion of Nanofillers to Cementitious Composites}

The effective dispersion of the nanomaterial is very important in developing self-sensing cementitious composites. If the mixing method cannot achieve a uniform dispersion of nanomaterials into the cementitious matrix, the full advantages of nanofillers cannot be exploited, which is not economic and efficient. The dispersion methods of nano reinforcements to cementitious composites can be divided into two categories: physical methods and chemical methods [3]. The physical methods include the use of high shear mixers or ultrasonicator. High shear mixing can separate filler from each other and smash filler, which decreases the aspect 
ratio. Ultrasonication can disperse fillers into mixing water and can avoid the damage to fillers. Usually, ultrasonication requires special equipment, i.e. bath or probe ultrasonicator. It also requires about 1-2 hours to disperse the fillers. The chemical methods involve the use of surfactant or superplasticizer to alter the filler surface structures. They are commonly used to improve the wettability of filler surfaces, which eases the dispersion and solubility. The physical methods and chemical methods can also be combined to well disperse the GNP particles.

\section{4. Electrical Resistivity Measurements}

\subsubsection{Electrode fabrication materials}

The materials used as electrodes should meet two requirements: low electrical resistance and stable electrically conductive property. Metal flake with or without holes, metal meshes, copper tape/wire, and conductive paint as shown in Figure 2 have commonly been used as electrodes in resistivity measurement of cement composites [3]. Copper tape usually applied together with silver paint and is attached on the surface of specimens, which does not damage the specimens [4,9]. The copper meshes and copper flake are embedded in the specimens. The size of the copper flake should be smaller than the cross section of specimens as it may break the specimens along the cross section where it is inserted [26]. But for copper mesh, the size is not very strict. However, the spacing pattern of the copper meshes should be chosen to be at least greater than the size of the largest diameter of sand. Otherwise, the cementitious paste will not be able to pass through the pattern during the fabrication process $[14,15,17]$. 

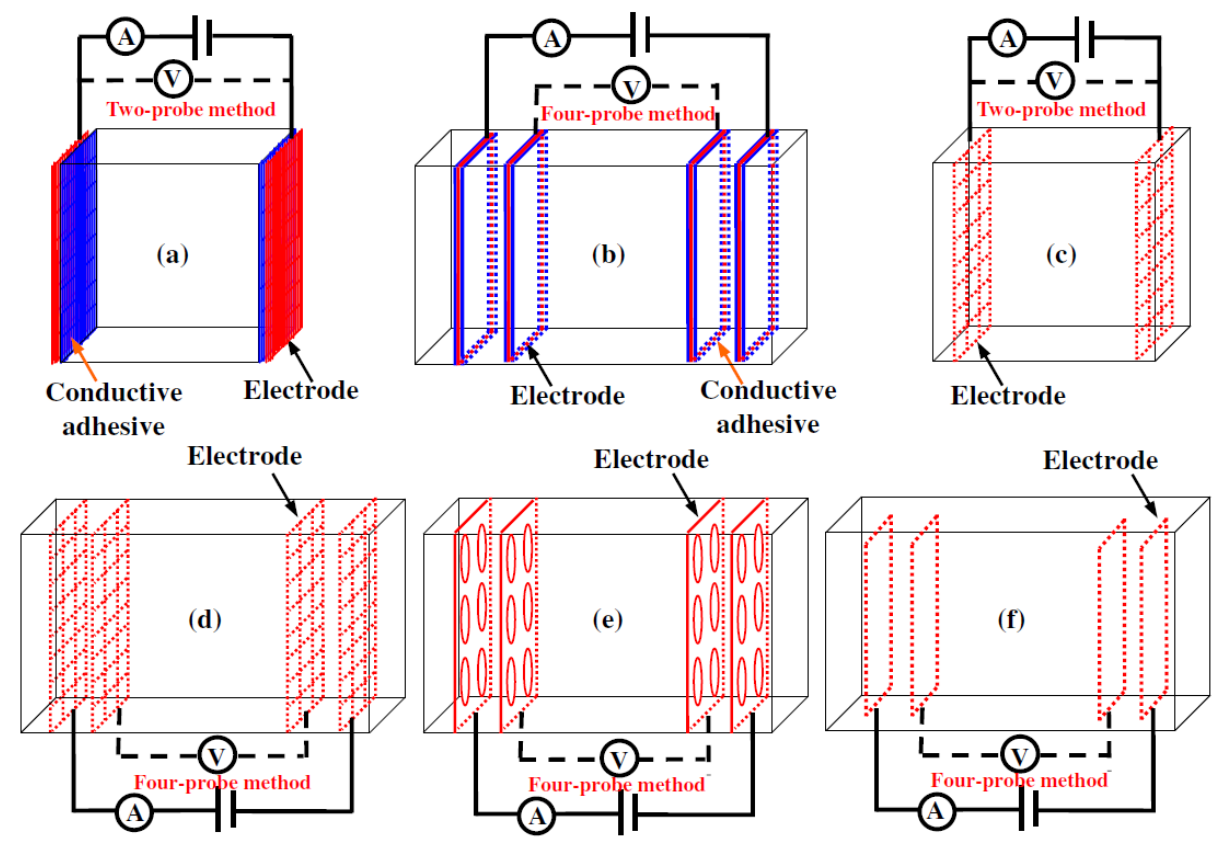

Figure 2. Commonly used electrode configurations for measuring specimens resistivity [3].

\subsubsection{Two-probe methods}

To measure the resistance using two-probe method, the current is applied between two probes as shown in Figure 3(a). A voltmeter is used to measure the voltage between two probes. The resistance is determined using the following equation:

$$
R=\frac{V}{I}
$$

The resistance depends on the volume of the specimens. Therefore, the resistivity is usually calculated as follows and used for comparison:

$$
\rho=\frac{R S}{L}
$$

where $S$ is the area of the cross-section, and $L$ is the distance of two probes. 


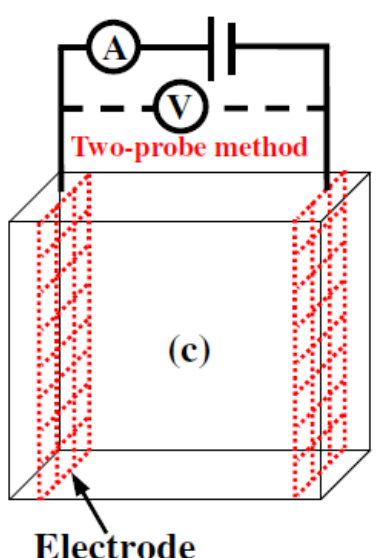

(a)

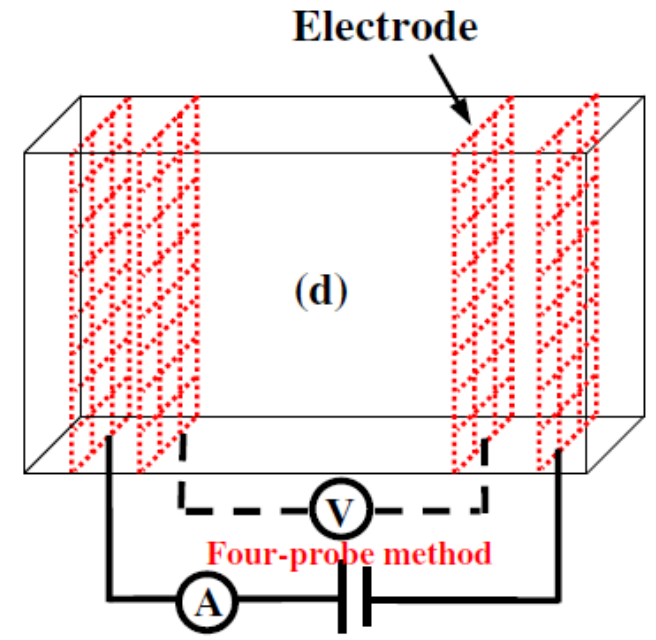

(b)

Figure 3. (a) two-probe method; (b) four-probe method.

\subsubsection{Four-probe methods}

In four-probe method, current is applied to the specimen through two outer probes. The probe measures the voltage of two inner probes. Resistance between two inner probe is determined using the following equation:

$$
R=\frac{V}{I}
$$

The resistance measured is the volume resistance of the area between two inner probes. The resistance should be converted to resistivity by the following equation:

$$
\rho=\frac{R S}{L}
$$

Where $S$ is the area of the cross-section, and $L$ is the length of the specimens.

Although both methods have been used in previous studies, the measurements with twoprobe method includes the contact resistance and is higher than those obtained from four-probe method [24]

\subsubsection{Power supply}

Direct current (DC) and alternating current (AC) power supply can be used to provide current through mortar specimens. Applying a DC current is simpler than using AC current. With 
a constant electrical field applied during the measurement, the movement and aggregation of the ions in the matrix will lead to an electrical polarization. As the rise in resistance is exponential, it is very difficult to measure the changes in electrical resistance cause by external force. Applying the current on specimens until the resistance reaches plateau can make the measurement more accurate. However, it might be hard to reach a constant plateau. Larger specimens need longer time as polarization is dependent on the specimen geometry. Although the use of the AC supply cannot completely eliminate polarization effect, it considerably reduces the polarization effects compared to the use of DC supply. [27] 


\section{EXPERIMENTAL DESIGN}

This chapter explains the materials and equipment used in this research. Three different methods used to develop GNP-reinforced cementitious composites are also described. The experimental tests conducted in this study are then discussed.

\section{1. Materials}

\subsubsection{Cement and sand}

Portland cement Type I/II and ASTM graded sand C778 were used in the mortar mixture. Fly ash used in some specimens was Class F fly ash in order to study the possibility of replacing some cement with fly ash.

\subsubsection{GNPS}

The GNPs used in this study were commercially produced by XG Science corporation [28]. In order to determine the type of GNP that would be used in this study, an analytical prediction of the percolation threshold was employed. Li and Kim [29] suggested the following equation to predict the percolation threshold of conducting polymer composites containing discshaped nanoparticles with high aspect ratios:

$$
V_{f}=\frac{27 \pi D^{2} t}{4\left(D+D_{I P}\right)^{3}}
$$

where $V_{f}$ is the critical volume fraction of ratio 3D nanoplatelets, $D$ is the diameter of GNP, $t$ is the thickness of GNP, and $D_{I P}$ is the interparticle distance. When the $D / t \geq 500, D_{I P}$ can be neglected mathematically. In this study, all types of GNP have the $D / t \geq 500$ except the GNP H-5 which was not discussed and used in this thesis.

For GNPs with a $D / t \geq 500$, Eq. (1) reduces to: 


$$
\mathrm{V}_{\mathrm{f}}=\frac{27 \pi}{4}\left(\frac{\mathrm{t}}{\mathrm{D}}\right)
$$

The results of percolation threshold calculations for different types of GNPs are shown in Table 1. The data of diameter, thickness and surface area was got from XG Science. It can be seen that Grade M GNPs with a diameter of $25 \mu \mathrm{m}$ has the lowest percolation threshold that is predicted by the equation (2), and thus was chosen for the experimental studies. Note that the effects of GNP characteristics such as aspect ratio and surface area on the conductivity of cementitious composites need to be thoroughly investigated, but this is outside of the scope of the current study. The properties of Grade M-25 GNPs are shown in Table 2 below.

Table 1. Calculations of percolation thresholds for different types of GNPs

\begin{tabular}{ccccc}
\hline GNP Type & $\begin{array}{c}\text { Diameter } \\
(\boldsymbol{\mu m})\end{array}$ & $\begin{array}{c}\text { Thickness } \\
(\mathbf{n m})\end{array}$ & $\begin{array}{c}\text { Surface Area } \\
\left(\mathbf{m}^{\mathbf{2}} \mathbf{/ g}\right)\end{array}$ & $\begin{array}{c}\mathbf{V}_{\text {tr }} \\
(\mathbf{V})\end{array}$ \\
\hline GNP H-15 & 15 & 15 & $50 \sim 80$ & 2.1 \\
GNP H-25 & 25 & 15 & $50 \sim 80$ & 1.3 \\
GNP M-5 & 5 & $6 \sim 8$ & $120 \sim 150$ & 3.4 \\
GNP M-15 & 15 & $6 \sim 8$ & $120 \sim 150$ & 1.1 \\
GNP M-25 & 25 & $6 \sim 8$ & $120 \sim 150$ & 0.7 \\
GNP C-300 & $<2$ & $1 \sim 2$ & 300 & 2.1 \\
GNP C-500 & $<2$ & $1 \sim 2$ & 500 & 2.1 \\
GNP C-750 & $<2$ & $1 \sim 2$ & 750 & 2.1 \\
\hline
\end{tabular}

Table 2. Properties of GNP M-25

\begin{tabular}{cc}
\hline Properties & Values \\
\hline Surface Area $\left(\mathrm{m}^{2} / \mathrm{g}\right)$ & $120 \sim 150$ \\
Diameter $(\mu \mathrm{m})$ & 25 \\
Thickness $(\mathrm{nm})$ & $6 \sim 8$ \\
Density $(\mathrm{g} / \mathrm{cc})$ & 2.2 \\
Carbon Content $(\%)$ & $>99.5$ \\
Tensile Modulus $(\mathrm{GPa})$ & 1000 \\
Tensile Strength $(\mathrm{GPa})$ & 5 \\
\hline
\end{tabular}




\subsubsection{Dispersant}

A polycarboxylate-based superplasticizer, AdvaCast 575, was used to disperse the GNPs into the mixing water and increase the workability of the GNP reinforced mortar. The efficiency of a surfactant in dispersing GNPs was also studied. A surfactant, sodium deoxycholate, NaDC (Sigma Aldrich) was selected for this study.

The amount of superplasticizer was chosen to be $50 \%$ by mass of GNPs based on recommendations of an earlier study [30]. However, when trial batches of mortars with 5\% and 7.5\% GNP were prepared, the amount of superplasticizer was not sufficient to obtain good workability of the mixture. Note that the Grade M-25 GNPs have a surface area that is about 380 times larger than Portland cement, which indicates the need for higher amounts of superplasticizer. Therefore, the amount of superplasticizer for the mortars with $5 \%$ and $7.5 \%$ GNP batches was recalculated to take into account the higher surface area of GNPs, and the dosage of superplasticizer for 5\%, 7.5\% and 10\% was increased to $40 \mathrm{ml}(41.20 \mathrm{~g}), 60 \mathrm{ml}(62.30$ g) and $80 \mathrm{ml}(83.00 \mathrm{~g})$, while the originally calculated values of 5\%,7.5\% and $10 \%$ were 14.60 $\mathrm{g}, 21.90 \mathrm{~g}, 29.15 \mathrm{~g}$.

To determine the required amount of surfactant, the recommendations from Zohhadi [12] was implemented. The study conducted by Zohhadi [12] compared the average hydrodynamic radius (AHR) values of GNP aqueous suspensions that contained different NaDC surfactant concentrations. The lowest AHR value represented the highest level of dispersion, and a surfactant to GNP weight ratio of seven was found to lead to a minimum AHR value. Therefore, a surfactant to GNP weight ratio of seven was used in this study.

\subsubsection{Ultrasonicator}

The ultrasonicator used in this study was a bath sonicator manufactured by BRANSON with frequency of $50 / 60 \mathrm{~Hz}$ and power of 240 watts

\section{2. Mixing Procedures}

Three different mixing methods were considered in this study to fabricate GNP reinforced mortar specimens considering the findings and suggestions of the study conducted by Al-Dahawi et al. [31]. In Method I, the GNP was measured and added to the total amount of 
mixing water containing superplasticizer. The beaker containing the solution was placed in a bath ultrasonicator for 1.5 hours. Before ultrasonication was completed, the cement and sand were mixed in a Hobart commercial mixer for $10 \mathrm{~min}$ at $125 \mathrm{rpm}$. Following this, the GNP solution was removed from the ultrasonicator and added to the dry materials over a period of 10 seconds. The mixing speed was increased to $300 \mathrm{rpm}$ and the materials were mixed for an additional 10 mins and then cast into molds.

In Method II, the dry materials including the GNP, sand and cement were first mixed in a Hobart commercial mixer for $10 \mathrm{mins}$ at $125 \mathrm{rpm}$. The mixing water was then added to the dry materials over 10 seconds. The mixer speed was increased to $300 \mathrm{rpm}$ and the superplasticizer was added into mixer over 30 seconds.

In Method III, the GNP and superplasticizer were measured out and added to the mixing water. A high-speed mixer (a kitchen-type blender) was used to mix the GNP suspension at 3000 rpm for $15 \mathrm{~min}$. During this time, the cement and sand were mixed in a Hobart commercial mixer at $125 \mathrm{rpm}$ for 10 mins. The GNP suspension was then added to the mixer over 10 seconds and mixing continued for an additional $10 \mathrm{mins}$ at $300 \mathrm{rpm}$. The mortar was then cast into the molds. Note that the last two methods do not require any special treatment techniques. The three mixing procedures are summarized and illustrated in Figure 4. In addition, the GNP-watersuperplasticizer suspension mixed using ultasonication (Method I) or high-speed shear mixer is shown in Figure 5 before and after mixing. 
Method I:

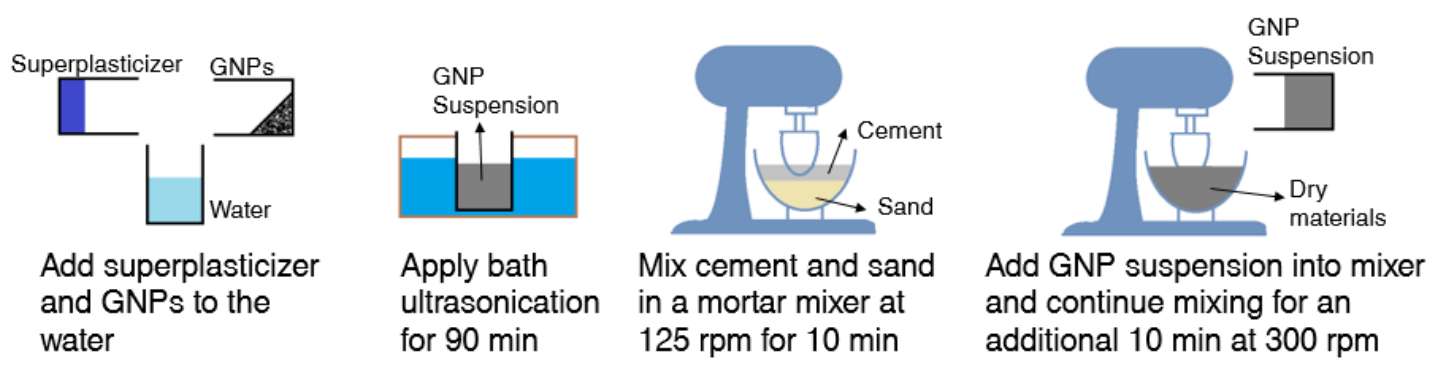

Method II:

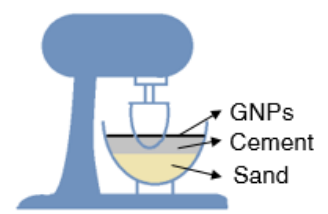

Mix cement, sand and GNPs in a mortar mixer at $125 \mathrm{rpm}$ for $10 \mathrm{~min}$

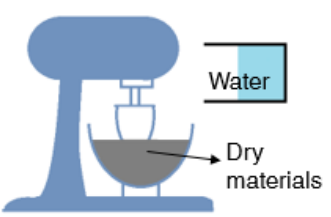

Add water into mixer Add superplasticizer into mixer over $10 \mathrm{~s}$ over $30 \mathrm{~s}$ and continue mixing for an additional $10 \mathrm{~min}$ at $300 \mathrm{rpm}$

Method III:

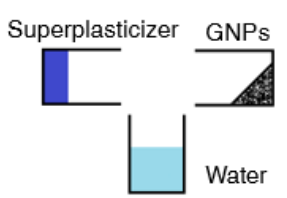

Add superplasticizer Mix the suspension and GNPs to the water

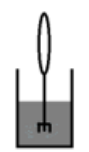

with a high-speed mixer at $3000 \mathrm{rpm}$ for $15 \mathrm{~min}$

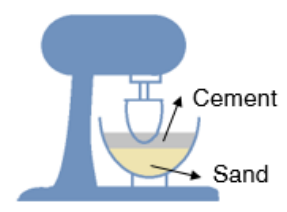

Mix cement and sand Add GNP suspension into mixer in a mortar mixer at $125 \mathrm{rpm}$ for $10 \mathrm{~min}$

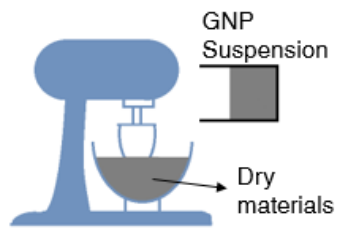
and continue mixing for an additional $10 \mathrm{~min}$ at $300 \mathrm{rpm}$

Figure 4. Fabrication Procedures. 


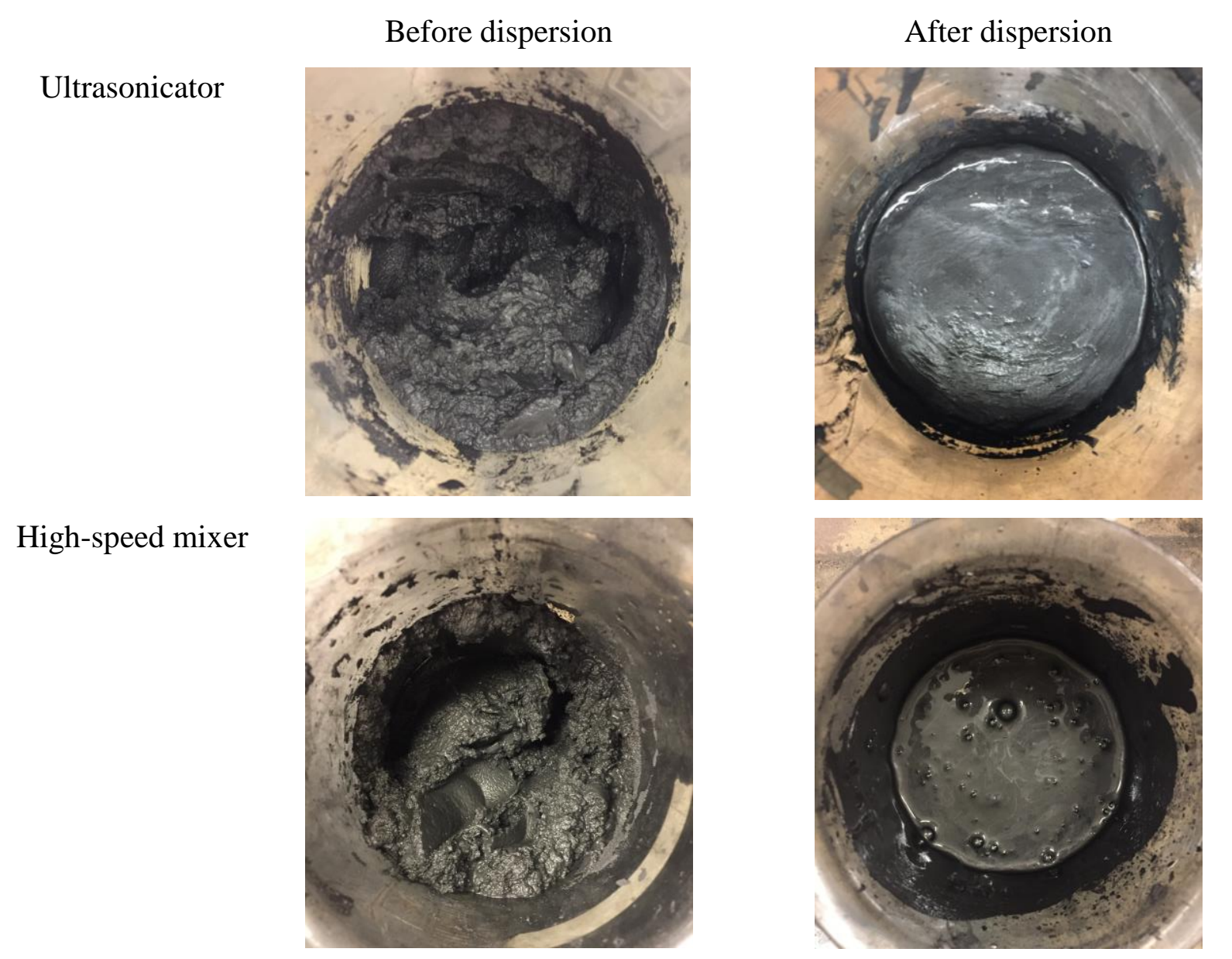

Figure 5. GNP solutions before and after dispersion via ultrasonication or high-speed shear mixing.

\section{3. Sample Preparation}

Seven separate batches of mortar containing various levels of graphene nanoplatelets were prepared using the three mixing methods described above. Each batch of mortar was prepared as per ASTM C109, maintaining a water to cement ratio of 0.485 . Standard prismatic mortar specimens of dimensions $40 \mathrm{~mm} \times 40 \mathrm{~mm} \times 160 \mathrm{~mm}$ containing GNPs at seven different concentrations $(0 \%, 0.1 \%, 1 \%, 2.5 \%, 5 \%, 7.5 \%$ and $10 \%$ by weight of the cement) were prepared using mixing Method I, Method II, and Method III discussed above. All the specimens were cured at room temperature and covered by plastic sheet.

To explore the possibility of replacing the cement with fly ash and assess the effect of adding fly ash, seven more batches were prepared using the third mixing method which were named as Method III-Fly ash. In these batches, $20 \%$ of cement was replaced with fly ash. 
Four copper mesh sheets were embedded into each specimen to serve as electrodes. The spacing between the outer probes were set as $120 \mathrm{~mm}$ and the spacing between the inner probes were set as $80 \mathrm{~mm}$. A schematic drawing of the prismatic specimens is shown in Figure 6.

Two more batches of mortar containing $2.5 \%$ of GNPs were prepared with all mixing methods. One of them used surfactant as dispersant instead of superplasticizer in order to study the effect of different dispersion chemicals. The specimens in the other batch was used to explore the influence of different types of electrodes. For these specimens, silver paint and copper tape served as electrodes instead of copper mesh. Figure 7 shows the cast specimens with installed copper mesh or copper tapes.

In addition, six batches (three with $7.5 \%$ and three with $10 \%$ ) of mortar cubic specimen (without fly ash) were prepared using three mixing methods for cyclic compressive tests. One batch of plain mortar was set as control group. Each specimen had dimensions of $50.8 \mathrm{~mm} \times$ $50.8 \mathrm{~mm} \times 50.8 \mathrm{~mm}$.

Table 3 summarizes the test plan for prismatic specimens. Table 4 shows the test plan for cubic specimens. 


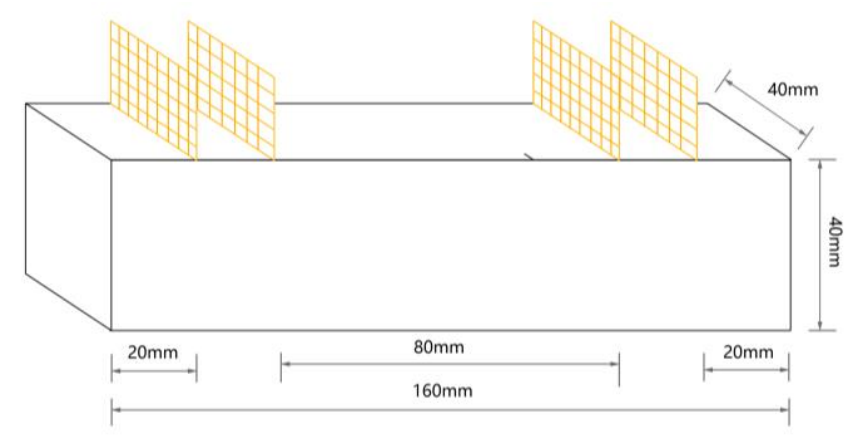

(a)

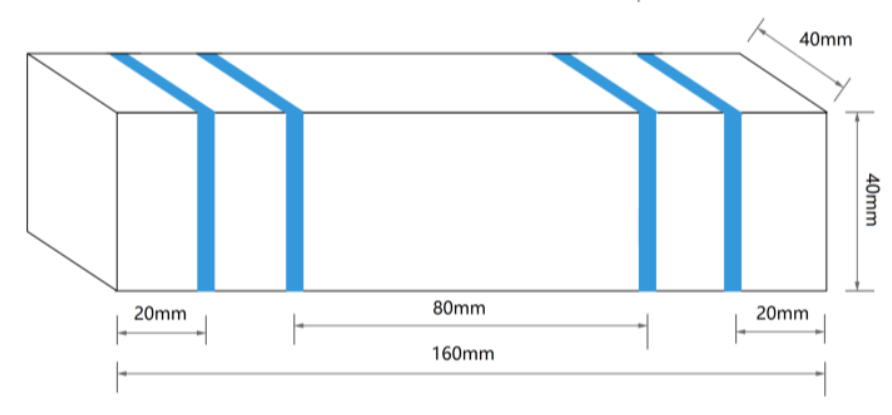

(b)

Figure 6. Prismatic specimens with (a) copper mesh and (b) copper tape.

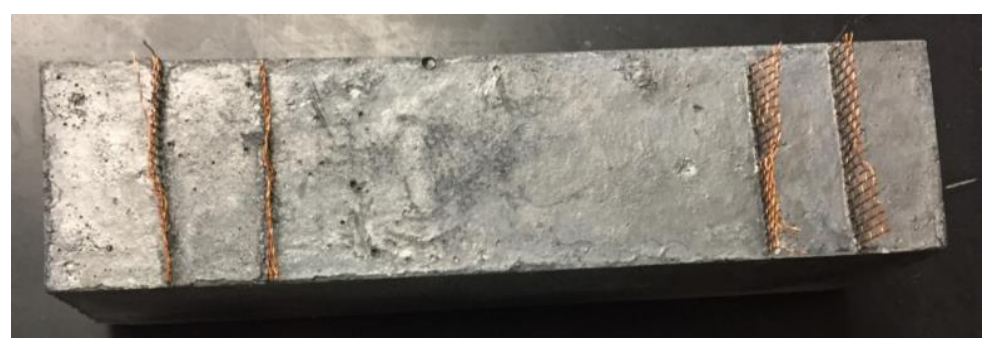

(a)

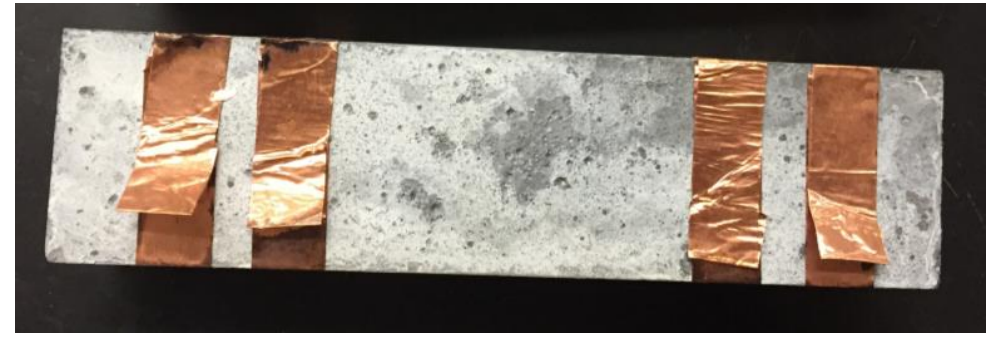

(b)

Figure 7. Real specimens embedded with (a) copper mesh and (b) copper tape. 
Table 3. Test plan for prismatic specimens

\begin{tabular}{|c|c|c|c|c|c|}
\hline $\begin{array}{l}\text { Mixing } \\
\text { method }\end{array}$ & $\begin{array}{c}\text { GNP } \\
\text { (wt\% of } \\
\text { cement) }\end{array}$ & $\begin{array}{c}\text { Specimen } \\
\text { No. }\end{array}$ & Dispersant & Electrodes & Test \\
\hline \multirow[t]{3}{*}{ Method I } & $0 \sim 10 \%$ & $1 \sim 21$ & Superplasticizer & Copper meshes & Cyclic \\
\hline & $2.5 \%$ & $22 \sim 24$ & Surfactant & Copper meshes & compression \\
\hline & $2.5 \%$ & $25 \sim 27$ & Superplasticizer & Copper tape & Bulk resistivity \\
\hline \multirow{3}{*}{ Method II } & $0 \sim 10 \%$ & $28 \sim 48$ & Superplasticizer & Copper meshes & Cyclic \\
\hline & $2.5 \%$ & $49 \sim 51$ & Surfactant & Copper meshes & compression \\
\hline & $2.5 \%$ & $52 \sim 54$ & Superplasticizer & Copper tape & Bulk resistivity \\
\hline $\begin{array}{l}\text { Method } \\
\text { III }\end{array}$ & $0 \sim 10 \%$ & $55 \sim 75$ & Superplasticizer & Copper meshes & $\begin{array}{c}\text { Cyclic } \\
\text { compression }\end{array}$ \\
\hline $\begin{array}{l}\text { Method } \\
\text { III with } \\
\text { Fly ash }\end{array}$ & $0 \sim 10 \%$ & 76 96 & Superplasticizer & Copper meshes & $\begin{array}{l}\text { Bulk resistivity } \\
\text { Cyclic } \\
\text { compression } \\
\text { Bulk resistivity }\end{array}$ \\
\hline
\end{tabular}

Table 4. Test plan for cubic specimens

\begin{tabular}{cccccc}
\hline Batch & $\begin{array}{c}\text { GNP } \\
\text { (wt } \% \text { of cement) }\end{array}$ & $\begin{array}{c}\text { Specimen } \\
\text { No. }\end{array}$ & $\begin{array}{c}\text { Mixing } \\
\text { method }\end{array}$ & Dispersant & Test \\
\hline 1 & 0 & $1 \sim 3$ & - & Superplasticizer & Compressive strength \\
2 & 7.5 & $4 \sim 6$ & I & Superplasticizer & Compressive strength \\
3 & 7.5 & $7 \sim 9$ & II & Superplasticizer & Compressive strength \\
4 & 7.5 & $10 \sim 12$ & III & Superplasticizer & Compressive strength \\
5 & 10 & $13 \sim 15$ & I & Superplasticizer & Compressive strength \\
6 & 10 & $16 \sim 18$ & II & Superplasticizer & Compressive strength \\
7 & 10 & $19 \sim 21$ & III & Superplasticizer & Compressive strength \\
\hline
\end{tabular}

\section{4. Conducted Tests}

\subsubsection{Bulk electrical resistivity tests}

Electrical resistivity measurements were conducted using a four-probe method. To measure the electrical resistance, two KEYSIGHT 34461A digital multimeters were used. A GWINSTEK programmable power supply was used to supply direct current (DC) up to $20 \mathrm{~V}$. One of the multimeters, which was connected to the outer probe and power supply, was used to measure the current intensity, and the other multimeter, which was connected to the inner probe, was used for voltage difference measurement. 
A concrete resistivity meter manufactured by Proceq was also used to measure the surface resistivity of the specimens. The four probes of the device were equally spaced at $50 \mathrm{~mm}$ and two other probes applied a steady current while two inner probes measured the current difference. This measurement technique was only used to measure resistivity of all the specimens cast using Method I and Method II. All the devices and measurement setups are shown in Figure 8.

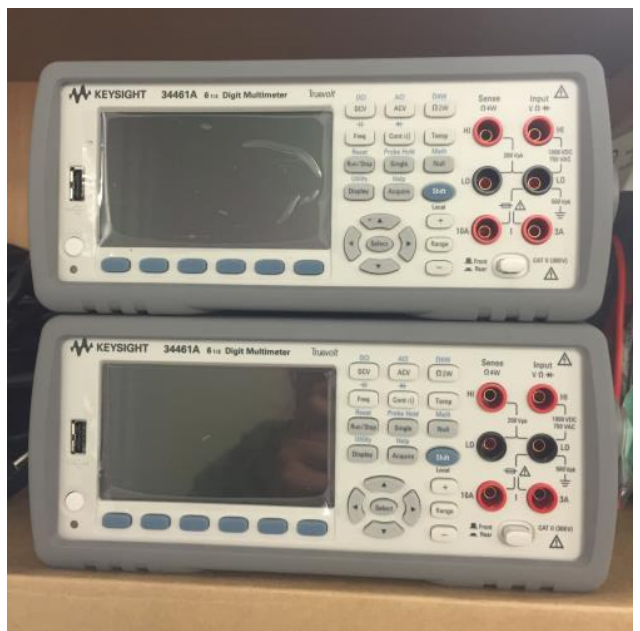

(a)

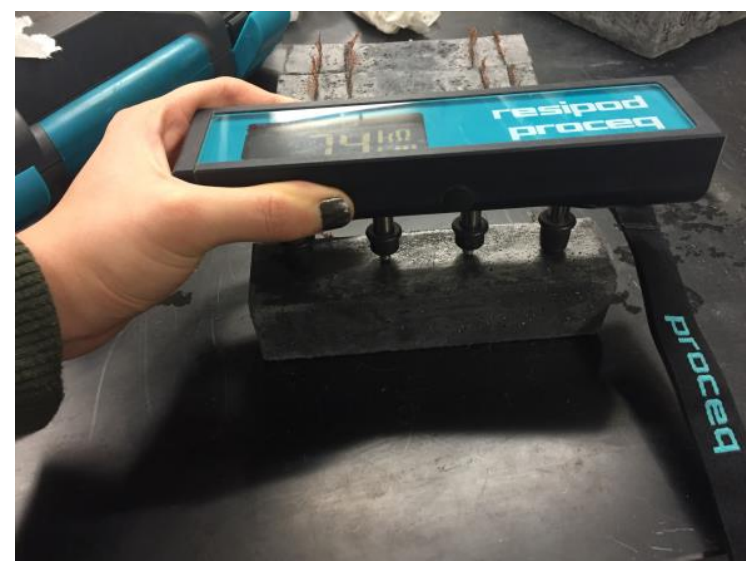

(c)

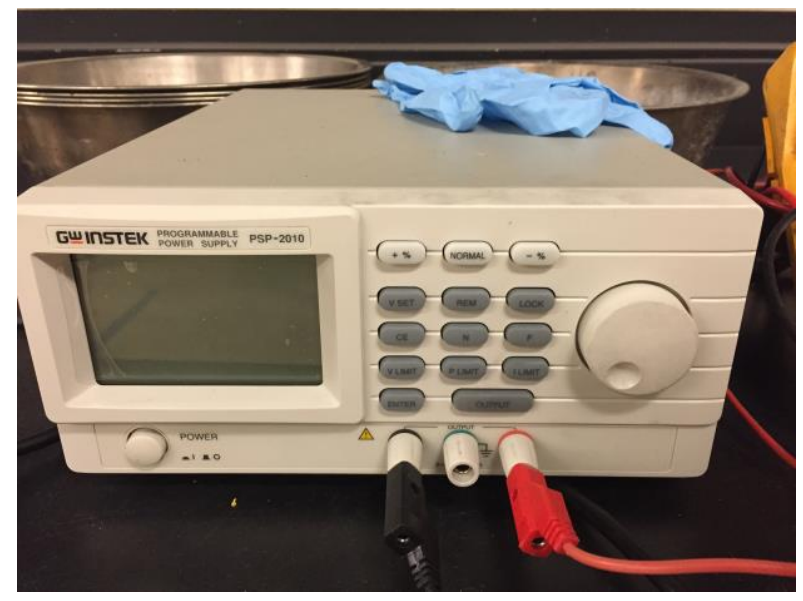

(b)

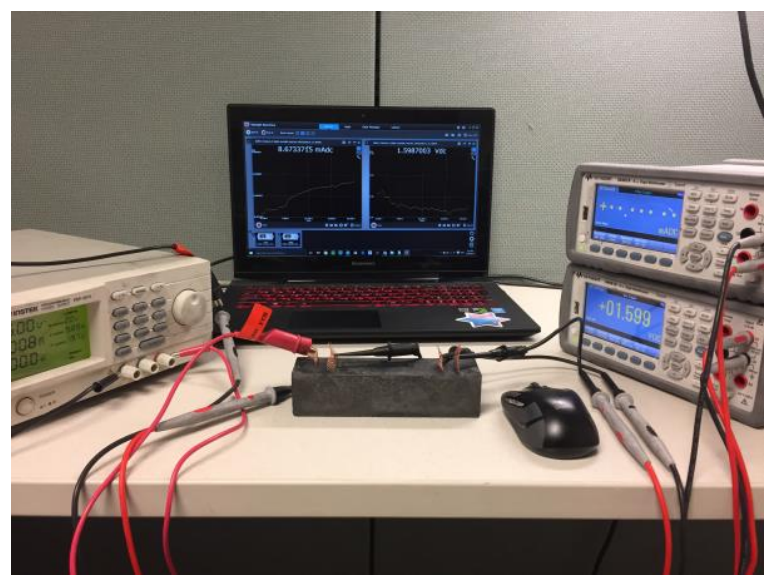

(d)

Figure 8. (a) Digital multimeters; (b) Programmable power supply; (c) Resistivity meter measurements; (d) Bulk resistivity measurements with four-probe method. 


\subsubsection{Cyclic compression tests}

A 22 kips MTS loading machine was used to conduct the cyclic compression tests. The test set-up was shown in Figure 9. The amplitude of load for the specimens was $10 \mathrm{kN}$ except for the specimens with $10 \%$ GNPs. For each specimen, the loading rate was $0.05 \mathrm{kN} / \mathrm{s}$ and the tests were conducted for 3 cycles.

As for specimens with $10 \%$ GNPs, three different amplitudes $(3 \mathrm{kN}, 5 \mathrm{kN}$ and $10 \mathrm{kN})$ of load were applied. For each load amplitude, the tests were conducted for 9 cycles.

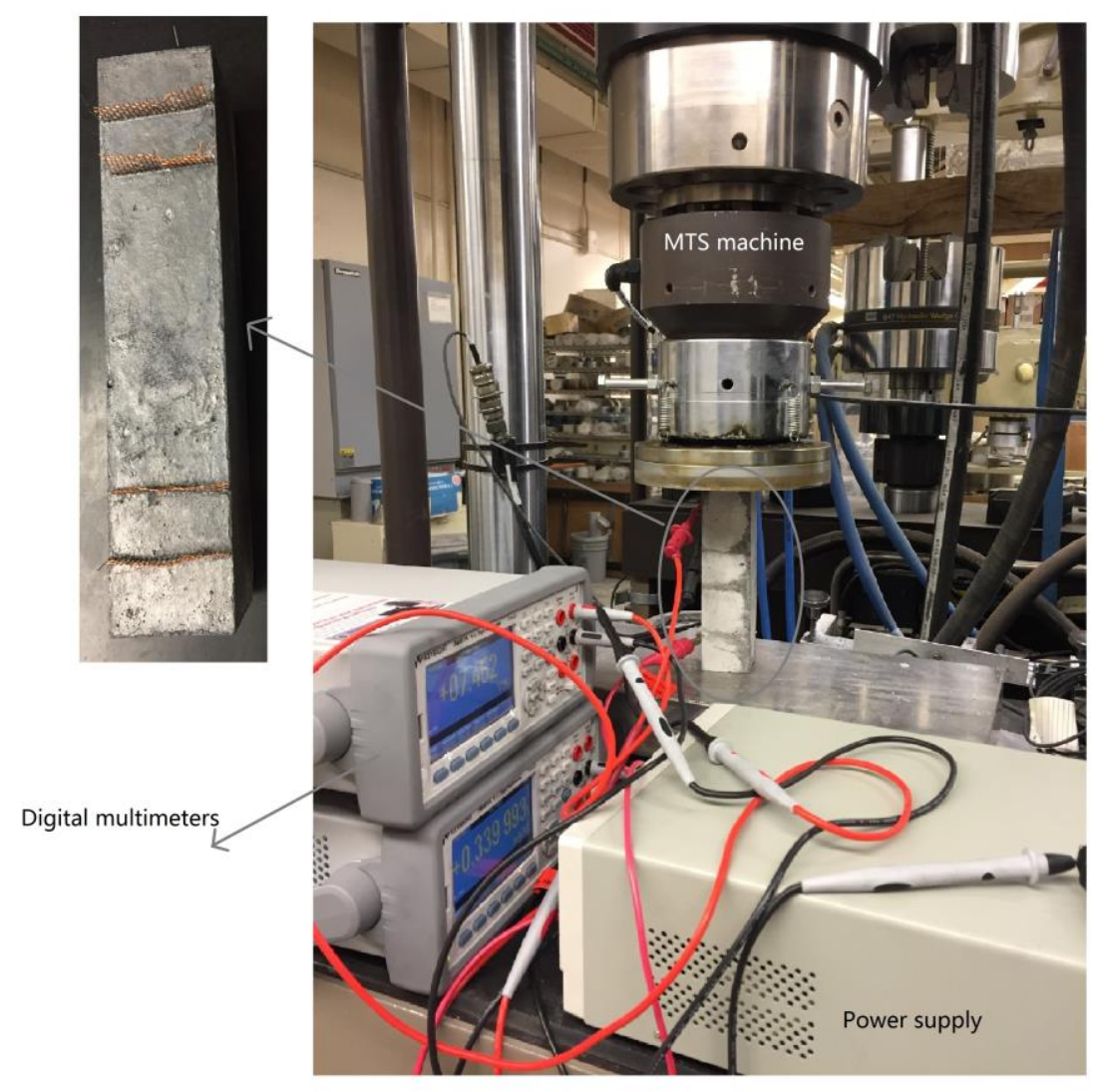

Figure 9. Cyclic compression test setup.

To evaluate the results, the fractional change in resistivity was calculated using the following equation:

$$
F C R=\frac{\rho_{t}-\rho_{0}}{\rho_{0}}
$$


where $\rho_{t}$ is the resistivity at time $t$ during the compression test; and $\rho_{0}$ is the resistivity measured prior to loading.

In addition, the gage factor was calculated for the specimens with $7.5 \%$ and $10 \%$ GNPs. To measure the strains in these specimens, $10 \mathrm{~mm}$ pre-wired gird strain gages, KFH-10-120-C111LM2R from Omega ${ }^{\circledR}$ were use in this study. Strain gages were installed at the middle of specimens to measure the strain during the cyclic compression tests as shown in Figure 10. Du et al. [24] suggested that the normalized change in resistance for an intact specimen could be attributed to the geometrical changes under strain and piezoresistive effect due to the resistivity change under strain, which could be calculated using the following equation:

$$
\Delta R / R=(1+2 v) \varepsilon+d \rho / \rho
$$

where $v$ is the poisson ratio of the material. For the material with negligible piezoresistive effect which was usually happened in metal, $d \rho / \rho$ equals zero and Eq. (3) can be rewritten as:

$$
\frac{\Delta R / R}{\varepsilon}=1+2 v
$$

where $\frac{\Delta R / R}{\varepsilon}$ is commonly called as the gage factor. For incompressible materials like metal, $v$ equals 0.5 , while for compressible materials, $v$ is less than 0.5 . So, the gage factor for a material with negligible piezoresistive effect will not be larger than 2. For GNP mortar specimens, if the gage factor calculated was larger than 2, this indicates that the GNP mortar specimens have piezoresistive effect.

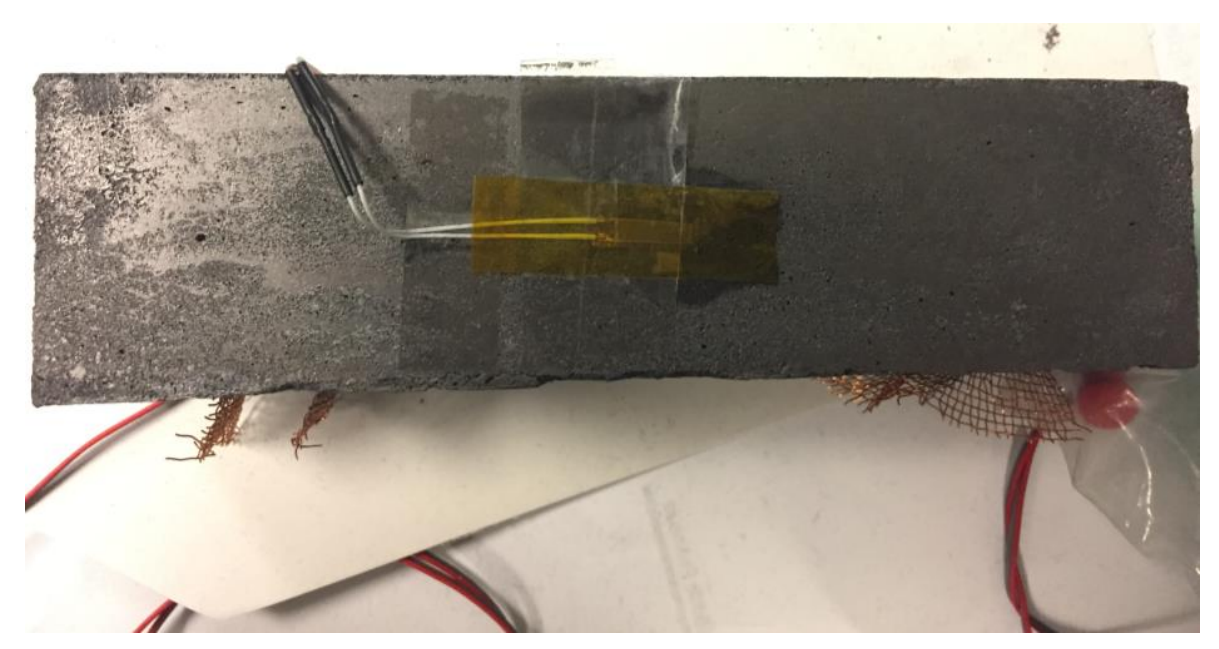

Figure 10. Specimen with the attached strain gage. 


\subsubsection{Scanning Electron Microscopy (SEM) imaging tests}

To better assess the dispersant quality of each mixing methods, SEM images were obtained for the specimens with 7.5\% GNPs for each mixing method. The specimens were broken into small pieces before the test. Quanta 650 from FEI was applied to obtain the SEM images. Figure 11 shows the test specimen inside the machine.

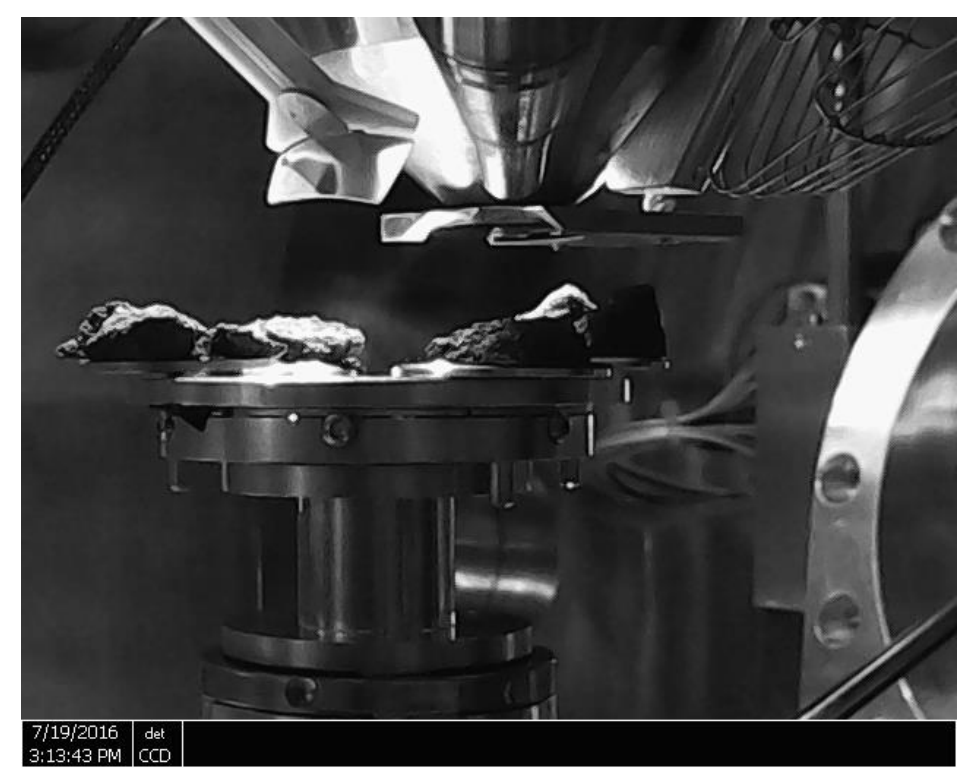

Figure 11. SEM image setup.

\subsubsection{Compressive strength tests}

Compressive strength tests were conducted on cubic specimens with $7.5 \%$ and $10 \%$ GNPs to study the influence of GNPs on compressive strength. One batch of plain mortar cubic specimens were served as the control group. A MTS 810 machine with 220 kips was used for testing and the loading rate was $1350 \mathrm{~N} / \mathrm{s}$ as per ASTM C109. 


\section{Results and Discussion}

In this chapter, SEM images and compressive strength of cubic specimens are discussed. The results of bulk resistivity and the response of cyclic compression test are also presented. The gage factors for each specimens tested under cyclic compression loads are then calculated. Lastly, a nonlinear regression model is used to predict the correlation between fractional change in resistivity and stain.

\section{1. SEM Images}

Figure 12 shows the SEM images obtained from GNP-mortar composites prepared with different mixing methods. It can be seen that Method II had larger agglomerations of GNPs compared to other mixing methods. The size of the agglomerations is random. The diameter of the largest agglomeration of GNPs is around $100 \mu \mathrm{m}$, while the diameter of GNPs is only $25 \mu \mathrm{m}$. Method I, where an ultrasonicator was used to disperse the GNPs, had almost the same dispersion with Method III, which used a high-speed mixer for dispersing GNPs. GNPs were equally distributed inside the specimens cast using Method I and Method III. The size of most of agglomeration in Method I is larger than $25 \mu \mathrm{m}$, while those in Method III are mostly smaller than $25 \mu \mathrm{m}$. This indicates that the high-speed mixer might break GNPs into even smaller pieces during the mixing process. In Figure 12(a), 12(b) and 12(c), there were a large quantities of tiny voids appearing inside the specimens. In Figure 12(d), fly ash was found everywhere inside the specimens. Compared to Figure 12(c), the tiny voids appeared in specimens with Method III were filled by fly ash in specimens cast using Method III with fly ash. 


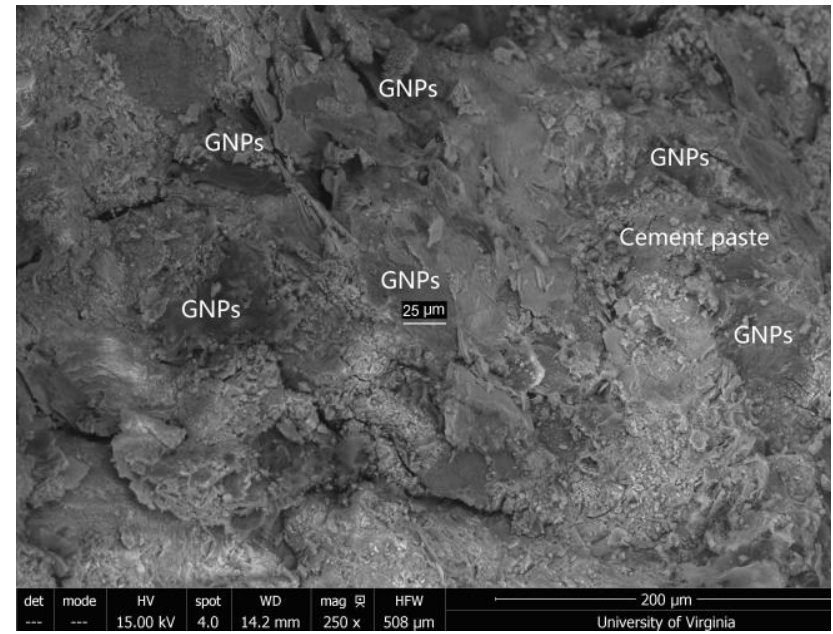

(a)

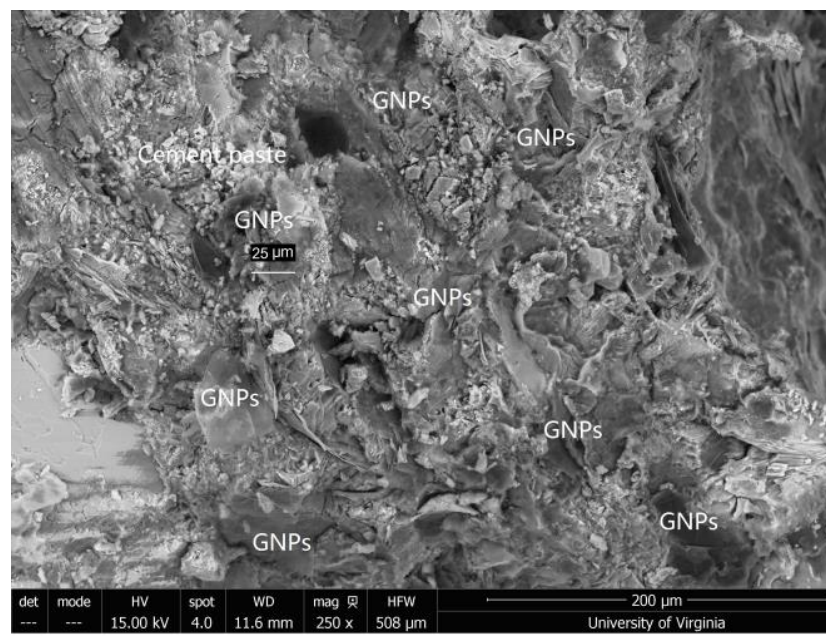

(c)

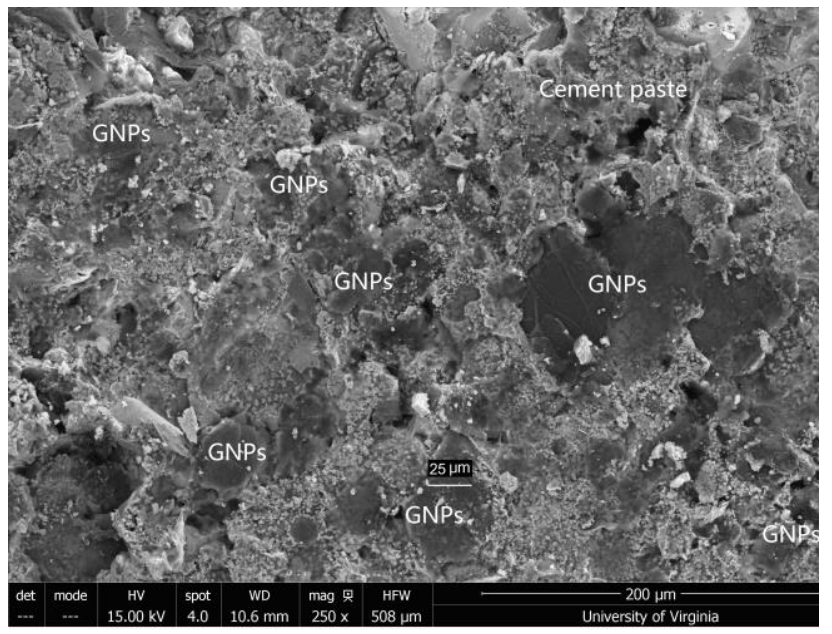

(b)

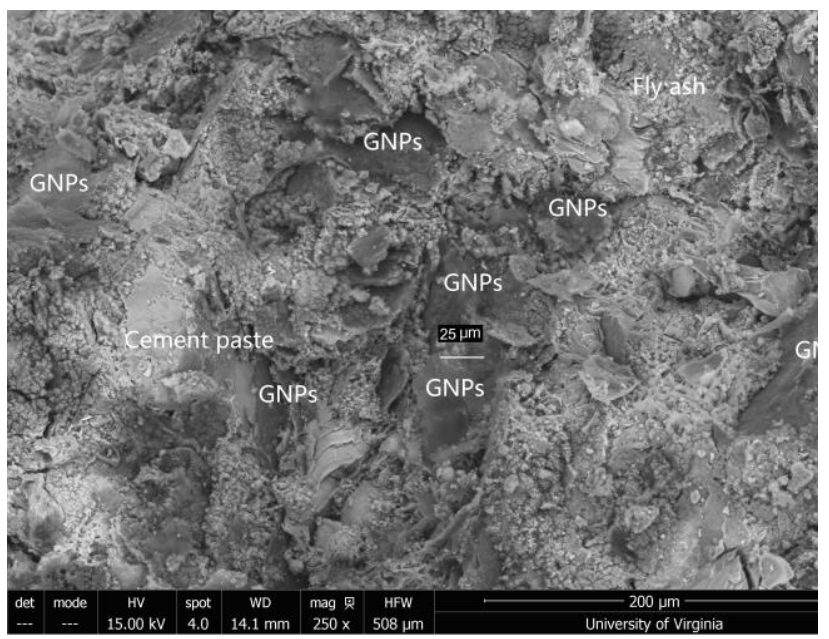

(d)

Figure 12. SEM images of specimens cast using (a) Method I; (b) Method II; (c) Method III and (d) Method III with fly ash.

\section{2. Compressive Strength Tests}

The cubic specimens were tested for the compressive strength as shown in Table 5. It can be seen that the plain mortar specimens have much higher strength than the specimens with $7.5 \%$ and $10 \%$ GNP. The average compressive strength of specimens with $7.5 \%$ GNP cast using Method II and Method III were very similar. But the strength of specimens cast using Method I was lower than the others. For specimens with $10 \%$ GNPs, the specimen with Method III still had the largest compressive strength, while the specimen with Method II had the lowest one. The 
strength of specimens significantly decreases with large amount of added GNPs. This may be due to the high dosage of superplasticizer used in this study. Though the high dosage of superplasticizer helped with the dispersion of GNPs, they also increase the setting time of mortar specimens, which might decrease the strength of specimens. In addition, during the high-speed shear mixing, a large quantity of air was entrapped in the mortar paste. So, there were a large number of tiny voids appeared in the specimens as discussed in SEM images section above. Finally, the curing condition of the specimens might have also affected the compressive strength of these specimens.

Table 5. Compressive strength of cubic specimens with varying GNP proportions cast using three different methods

\begin{tabular}{|c|c|c|c|c|}
\hline Batch & GNP\% & Specimens & $\begin{array}{c}\text { Compressive strength } \\
\text { (MPa) }\end{array}$ & Average \\
\hline \multirow[t]{3}{*}{ Plain } & 0 & 1 & 42.20 & 41.03 \\
\hline & & 2 & 40.89 & \\
\hline & & 3 & 39.99 & \\
\hline \multirow[t]{6}{*}{ Method I } & 7.5 & 1 & 16.89 & 15.74 \\
\hline & & 2 & 14.69 & \\
\hline & & 3 & 15.65 & \\
\hline & 10 & 1 & 15.38 & 16.20 \\
\hline & & 2 & 16.82 & \\
\hline & & 3 & 16.41 & \\
\hline \multirow[t]{6}{*}{ Method II } & 7.5 & 1 & 20.89 & 20.98 \\
\hline & & 2 & 20.75 & \\
\hline & & 3 & 21.30 & \\
\hline & 10 & 1 & 12.29 & 12.83 \\
\hline & & 2 & 14.06 & \\
\hline & & 3 & 12.14 & \\
\hline \multirow[t]{6}{*}{ Method III } & 7.5 & 1 & 22.06 & 21.9 \\
\hline & & 2 & 22.61 & \\
\hline & & 3 & 21.03 & \\
\hline & 10 & 1 & 20.95 & 20.49 \\
\hline & & 2 & 16.5 & \\
\hline & & 3 & 20.02 & \\
\hline
\end{tabular}




\section{3. Bulk Resistivity}

The electrical resistivity measurements were made at 1 day, 7 days, 14 days and 28 days for the specimens cast using Method I, Method II, Method III and Method III with Fly Ash. Figure 13-16 show the average resistivity as well as the standard deviation of the all the mortar specimens with seven different concentrations. It can be seen that the resistivity increased for most of the specimens with the increased curing age, which can be attributed to the change in the microstructure due to hydration processes that leads fine pores. However, the rate of the increases was reduced with the extended curing. It is obvious that there is a clear difference between 1-day and 7-day measurements for the specimens, while the resistivity measurements at 14-day and 28-day are quite similar for the same specimens. This also indicates that the hydration reacted faster in the first 14-day period. But when the GNP concentrations reached 5\% or higher, the 7-day, 14-day and 28-day measurements were almost the same. The resistivity of most of these specimens even decreased after 7-day. This may due to the different GNP concentrations. At low concentration, the GNPs were not enough to form a complete network. During the hydration reaction process, the amount of water decreased, reducing the conductivity of specimens, which induced the increase in resistivity measurements. But at higher concentrations, the amount of GNPs was sufficient for forming a complete network. The hydration reaction helps GNP particles combined better than before, which made the resistivity decreasing. 

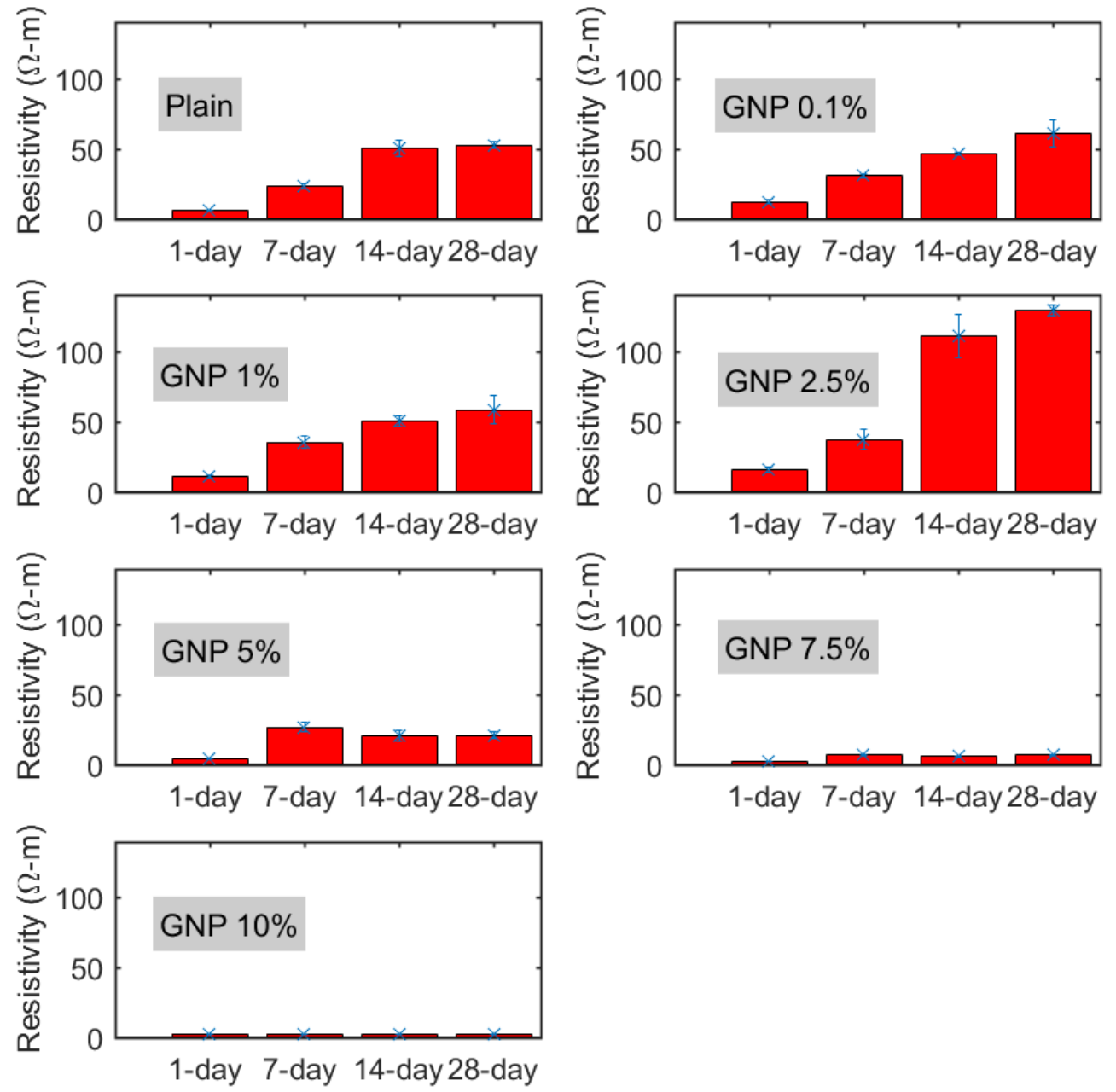

Figure 13. Electrical resistivity of specimens cast using Method I. 

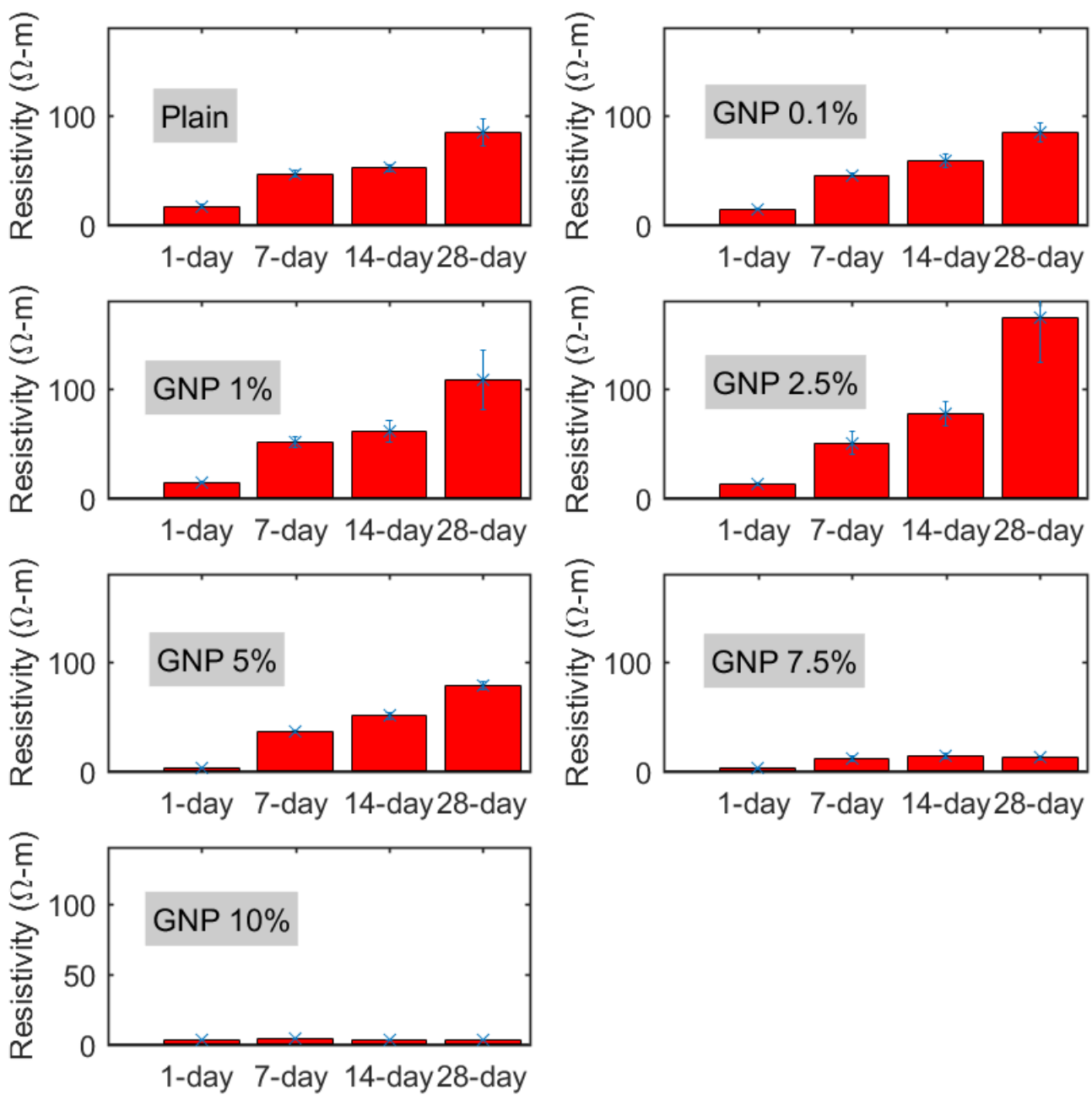

Figure 14. Electrical resistivity of specimens cast using Method II. 

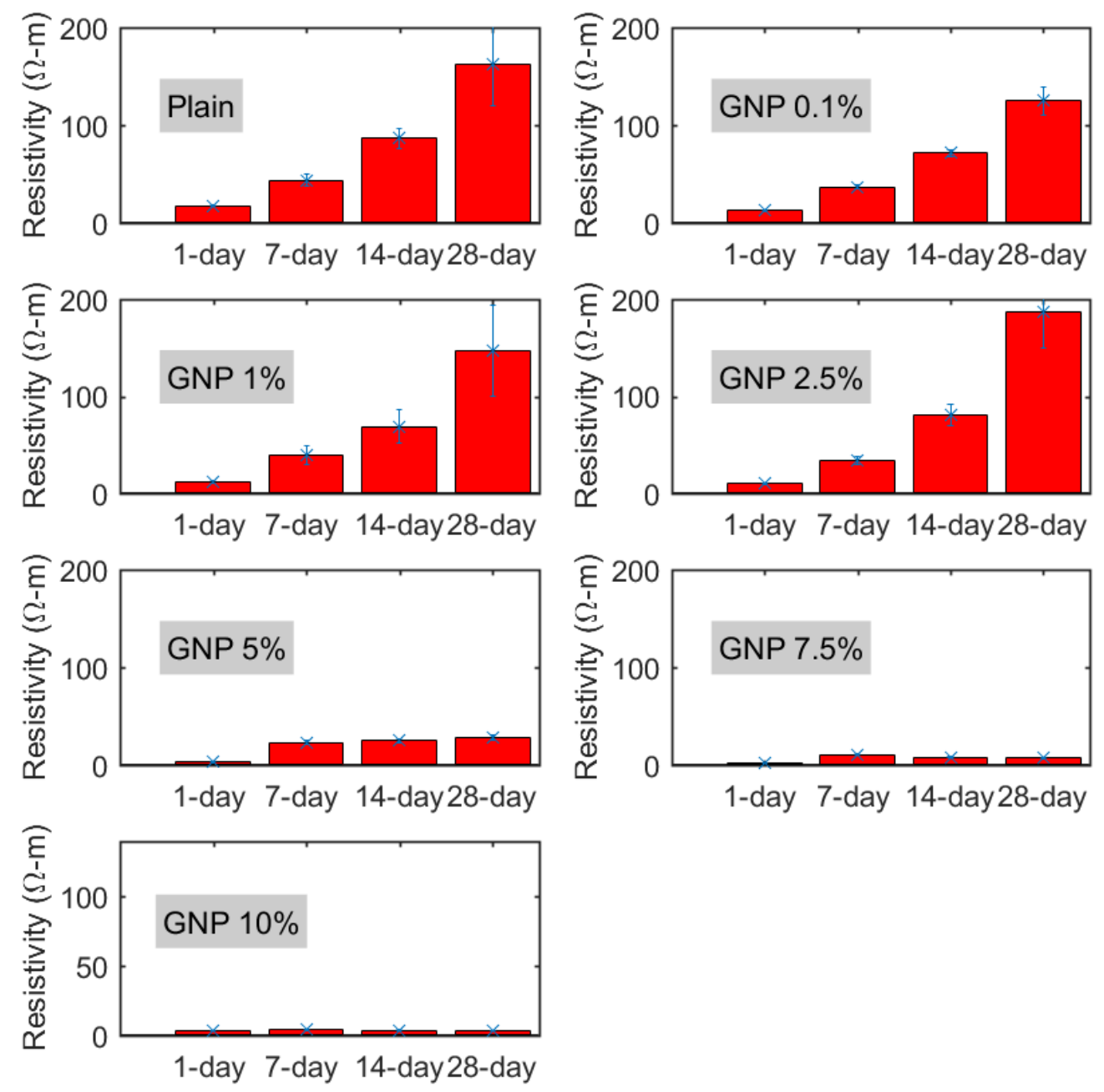

Figure 15. Electrical resistivity of specimens cast using Method III. 

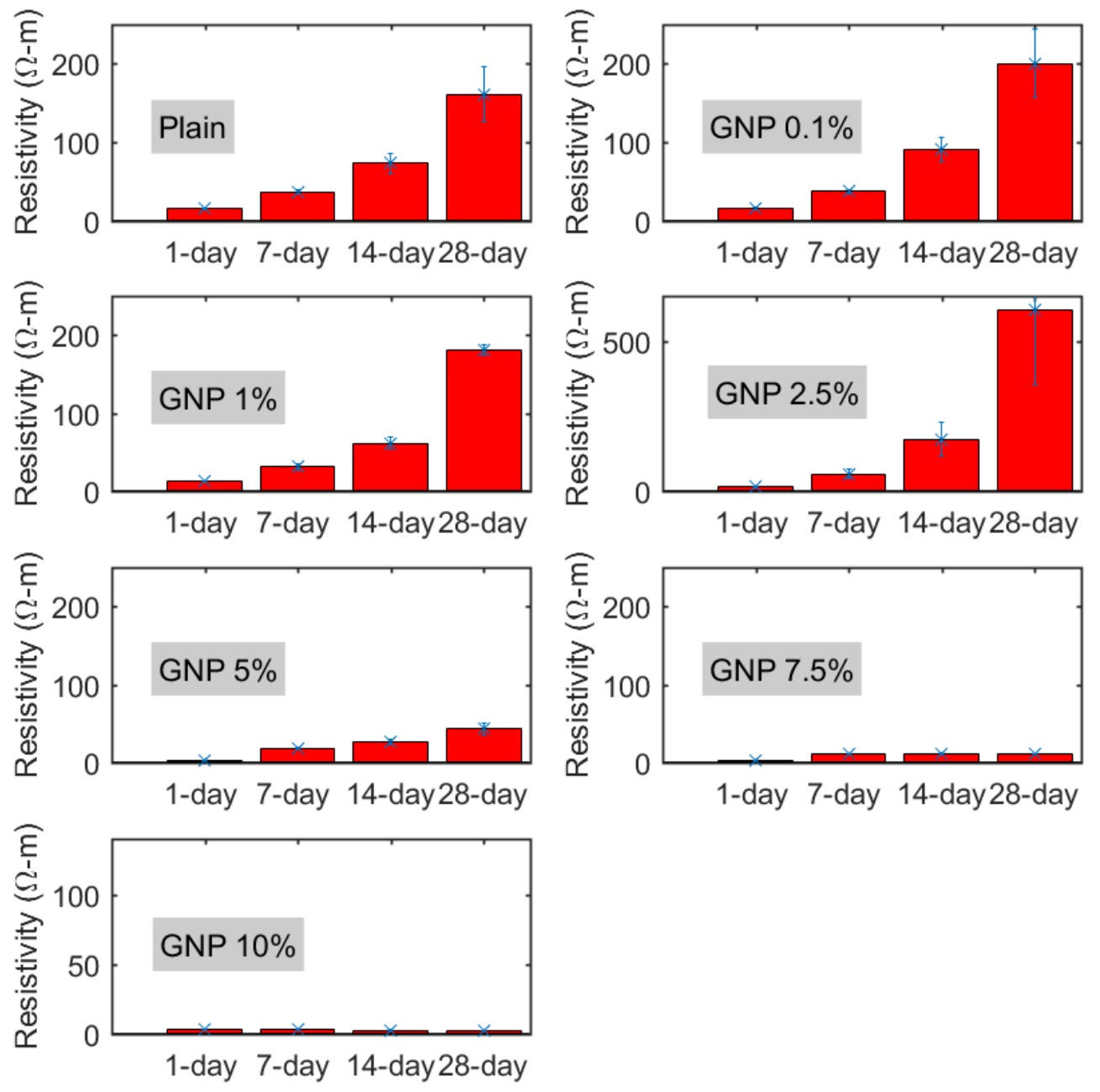

Figure 16. Electrical resistivity of specimens cast using Method III with Fly Ash.

Figure 17 shows the variation of the average values of resistivity of the specimens with different amount of GNPs. Although the change in resistivity with the GNP ratio was not the same for different curing ages, overall there was a relatively sharp decrease in the electrical resistivity when the GNP ratio was over $5 \%$. The addition of GNP less than $5 \%$ by weight of cement did not improve the electrical conductivity as compared to the plain mortar as the amount of GNP was not enough to form a conductive network. In fact, for all mixing methods, the resistivity of the specimens with $2.5 \%$ GNP was considerably higher than the plain mortar specimens. This can be attributed to the agglomerates that occurred in the matrix for these specimens due to poor dispersion of the GNP. When GNP ratios were less than 5\%, the amount 
of superplasticizer was chosen to be $50 \%$ by mass of GNP, which may not be sufficient for $2.5 \%$ GNP ratio, though it helps increase the workability. The largest decrease in the resistivity was observed for $7.5 \%$ GNP ratio. Therefore, the amount of GNP might exceed the percolation threshold for that GNP concentration. Note that for the specimens with 2.5\%, 5\%, 7.5\% and 10\% GNPs by weight of cement, the corresponding volume fraction of GNPs in the mortar mixture are $0.6 \%, 1.1 \%, 1.5 \%$ and $2.1 \%$.

In Section 3.1, the percolation threshold was predicted as $0.7 \%$ by volume of mixture using the equation suggested by Li and Kim for Type M-25 GNPs [29]. Note that the analytical prediction suggests a lower bound as the actual GNP particles are not uniform. In addition, the analytical equation was proposed to predict the percolation threshold of conducting polymer composites containing GNP, i.e. not cementitious composites. The experimental results indicate that the critical volume ratio should be over $1 \%$. The predicted result from the analytical equation underestimates the actual percolation threshold. 
(a)

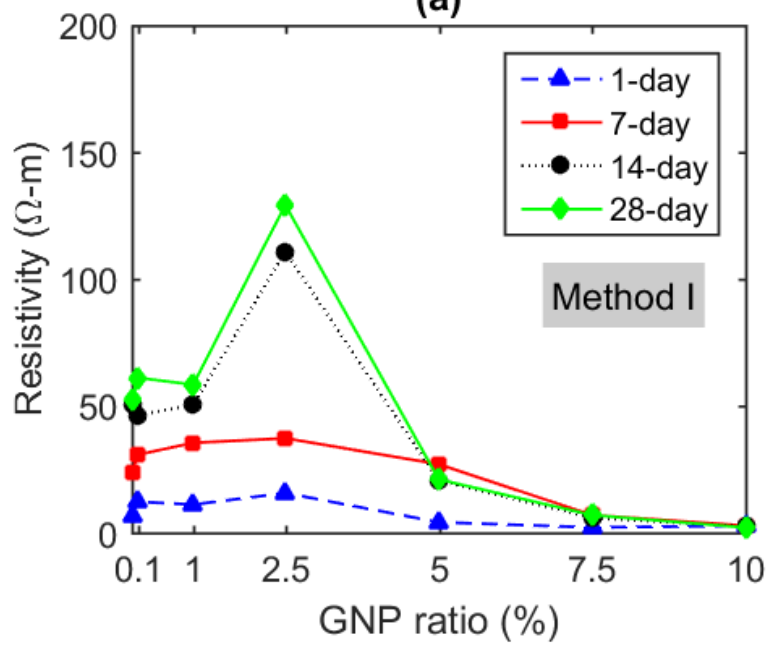

(c)

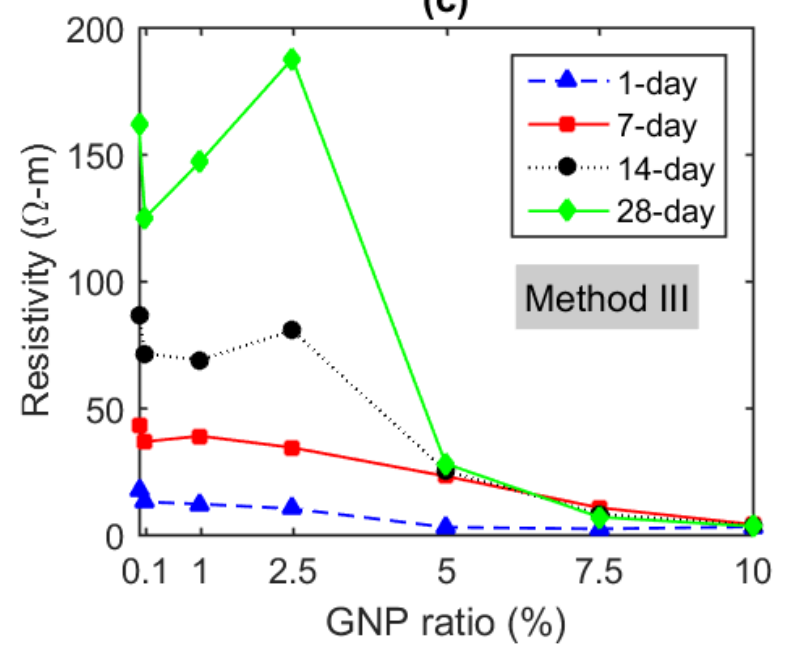

(b)

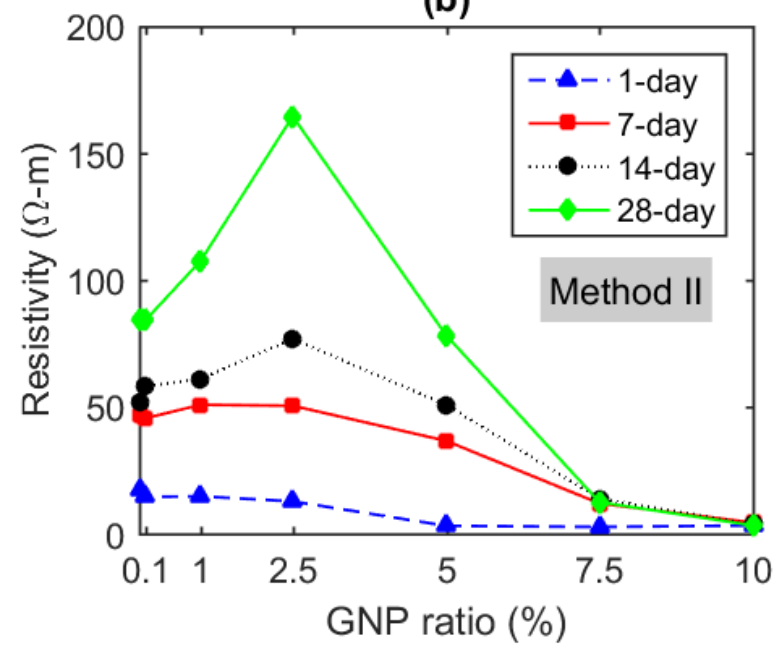

(d)

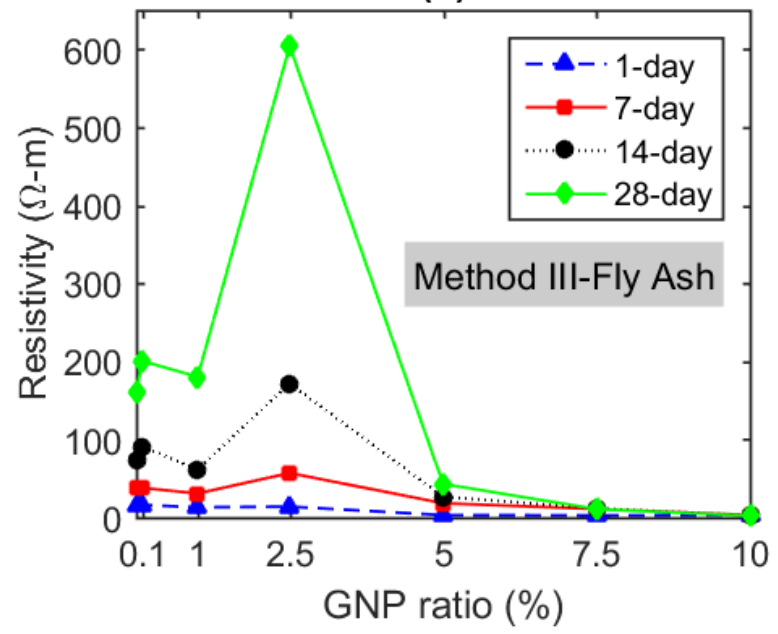

Figure 17. Electrical resistivity of mortar specimens with different GNP concentrations cast using (a) Method I; (b) Method II; (c) Method III and (d) Method III with Fly Ash.

To better assess the conductivity of mortar specimens prepared with different techniques, Figure 18 illustrates the electrical resistivity of the specimens containing 5\%, 7.5\% and 10\% GNPs at different curing ages. Recall that the mixing Method I employs ultrasonication to disperse GNPs while Method II and III rely on direct mixing of GNPs into the mortar mixture. For both 5\% and 7.5\% GNP ratio, the specimens cast using Method II produced higher resistivity values compared to the other two mixing methods. For $10 \%$ GNPs, the specimens cast using Method II obtained higher resistivity values at an early curing age, but after 14 days the resistivity values were almost the same with those of specimens cast using other two methods. 
The superplasticizer used in this study was a polycarboxylate-based superplasticizer and operated according to steric hindrance as dispersant. A steric dispersant works more efficiently if it is adsorbed first. In Method III, the GNP particles were first mixed with the superplasticizers before mixing them with the dry materials, a better dispersion, i.e. lower resistivity, was observed compared to the specimens cast using Method II, where the GNPs were first mixed with sand and cement. When the results of the specimens cast using Method I and Method III are compared, it can be seen they produce similar resistivity values for both the specimens with $5 \%$, $7.5 \%$ and $10 \%$ GNP ratios and at different curing ages. When $20 \%$ of the cement was replaced with fly ash in the specimens cast using Method III, there is a slight increase in electrical resistivity measurements, except the specimens with $10 \%$ GNPs. From SEM image shown before, fly ash would fill in tiny pores inside specimens, which might block the connections of GNPs, when the GNP ratio was much higher, more GNPs formed connections which may not be influenced by the fly ash.

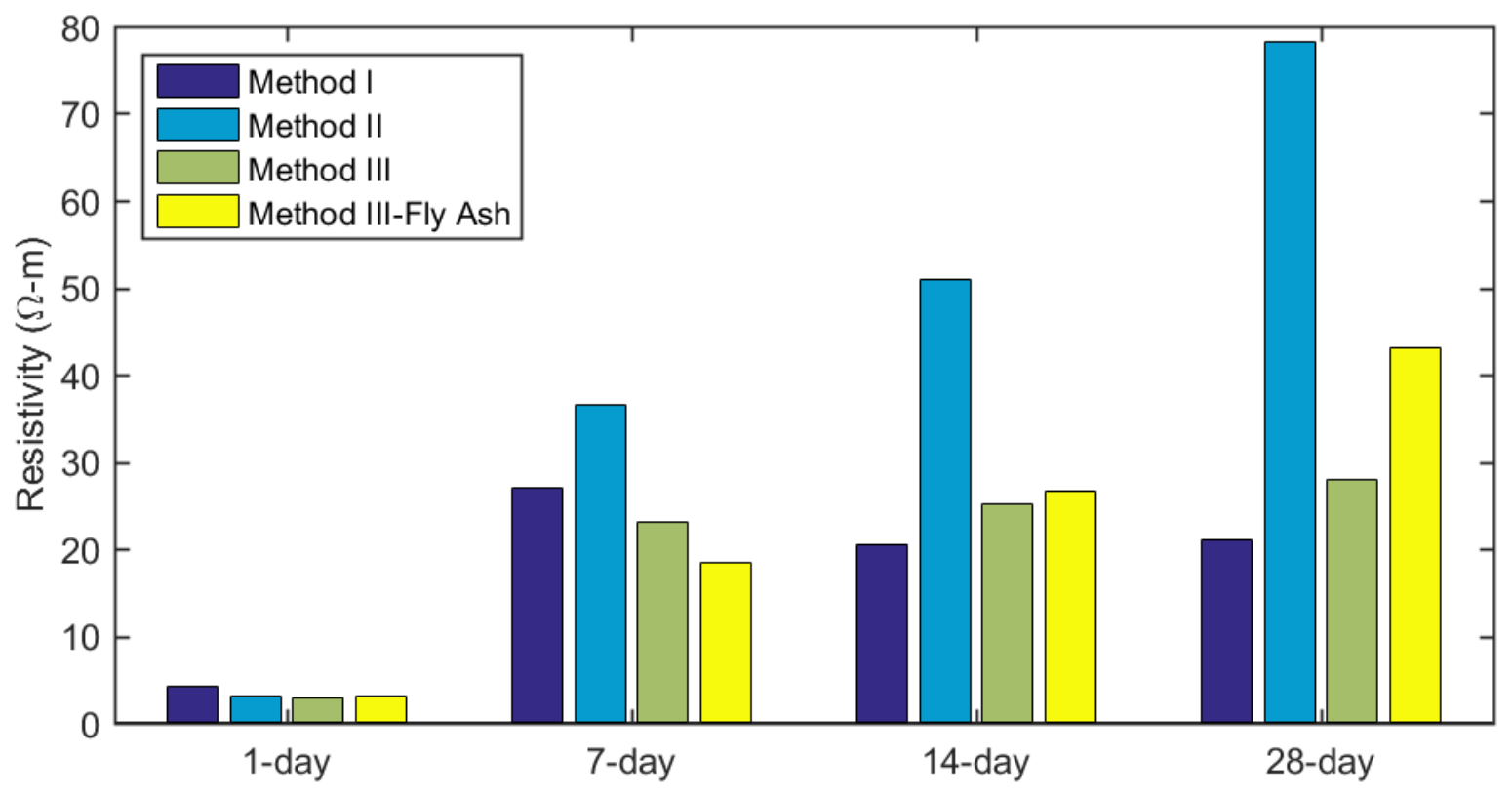

(a) 


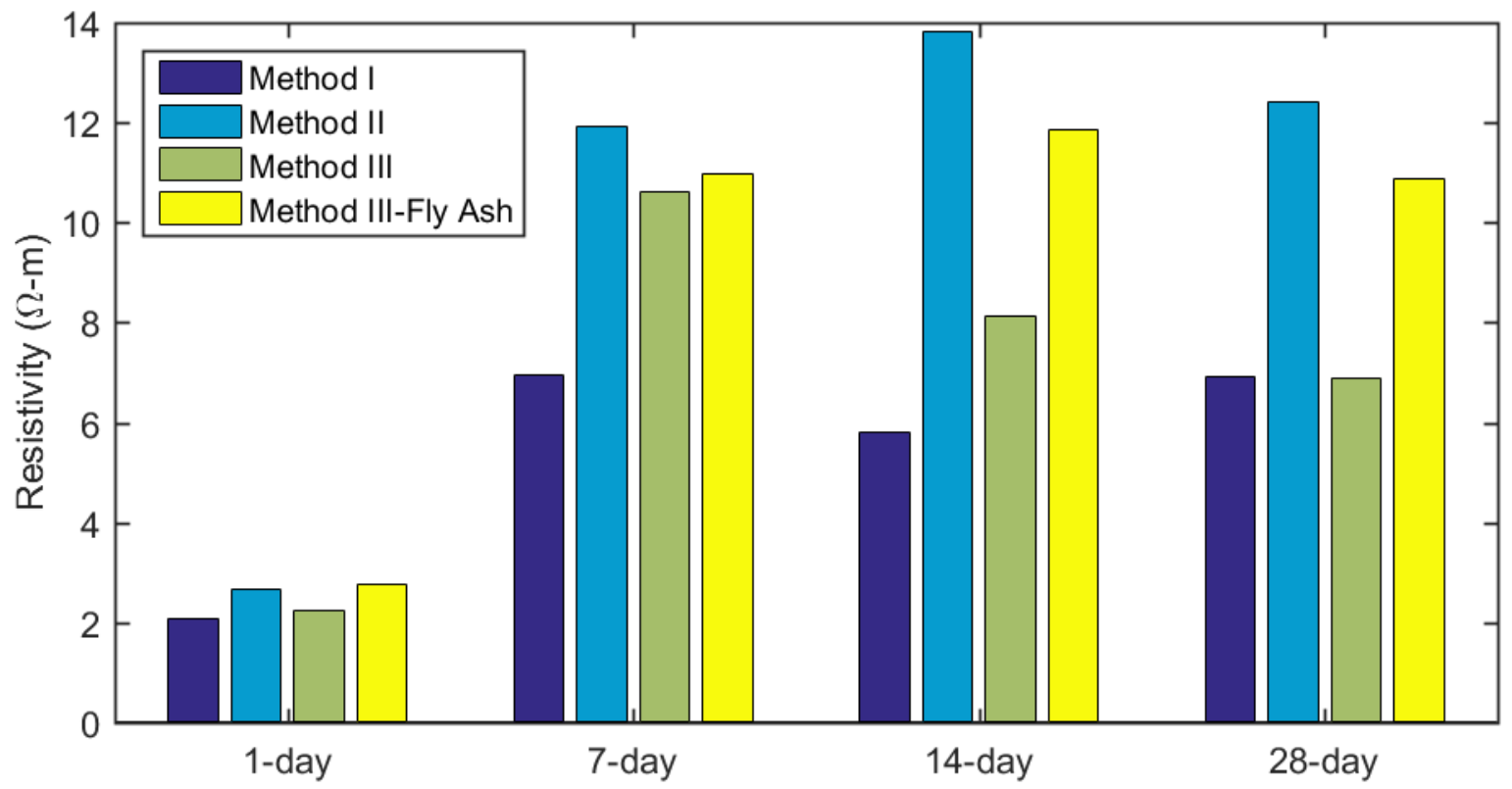

(b)

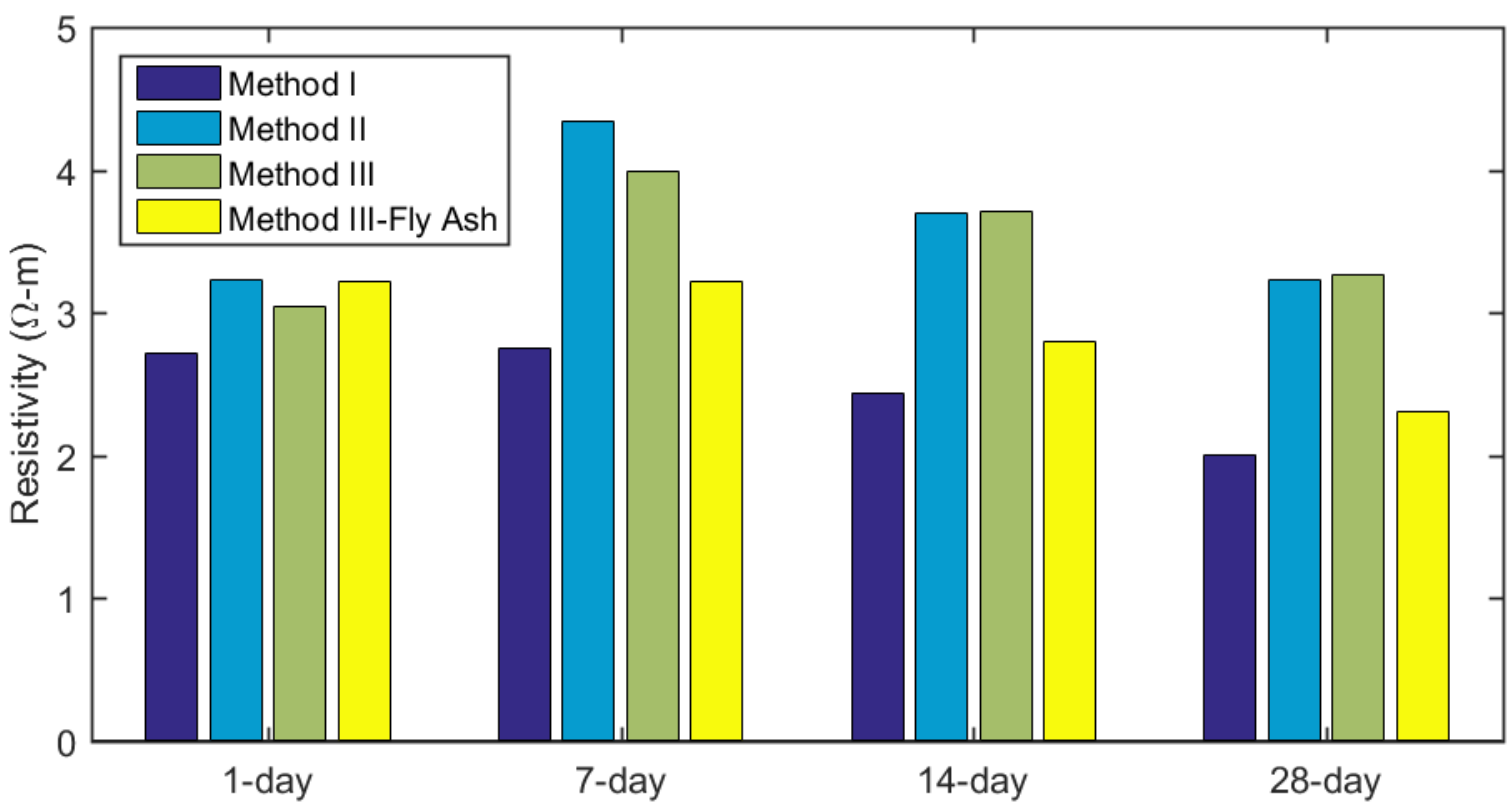

(c)

Figure 18. Electrical resistivity of mortar specimens with (a) $5 \%$; (b) $7.5 \%$ and (c) $10 \%$ GNPs at different curing age. 


\section{4. Effect of Dispersant}

Figure 19 illustrates the electrical resistivity measurements for the specimens with $2.5 \%$ GNP prepared with different dispersants: a surfactant and a superplasticizer. For mixing Method II, the resistivity of the specimens with surfactant at different curing ages was higher than that of specimens with superplasticizer as shown in Figure 19(b). On the other hand, for mixing Method I, the resistivity of the specimens prepared with surfactant was lower than that of specimens with superplasticizer except at 7 days as shown in Figure 19(a). This indicates that the mixing of the surfactant with ultrasonication might be more effective than sole mechanical mixing of the surfactant in the composite. However, further investigations are needed to evaluate the effect of different dispersants on the electrical resistivity of mortar composites.
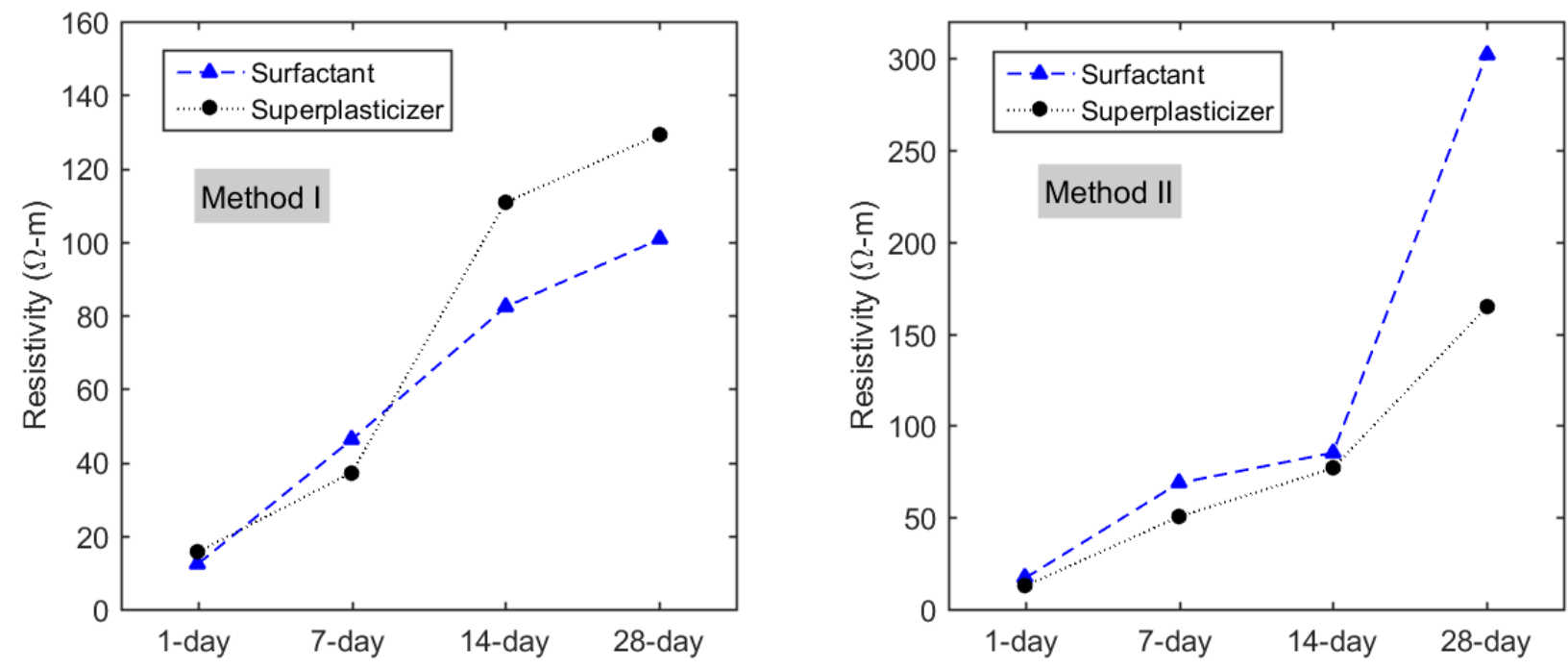

Figure 19. Electrical resistivity of specimens with 2.5 GNPs dispersed with surfactant or superplasticizer using (a) Method I and (b) Method II.

\section{5. Effect of Different Measurement Techniques}

In order to evaluate the effect of different measurement techniques, two batches of specimens with each mixing method were chosen. One batch with 2.5\% GNPs embedded copper meshes was named Batch 1, while the other batch with 2.5\% GNPs cooperated with copper tape was called Batch 2. A resistivity meter was also applied on the side surface of the chosen specimens as control group. The electrical resistivity measurements obtained using different 
measurement methods are listed in Table 6. As shown in the Table 6, the resistivity values measured by the resistivity meter were much higher than those measured with the copper tapes and the embedded copper meshes. For the specimens cast using Method I, using the ratio of the resistivity measurements obtained with resistivity meter in the Batch 1 and Batch 2, the resistivity of Batch 2 can be calculated to be $86.4 \Omega-\mathrm{m}$ if the copper meshes were used to measure the resistivity. This value is very close to the resistivity measured using copper tape for Batch 2, which suggest that measurements with the copper tape and copper mesh produce similar results. Similar observations were made for the specimens cast using Method II and III. Although the resistivity measured with the resistivity meter had higher values as compared to those made with embedded meshes, a similar trend of change with different GNP ratios were observed for both measurement methods as shown in Figure 20.

Table 6. Resistivity measurements with different methods at 28 days of specimens cast using Method I; Method II and Method III

\begin{tabular}{cccc}
\hline Mixing method & Batch & Measurement & $\begin{array}{c}\text { Average Resistivity, } \\
\mathbf{\rho}(\mathbf{\Omega}-\mathbf{m})\end{array}$ \\
\hline Method I & 1 & Resistivity meter & 670.2 \\
& 1 & Copper meshes & 129.2 \\
& 2 & Resistivity meter & 448.3 \\
Method II & 2 & Copper tape & 85.1 \\
& 1 & Resistivity meter & 685.8 \\
& 1 & Copper meshes & 164.5 \\
Method III & 2 & Resistivity meter & 428.4 \\
& 2 & Copper tape & 90.0 \\
& 1 & Resistivity meter & 747.3 \\
& 1 & Copper meshes & 187.55 \\
& 2 & Resistivity meter & 901.7 \\
& 2 & Copper tape & 246.3 \\
\hline
\end{tabular}



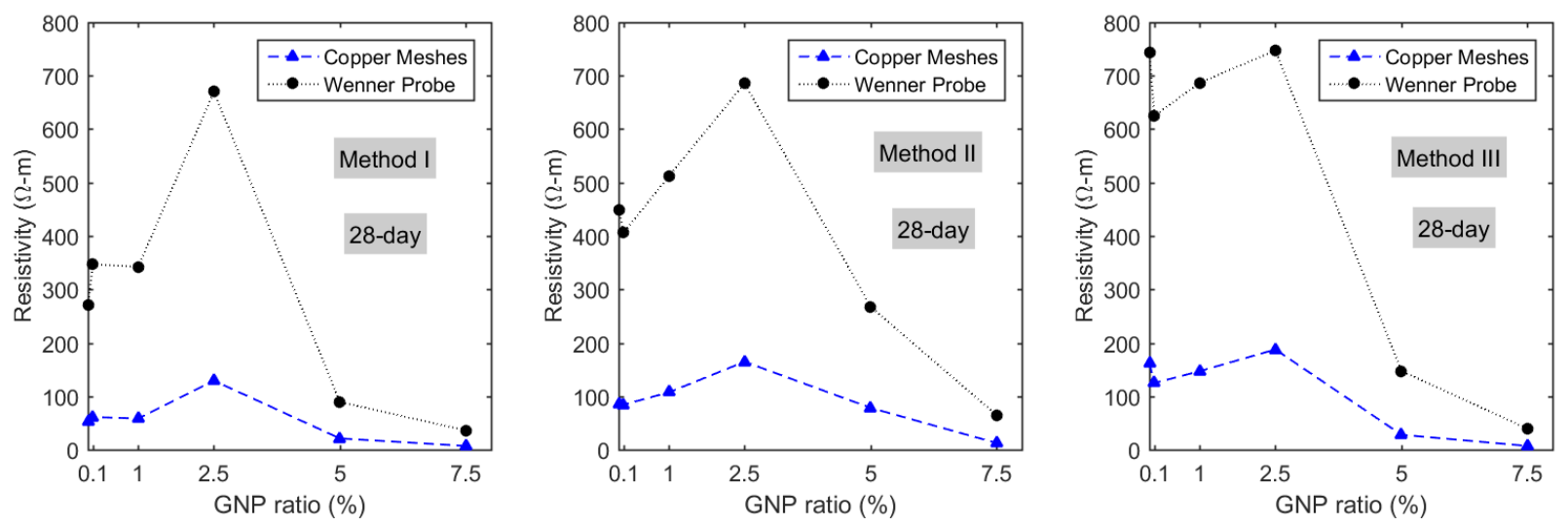

Figure 20. Comparison of results measured using Wenner Probe and Copper meshes.

\section{6. Cyclic Compression Test Results}

\subsubsection{Results for mortars with $0 \%$ to $7.5 \%$ GNPs}

Figures 21 to 28 show the cyclic compression response of the specimens prepared by the selected methods. In the figures, the blue line represents the loading cycle, while the orange line represents the fractional change in resistivity response to the load. It can be seen that at low GNP concentrations $(<5 \%)$, the response did not show a clear correspondence between the applied load and the change in resistivity, but when GNP ratio exceeded 5\%, correlation was observed.

For the higher concentrations, the resistivity values decreased with an increase in compression load, while the resistivity increased during the unloading during each loading cycle. The response was more nonlinear for the specimens with 5\% GNPs compared to those of the specimens with $7.5 \%$ GNPs. In particular, the rate of decrease in resistivity is reduced with increasing load.

It can be also seen that the fractional changes in resistivity of most of the specimens did not return to zero after completion of each loading cycle. The fractional change in resistivity of these specimens were negative after every cycle, which means that the resistivity of specimen was smaller than the resistivity of the specimen at the initial state. This might be attributed to the polarization effect that will be discussed in the next section and possibly the large amount of tiny voids inside of the specimens at the beginning of the test. During the high-speed mixing time, air was introduced into the mortar paste, which resulted in voids in the specimens after curing. The 
tiny voids might break up after loading the compression load. Thus, more surface area attached together which made the specimens more conductive and also decreased the resistivity values of the specimens.

When the test results for Method I and Method III are compared, it can be seen that the amplitudes of fractional changes are usually higher for the specimens cast using Method III, indicate better piezoresistive behavior. 

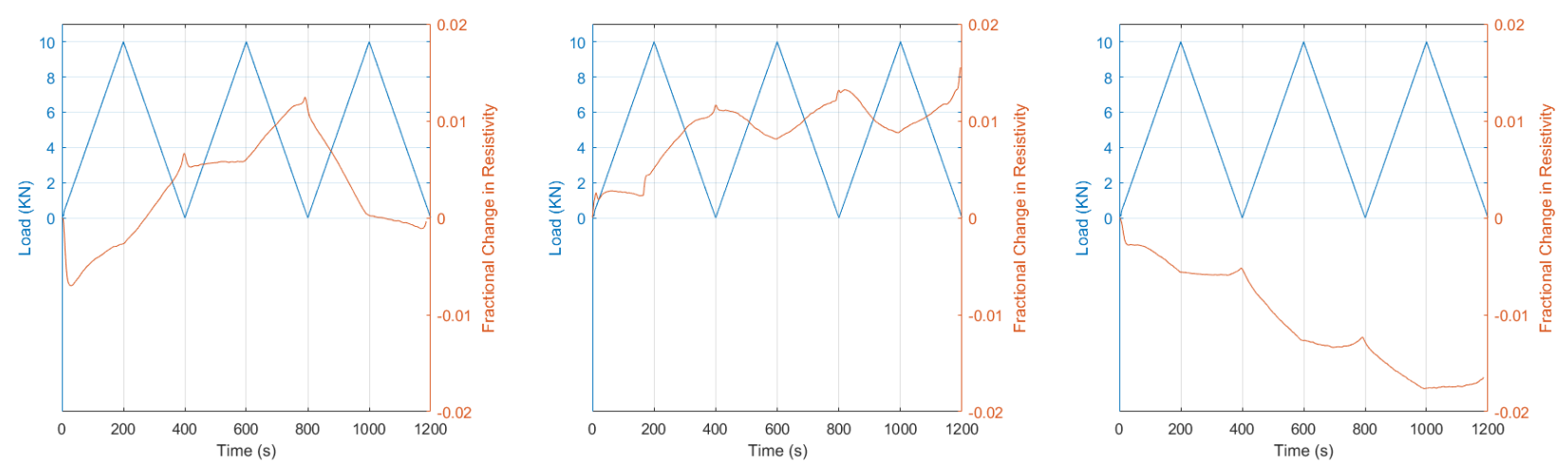

(a)
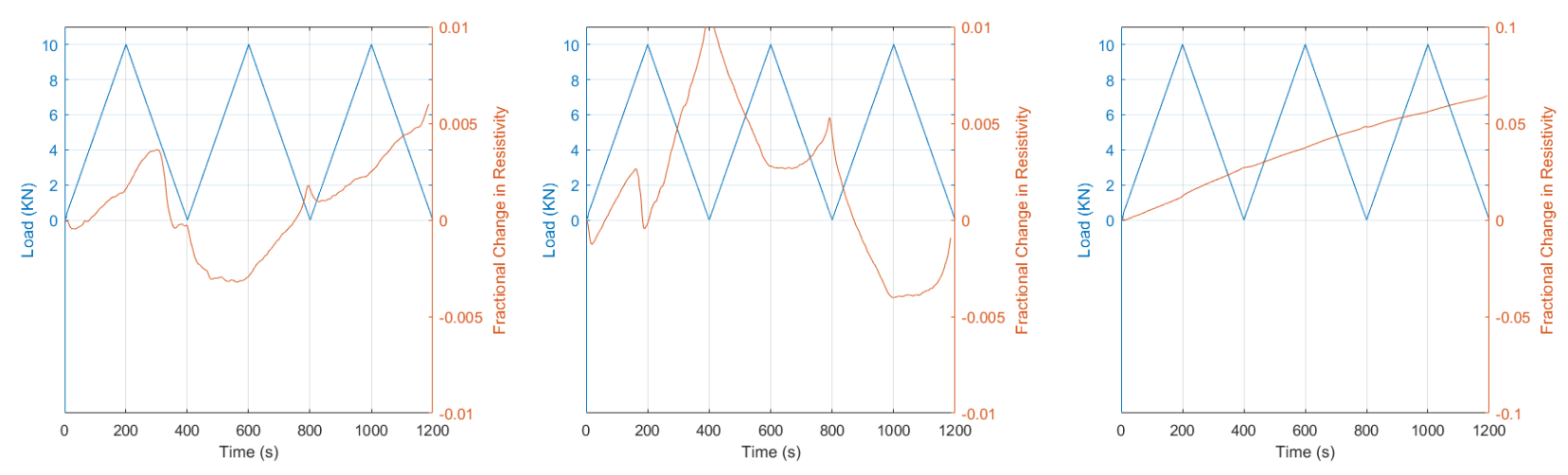

(b)
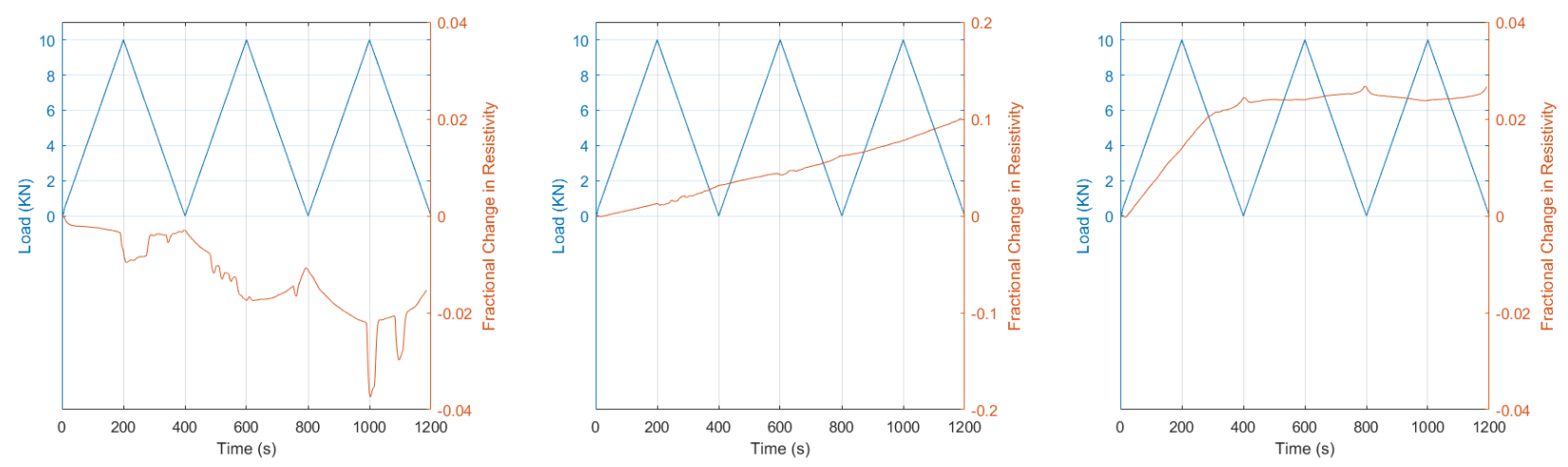

(c)

Figure 21. Cyclic compression response of specimens cast using Method I with (a) $0 \%$ GNPs; (b) 0.1\% GNPs; (c) 1\% GNPs. 

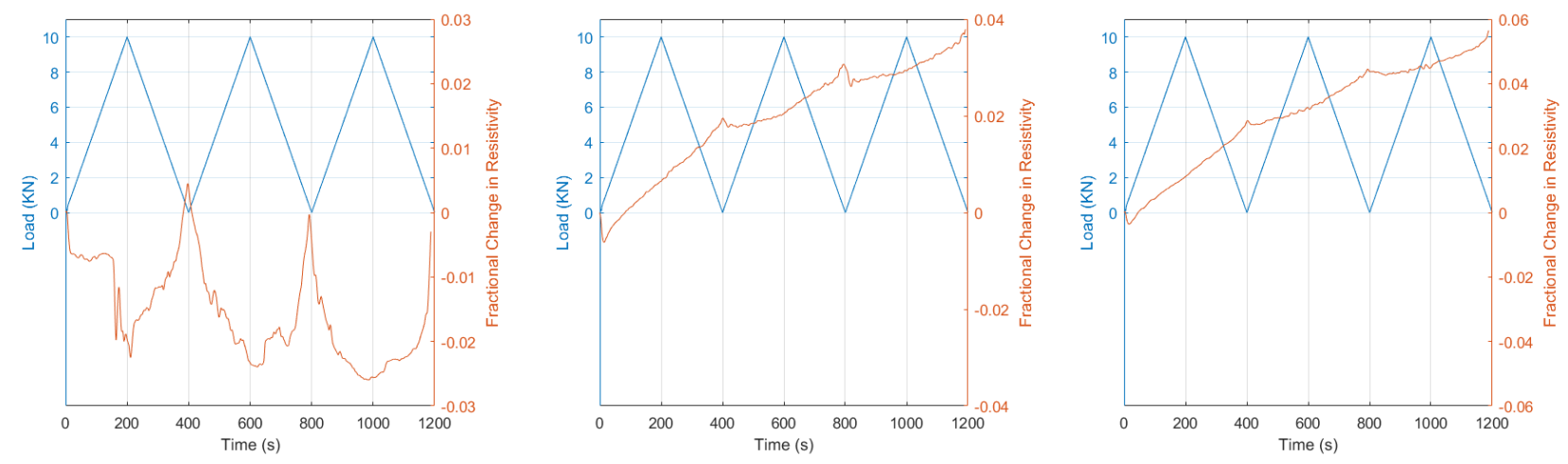

(a)
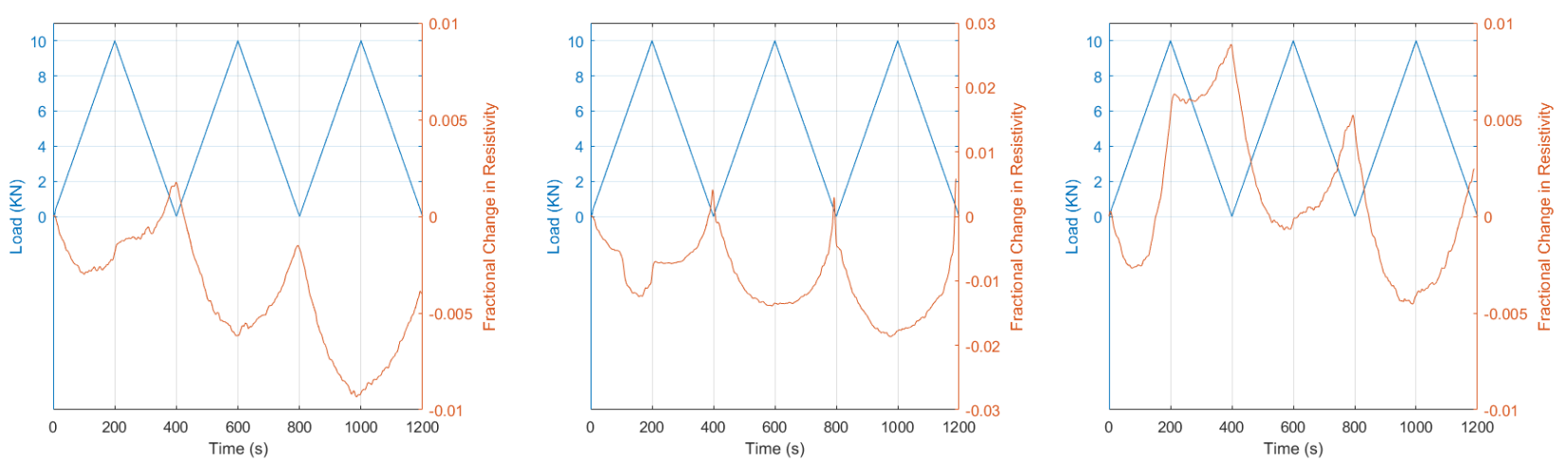

(b)
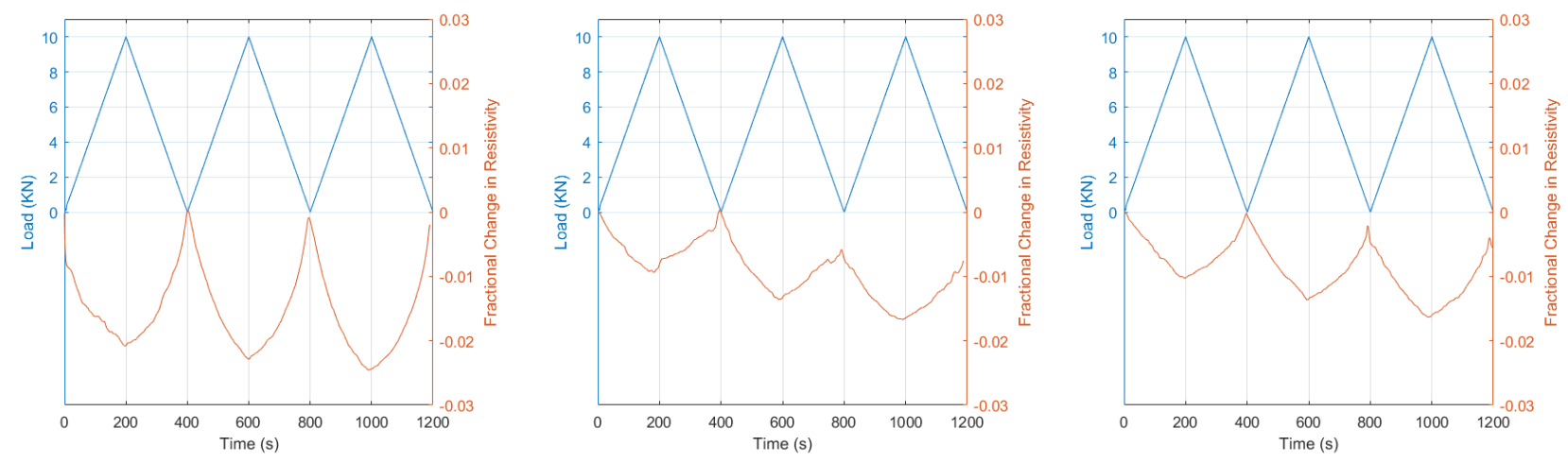

(c)

Figure 22. Cyclic compression response of specimens cast using Method I with (a) $2.5 \%$ GNPs; (b) 5\% GNPs; (c) 7.5\% GNPs. 

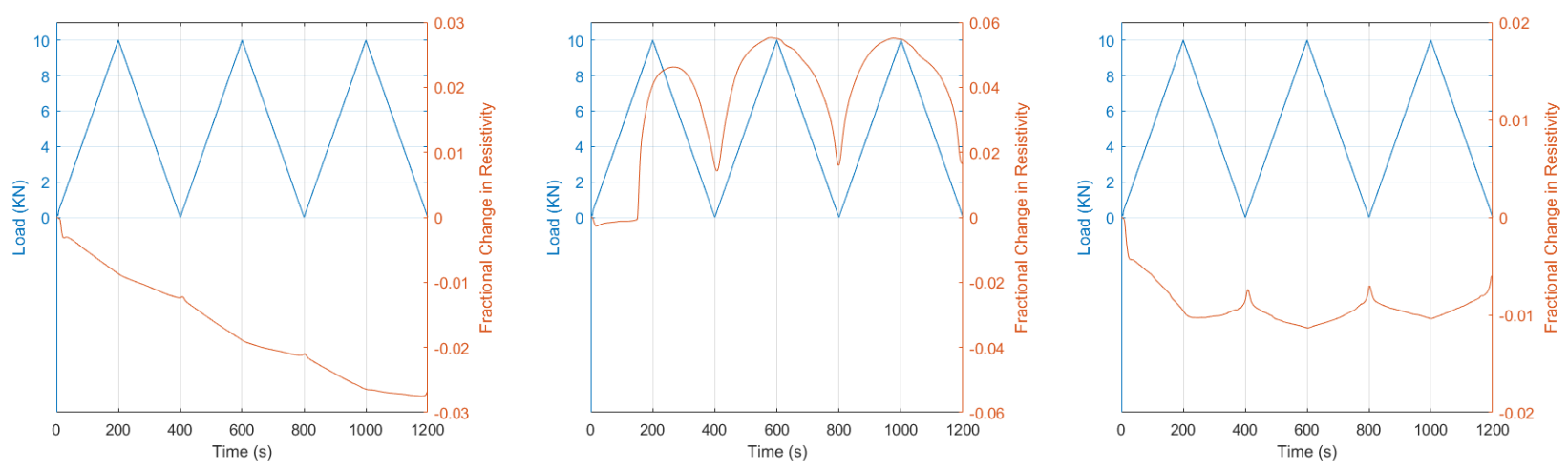

(a)
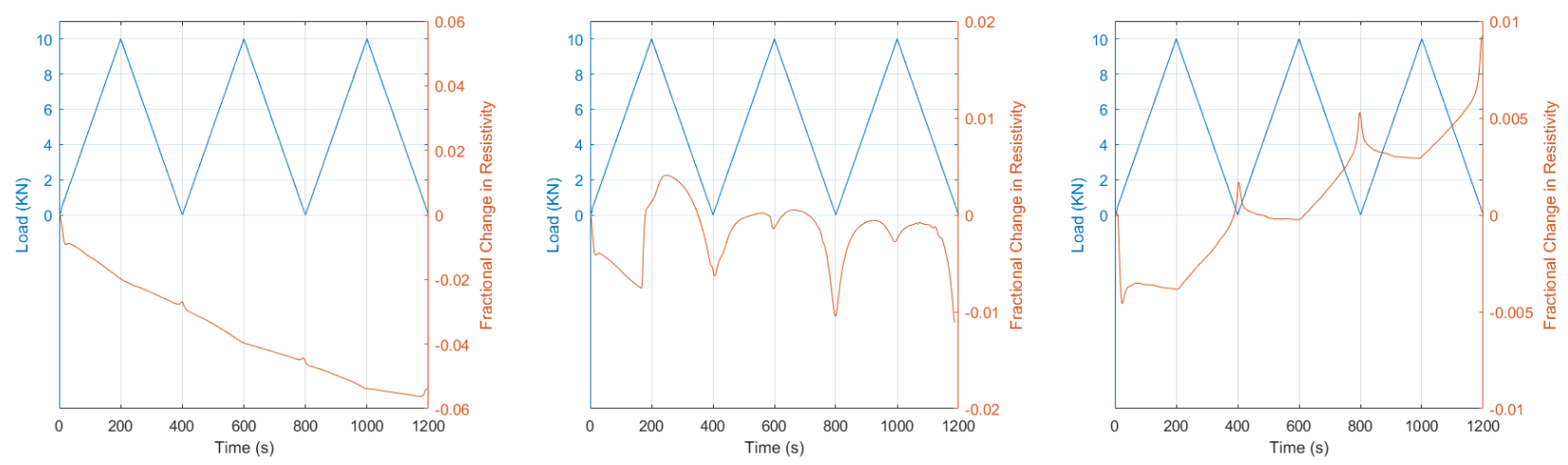

(b)
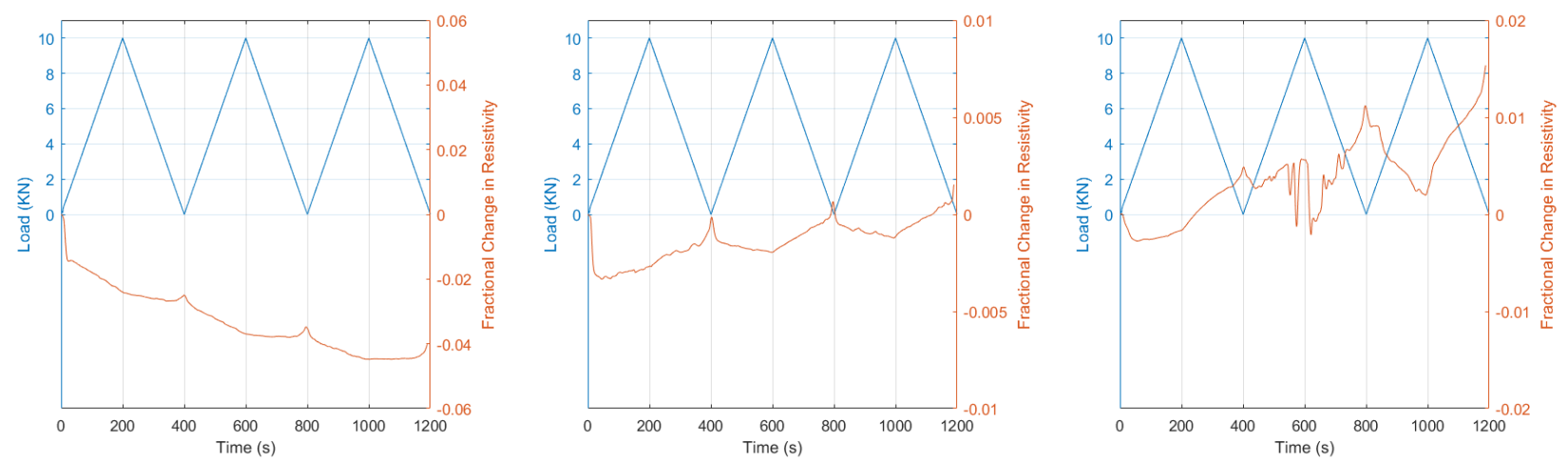

(c)

Figure 23. Cyclic compression response of specimens cast using Method II with (a) $0 \%$ GNPs; (b) 0.1\% GNPs; (c) 1\% GNPs. 

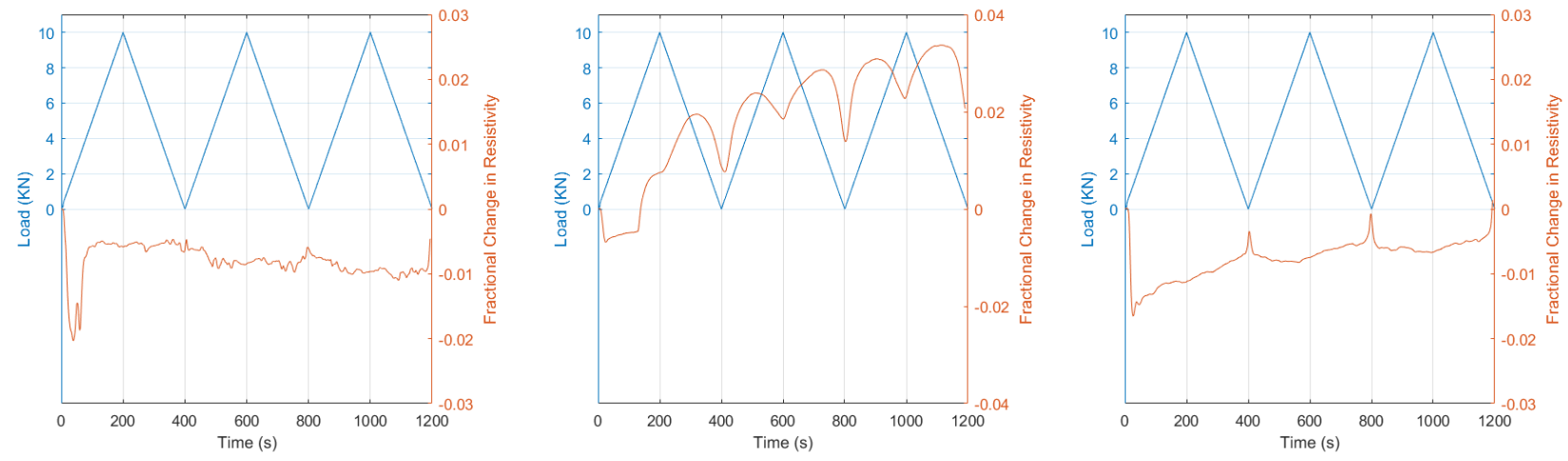

(a)
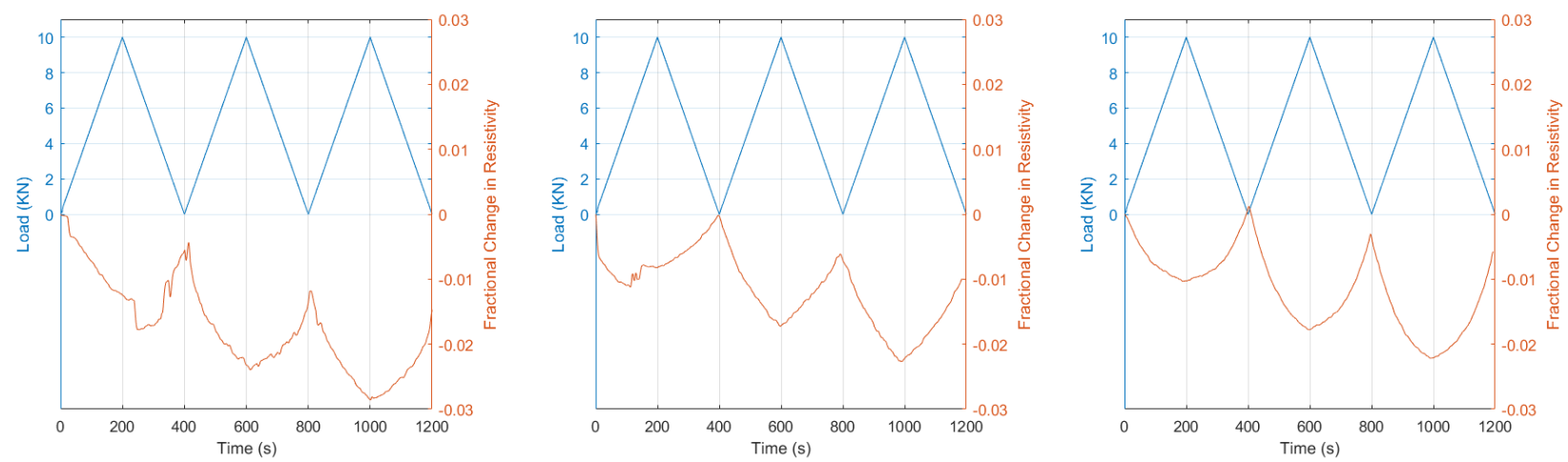

(b)
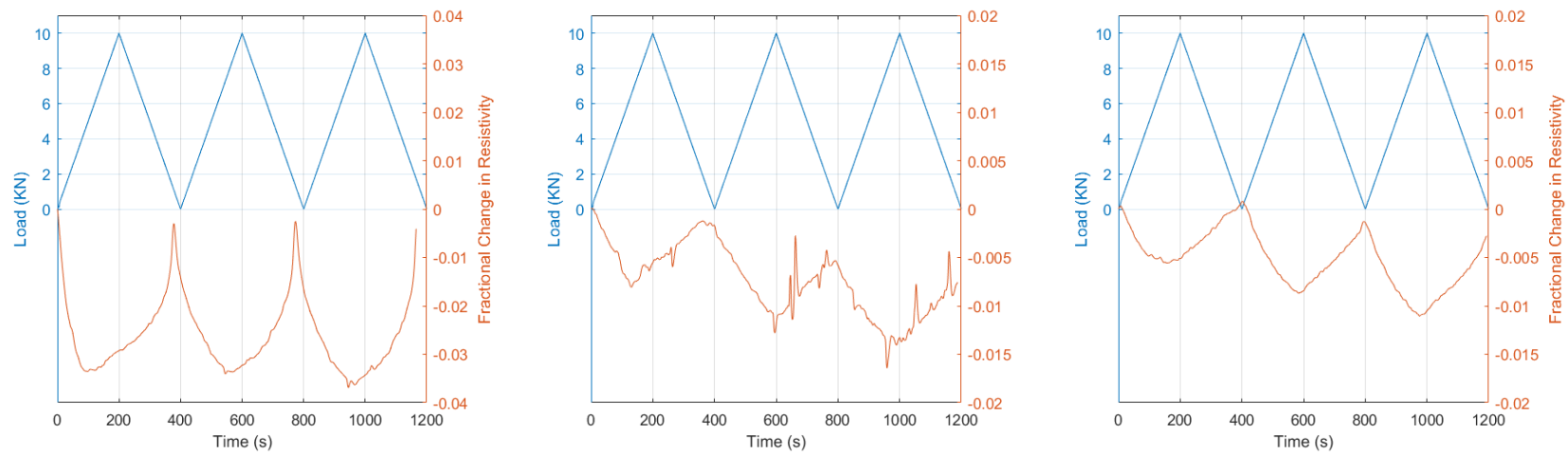

(c)

Figure 24. Cyclic compression response of specimens cast using Method II with (a) $2.5 \%$ GNPs; (b) $5 \%$ GNPs; (c) $7.5 \%$ GNPs. 

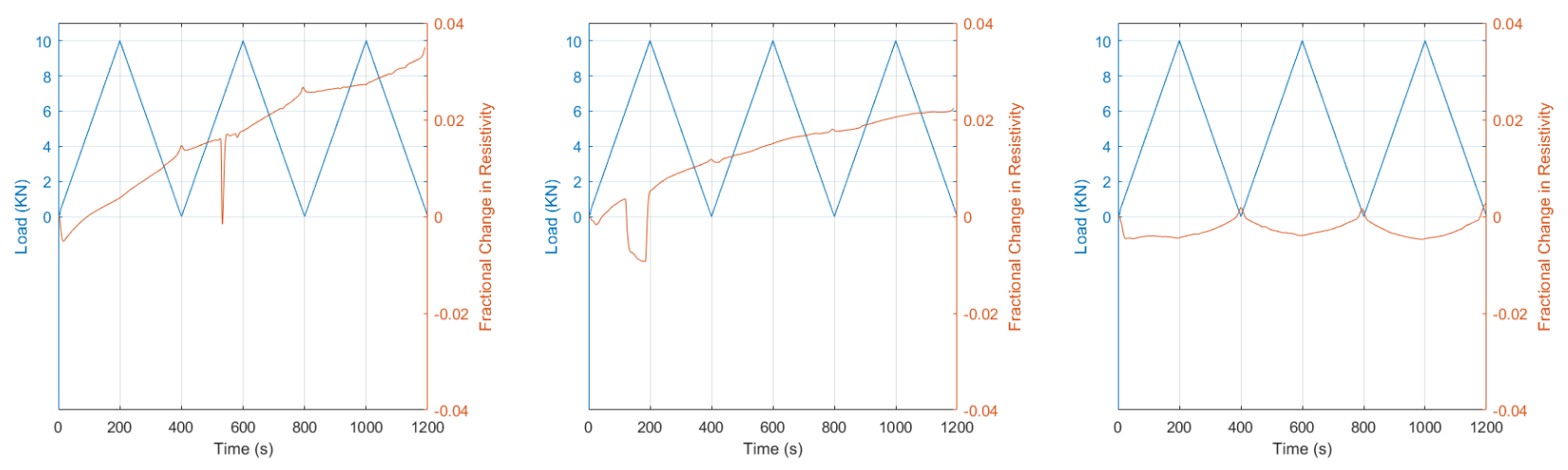

(a)
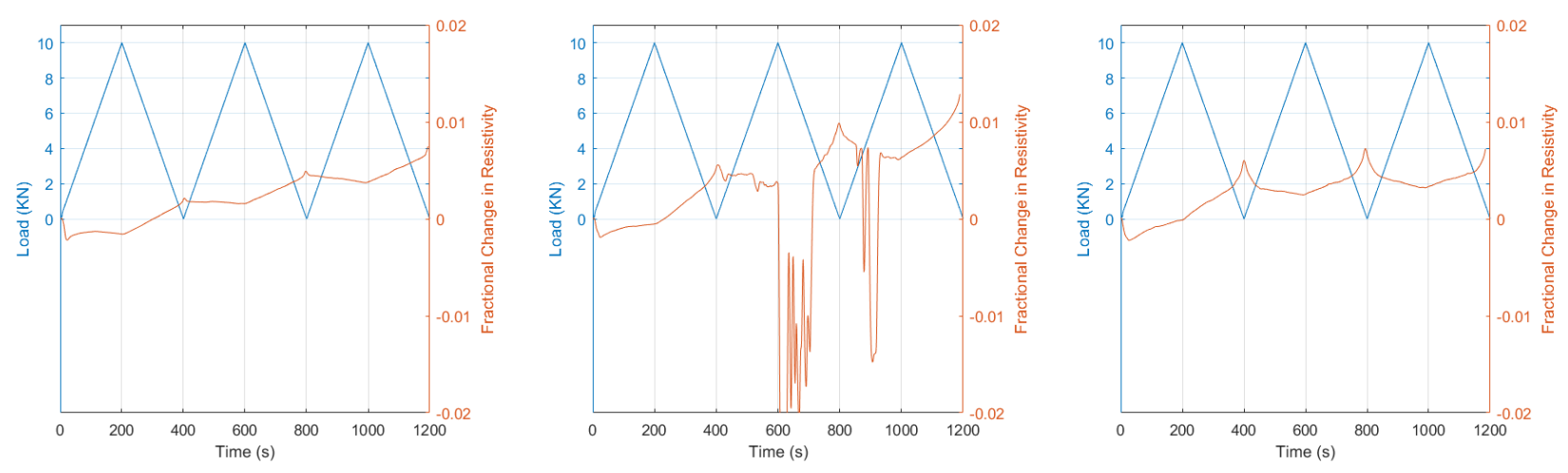

(b)
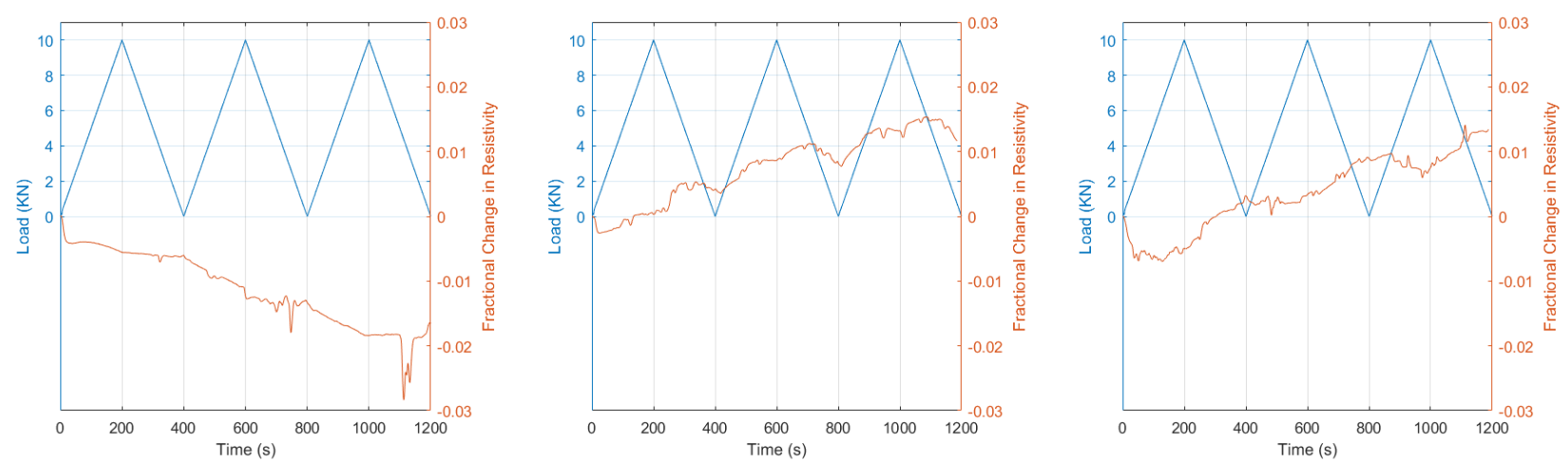

(c)

Figure 25. Cyclic compression response of specimens cast using Method III with (a) $0 \%$ GNPs; (b) 0.1\% GNPs; (c) 1\% GNPs. 

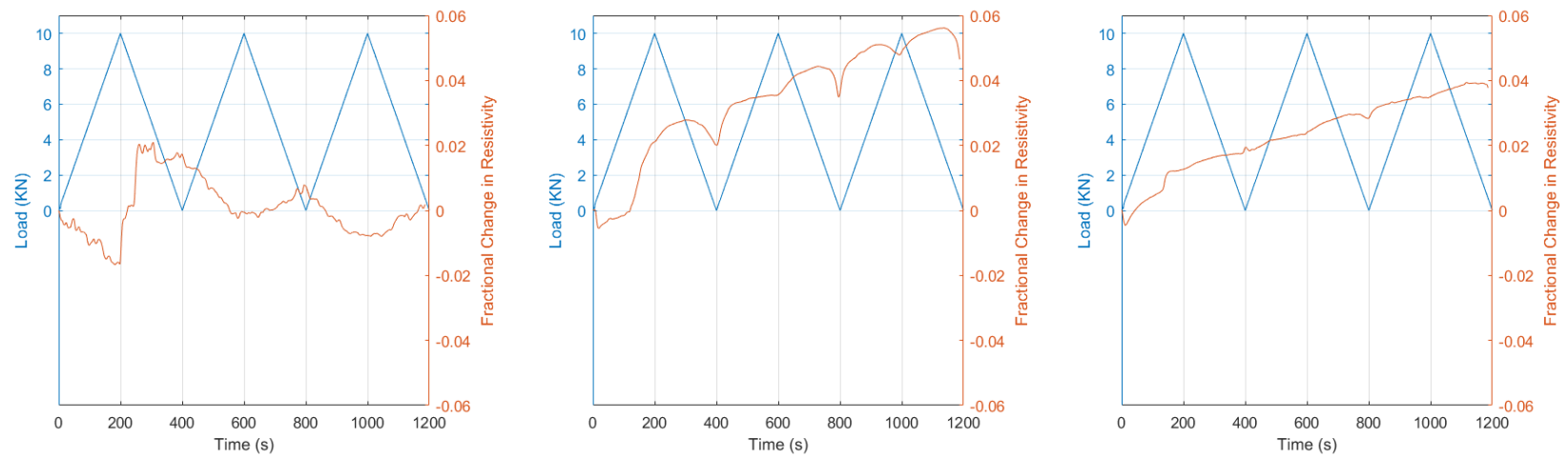

(a)
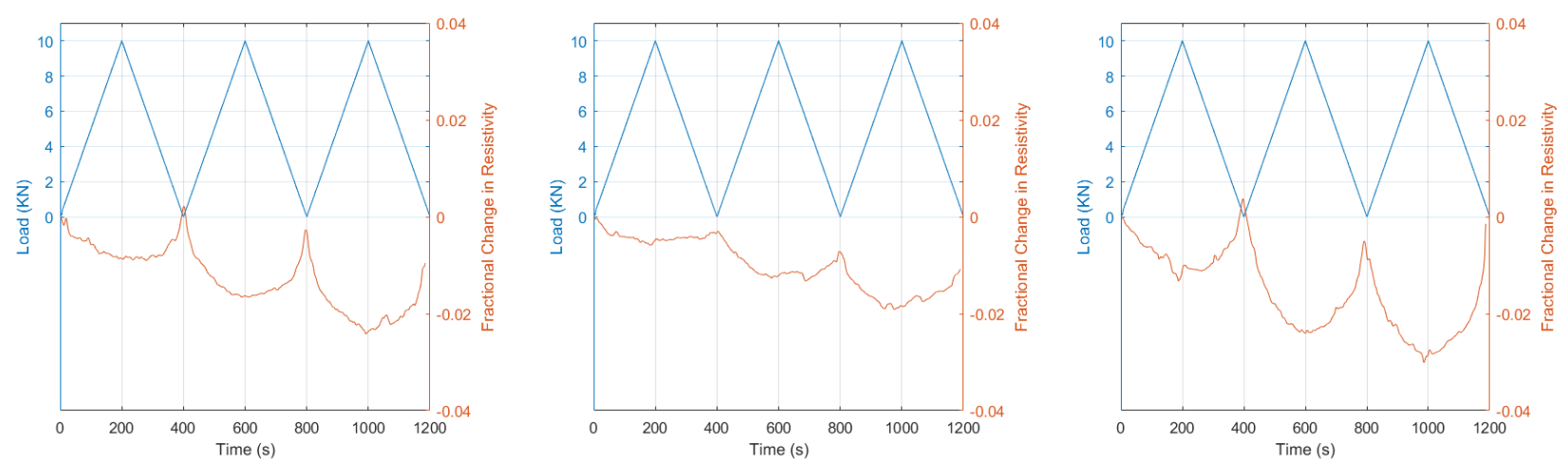

(b)
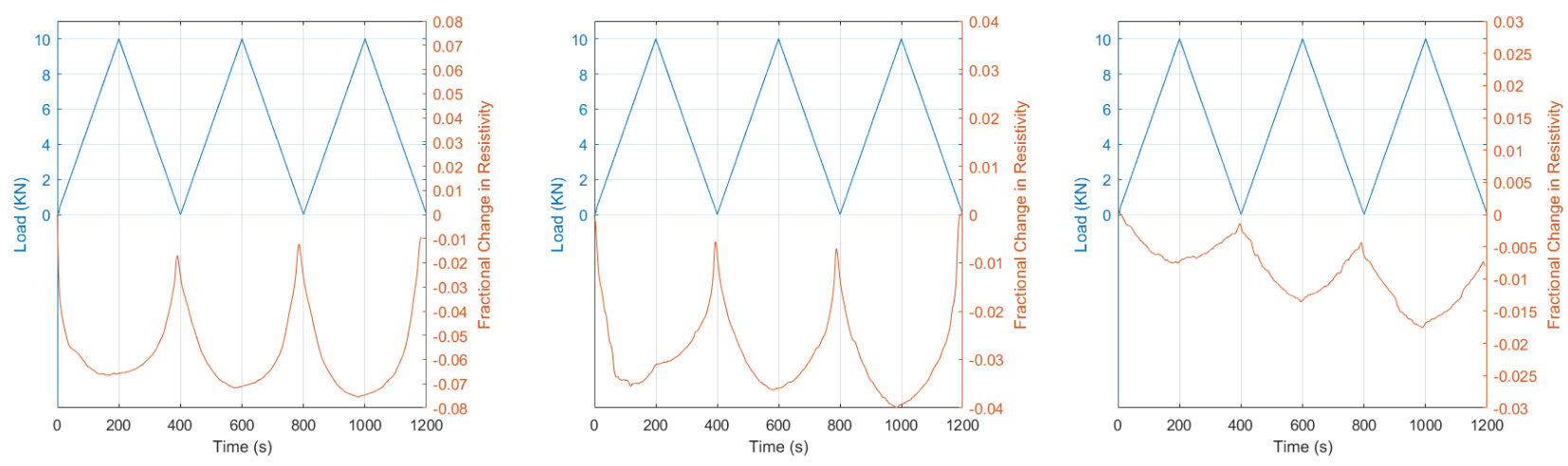

(c)

Figure 26. Cyclic compression response of specimens cast using Method III with (a) $2.5 \%$ GNPs; (b) $5 \%$ GNPs; (c) $7.5 \%$ GNPs. 

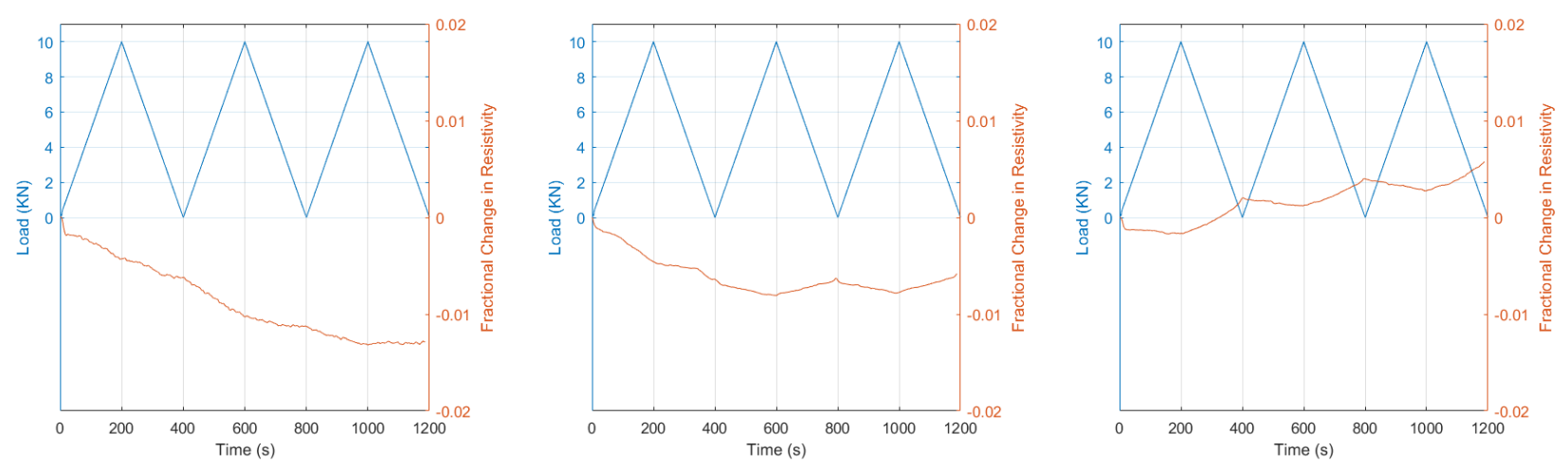

(a)
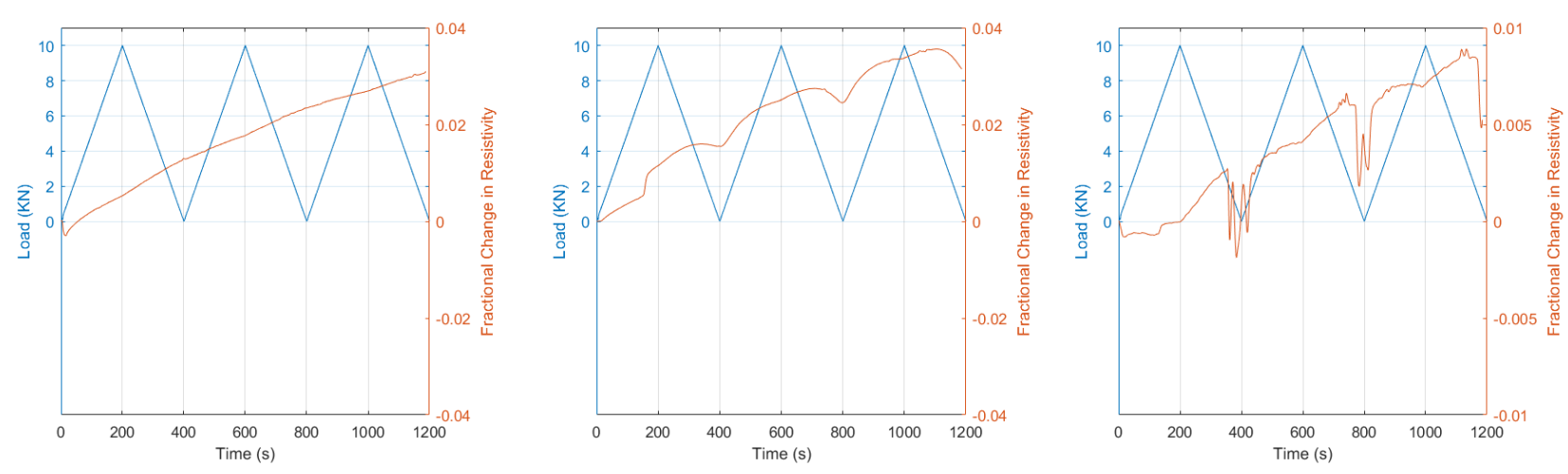

(b)
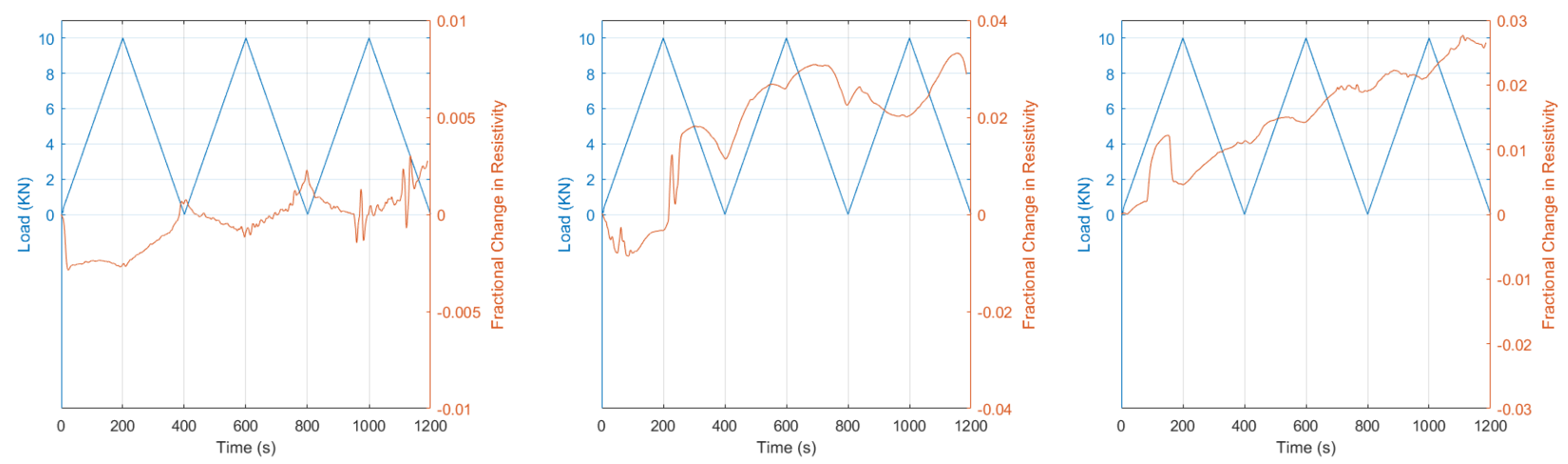

(c)

Figure 27. Cyclic compression response of specimens cast using Method III with Fly Ash with (a) 0\% GNPs; (b) 0.1\% GNPs; (c) 1\% GNPs. 

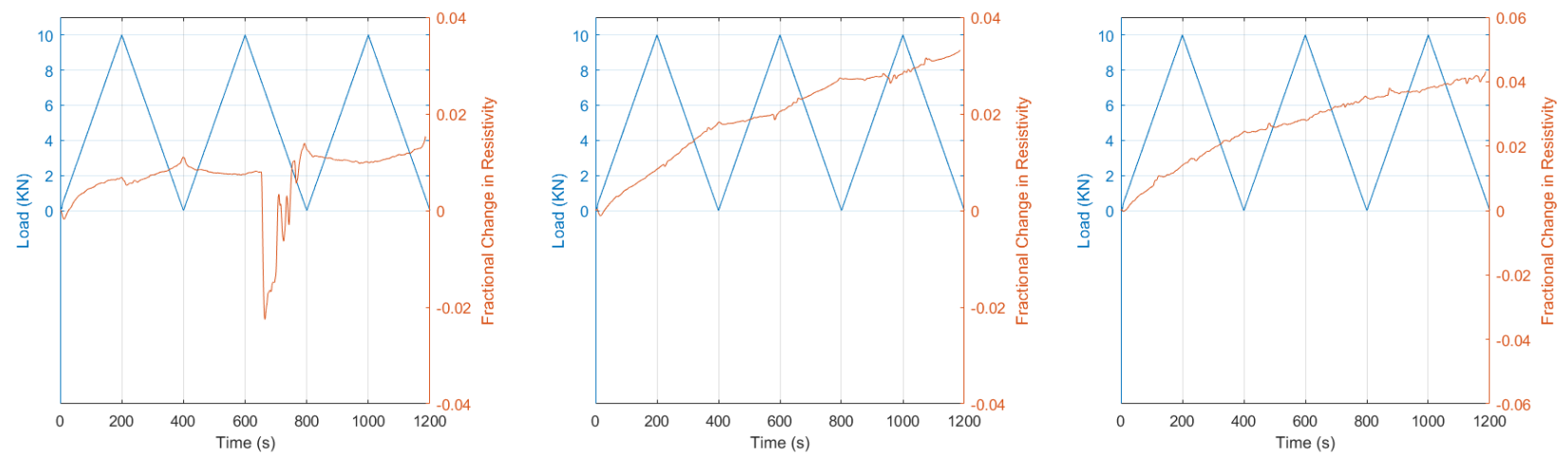

(a)
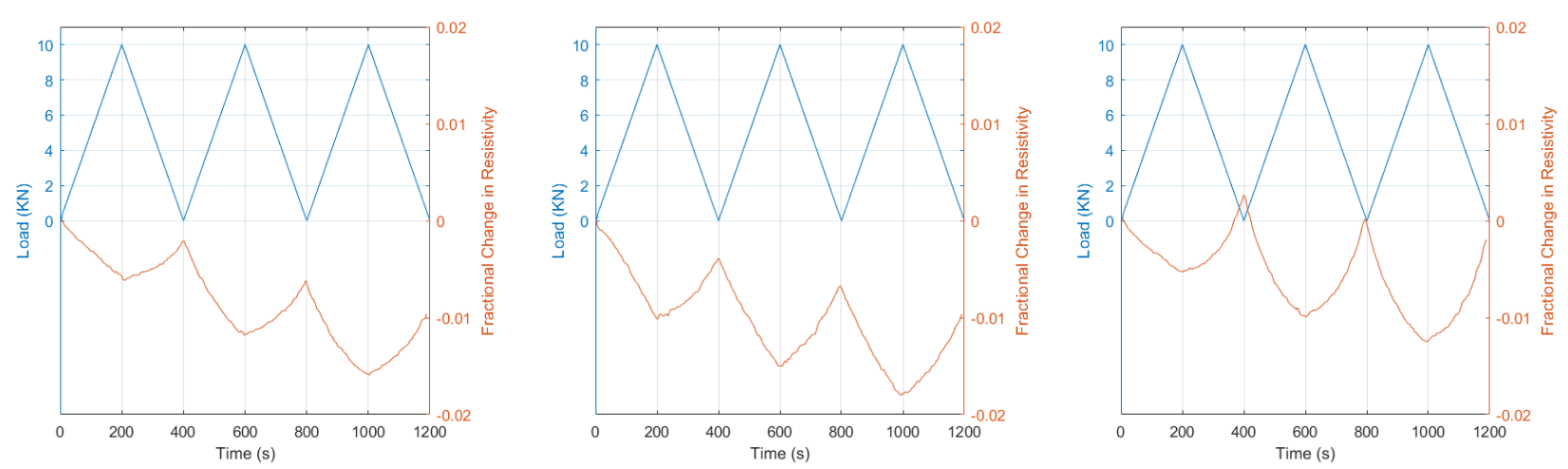

(b)
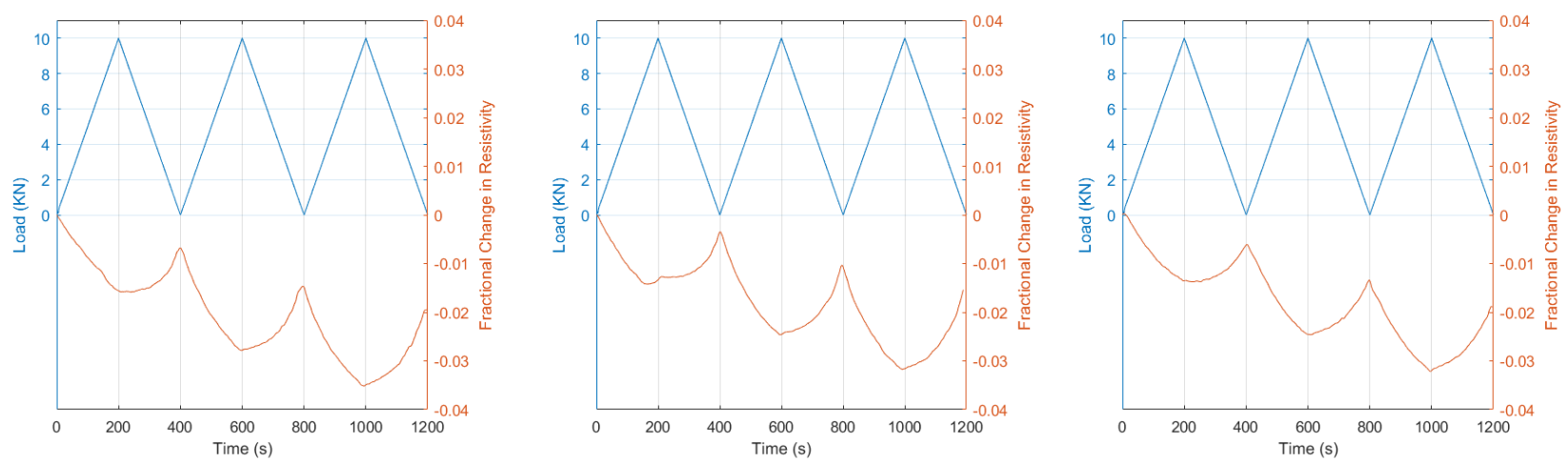

(c)

Figure 28. Cyclic compression response of specimens cast using Method III with Fly Ash with (a) 2.5\% GNPs; (b) 5\% GNPs; (c) $7.5 \%$ GNPs. 


\subsubsection{Results for mortars with $10 \%$ GNPs}

As discussed in previous sub-section, the resistivity values decreased during the cyclic compression tests. One reason for this decrease might be the use of DC power supply during the measurements. As a DC electrical field is applied during the electrical resistance measurement, the movement and aggregation of the ions in concrete matrix will lead to an electrical polarization in the composite. It is difficult to measure the changes accurately in resistance of the composite caused by external loading with the DC measurement, but the polarization effect in this measurement can be nullify by applying the DC voltage potential well ahead of the loading the composite such that all the resistance values reach a constant plateau [3]. In order to eliminate the polarization effect caused by DC measurement, the specimens with $10 \%$ GNPs were charged with the DC voltage potential for four hours before the cyclic compression test. The resistivity change of the specimens cast using different mixing methods during these four hours are shown in Figure 29. It can be seen that the resistivity of all specimens decreased as time going. The resistivity was still decreasing after four hours but the rate of decrease was very small compared to the initial rate. 


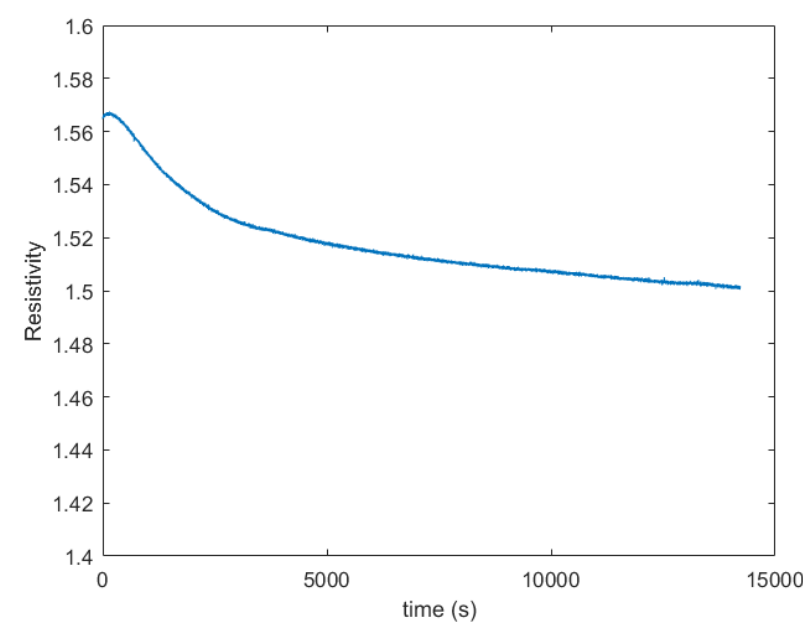

(a)

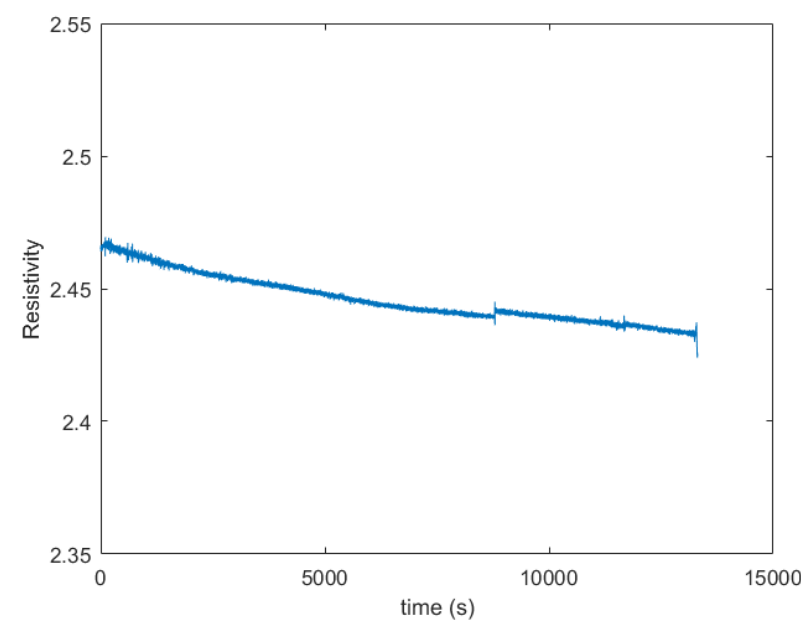

(c)

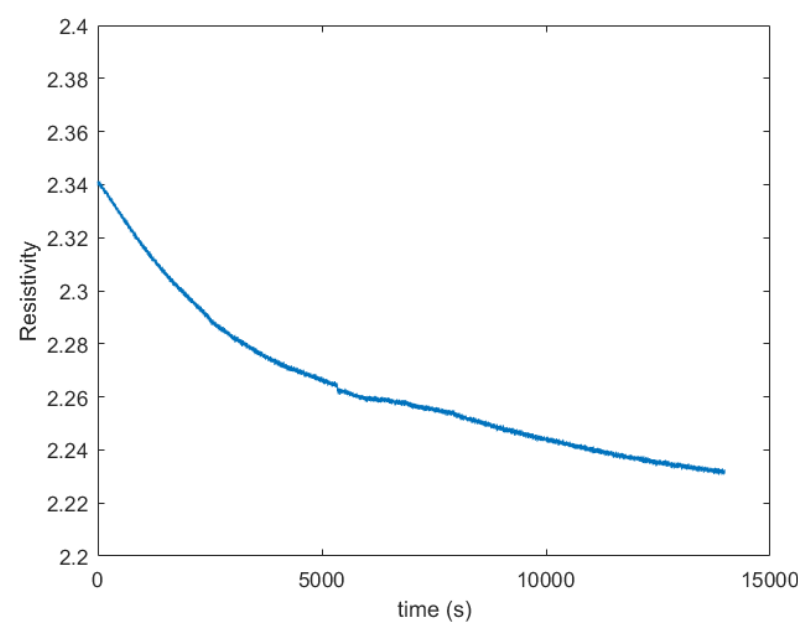

(b)

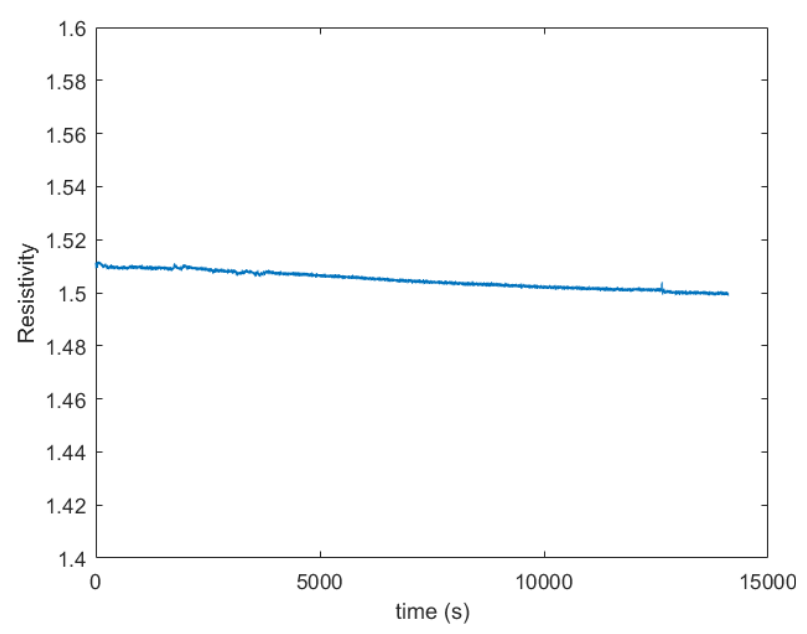

(d)

Figure 29. Fractional change in resistivity of specimens in 4 hours cast using (a) Method I; (b) Method II; (c) Method III; (d) Method III with fly ash.

After 4 hours, all the specimens were tested for cyclic compression test at different load levels. Figure 30 shows the test results of specimens cast using different mixing methods. A similar relation between the applied load and fractional change in resistivity as what was discussed earlier was observed. With the increase in load amplitude, the vertex of the parabola also increased. There was still a drift in the fractional change in resistivity of specimens after each cycle completed except for the specimens prepared by Method III with fly ash. The drift 
was larger in the specimens cast using Method I and II compared to those cast with Method III. In Figure 29, the resistivity of specimens cast using Method III and Method III with fly ash were approaching a plateau. So, in Figure 30(c) and (d), the drift was mainly due to the tiny voids inside the composite, but in Figure 30(a) and (b), the drift was caused by both tiny voids and the polarization effect.

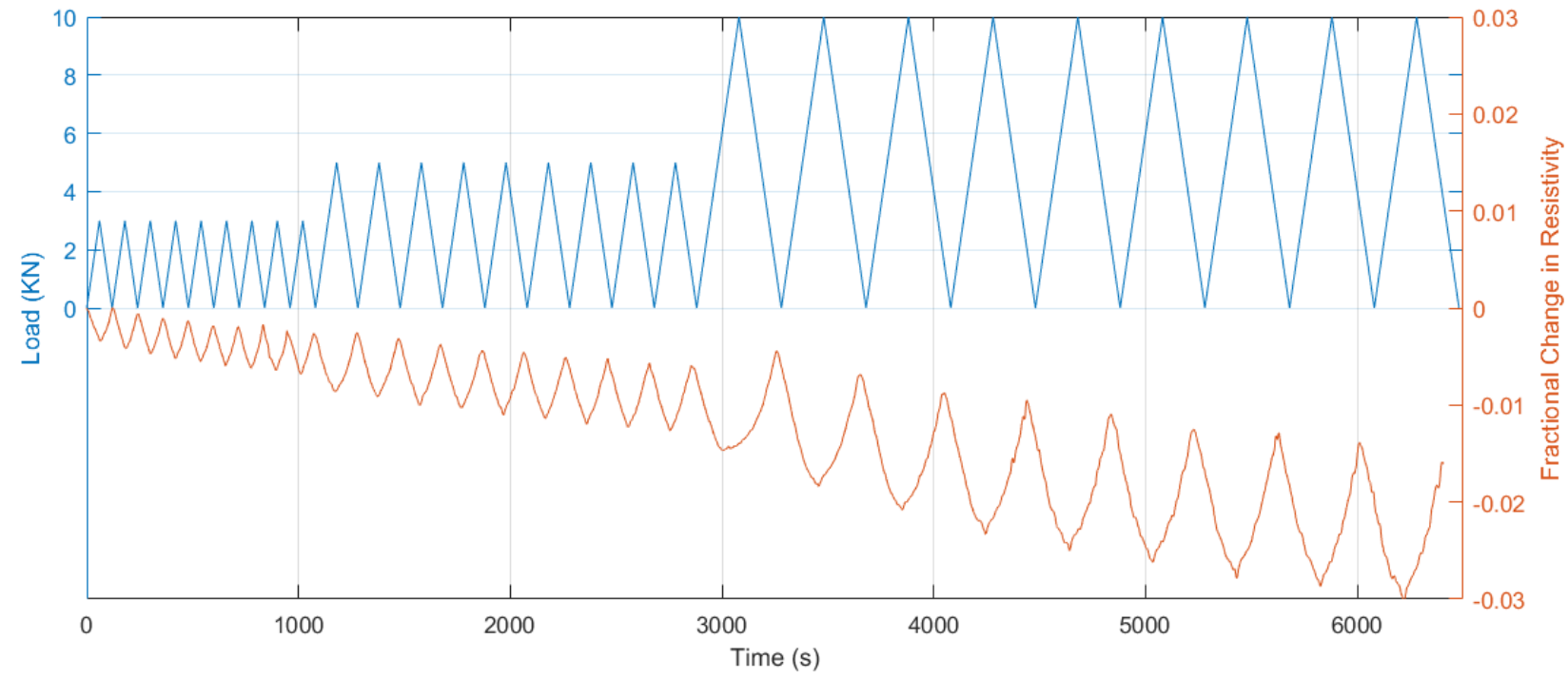

(a)

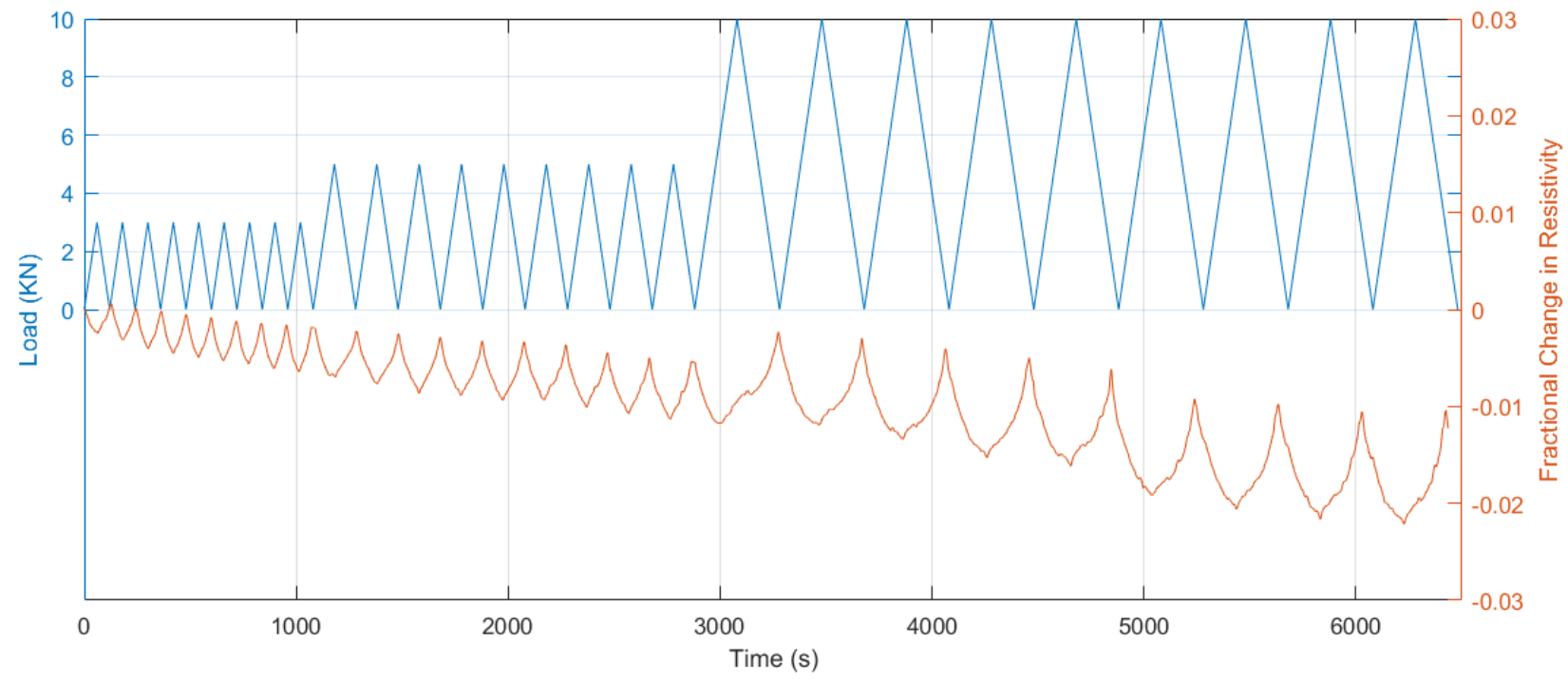

(b) 


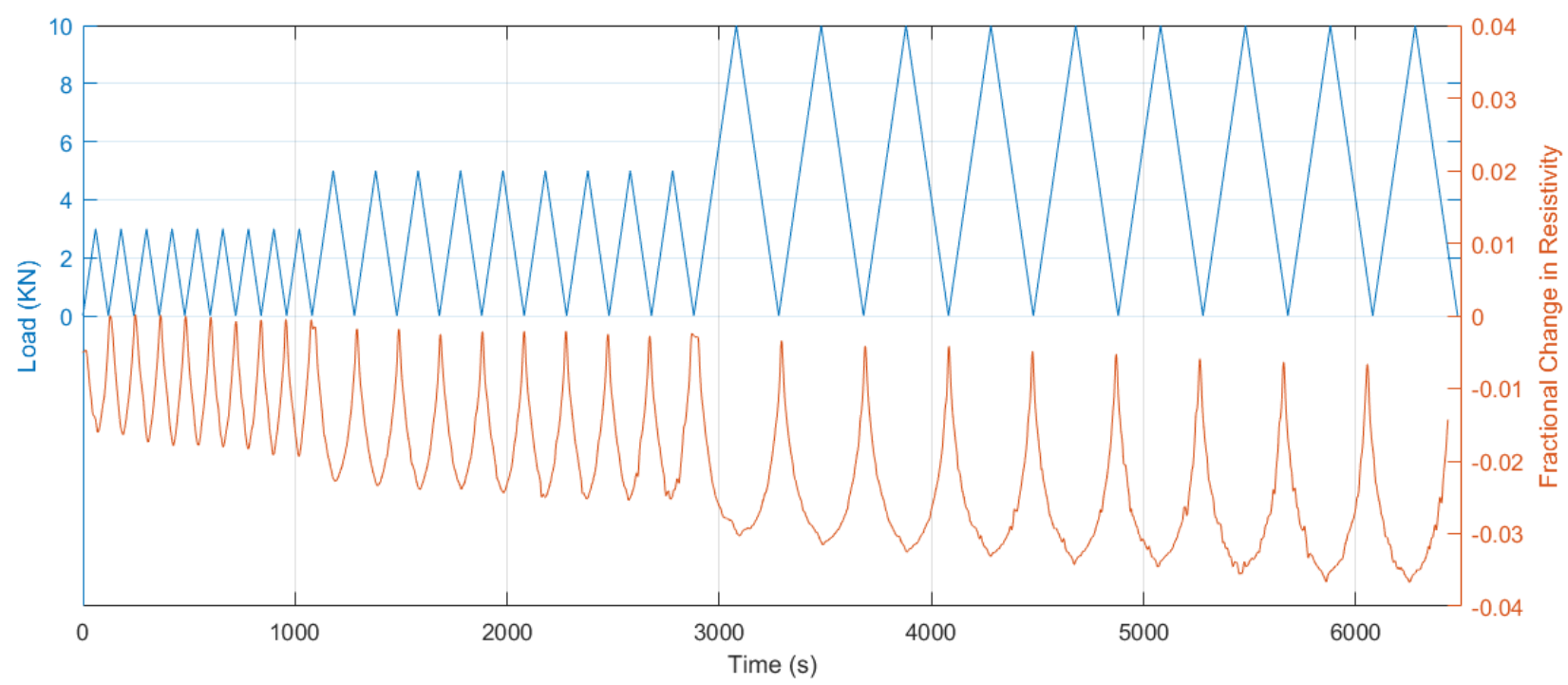

(c)

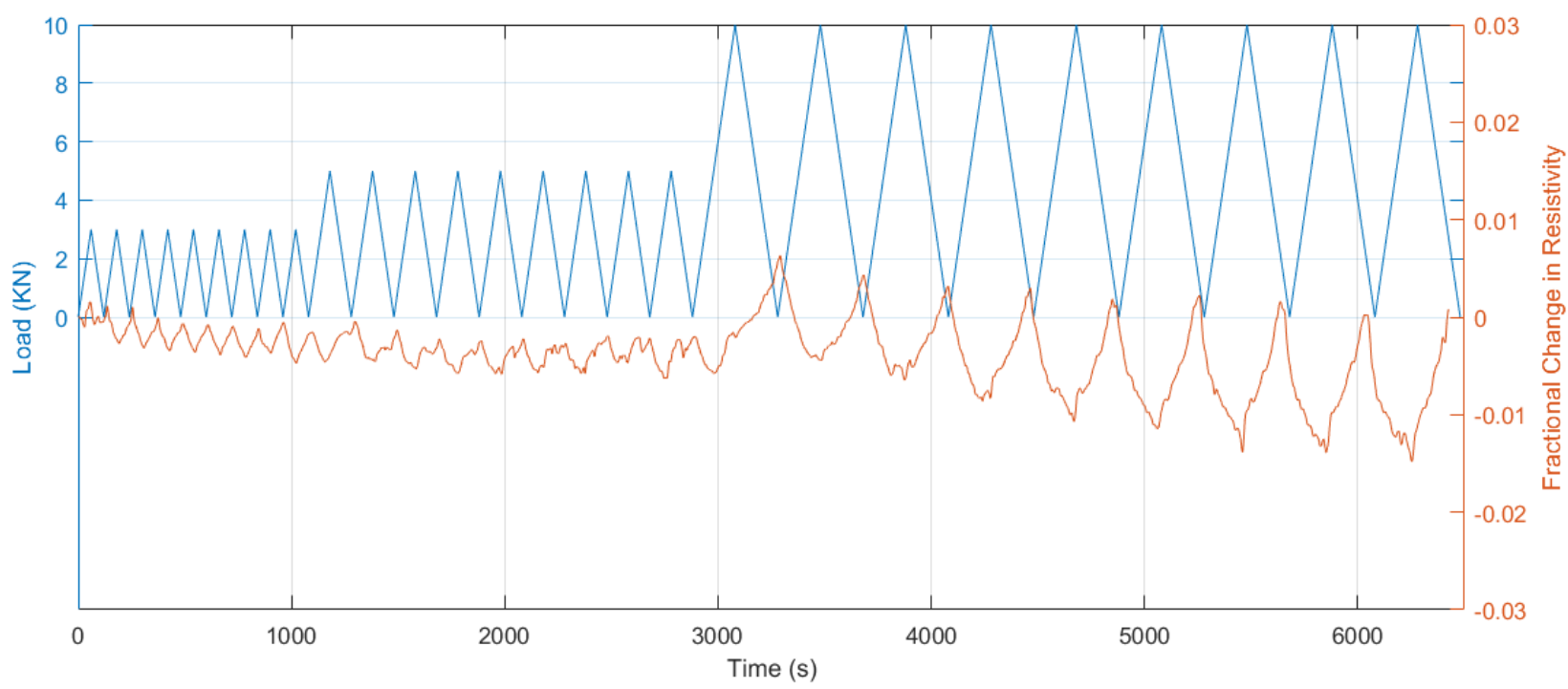

(d)

Figure 30.Cyclic compression response of specimens with 10\% GNPs cast using (a) Method I; (b) Method II; (c) Method III and (d) Method III with Fly Ash. 


\section{7. Gage Factor}

Figure 31 shows the variation of the strain and the fractional change in resistivity with time for specimens with $7.5 \%$ GNPs cast using all methods, while Figure 32 illustrates the fractional change in resistivity versus strain and the linear regression of this relationship. The fractional change in resistivity can be calculated using the equation:

$$
\Delta R / R=S \varepsilon
$$

where $S$ is the gage factor. With a larger gage factor, a very small change in strain can induce a great change in fractional change in resistivity, which makes the specimen be more sensitive to the strain changes.

The gage factor of specimens cast using Method III (125.29) was much higher than those of specimens cast using other two other methods and the specimens using Method III with fly ash (48.94). The gage factor of specimens cast using Method I (64.50) and II (69.59) were similar. The specimen cast using Method III with fly ash has the lowest gage factor. So, the specimens cast using Method III are more sensitive to strain changes compared to other specimens. 


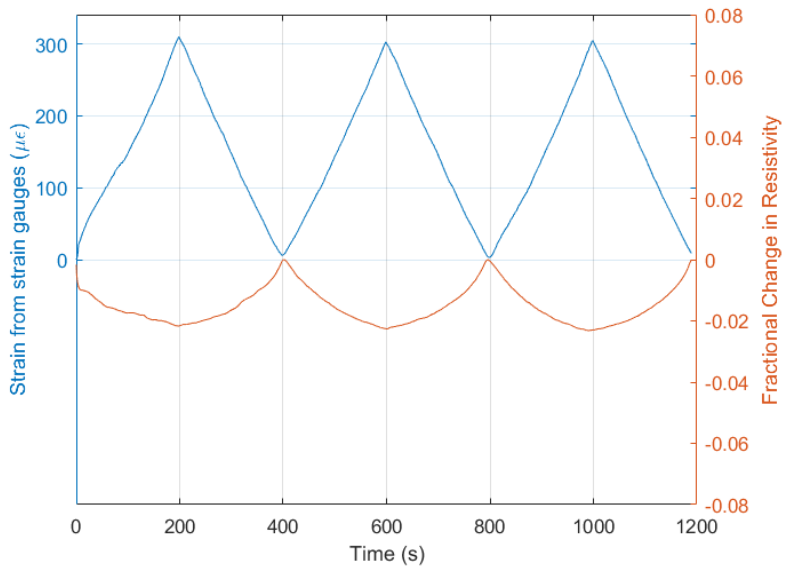

(a)

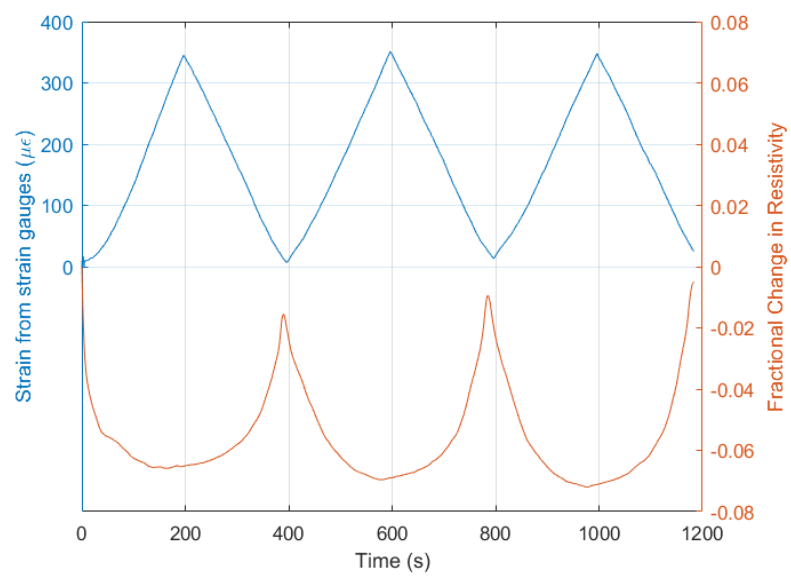

(d)

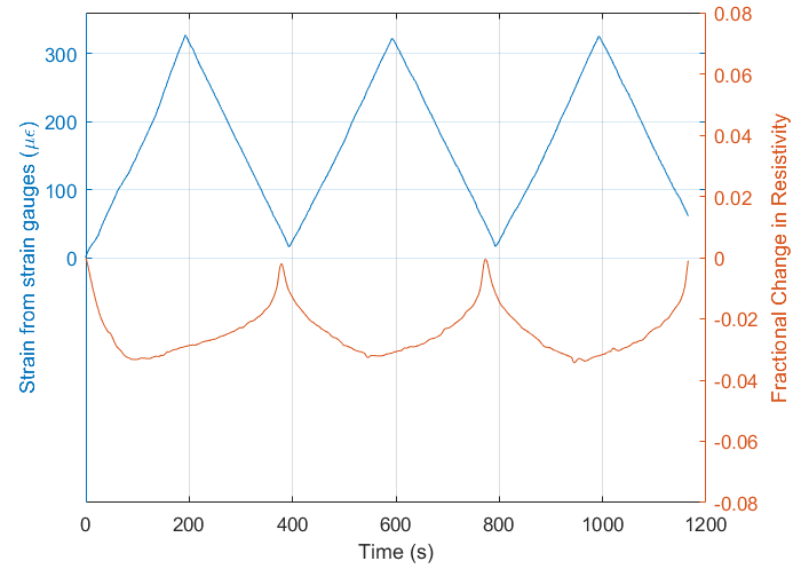

(b)

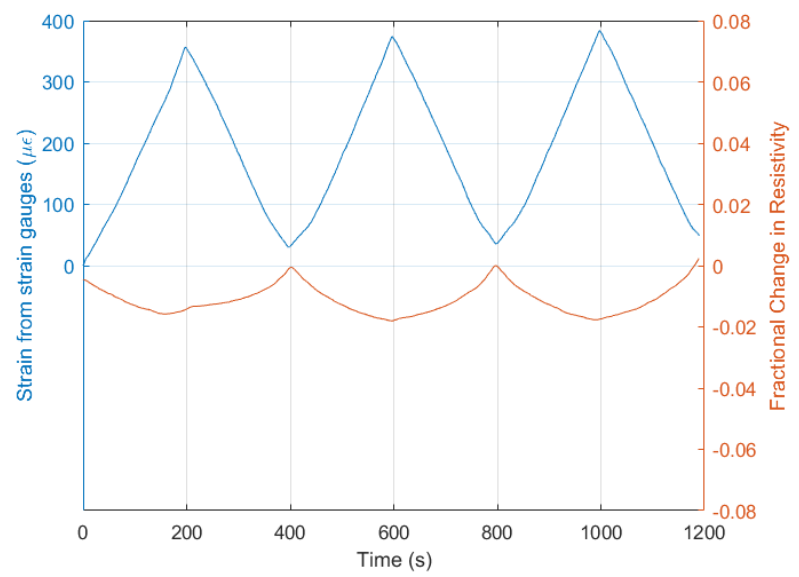

(c)

Figure 31. Strain and fractional change in resistivity of specimens with $7.5 \%$ GNPs cast using (a) Method I; (b) Method II; (c) Method III; (d) Method III with fly ash. 


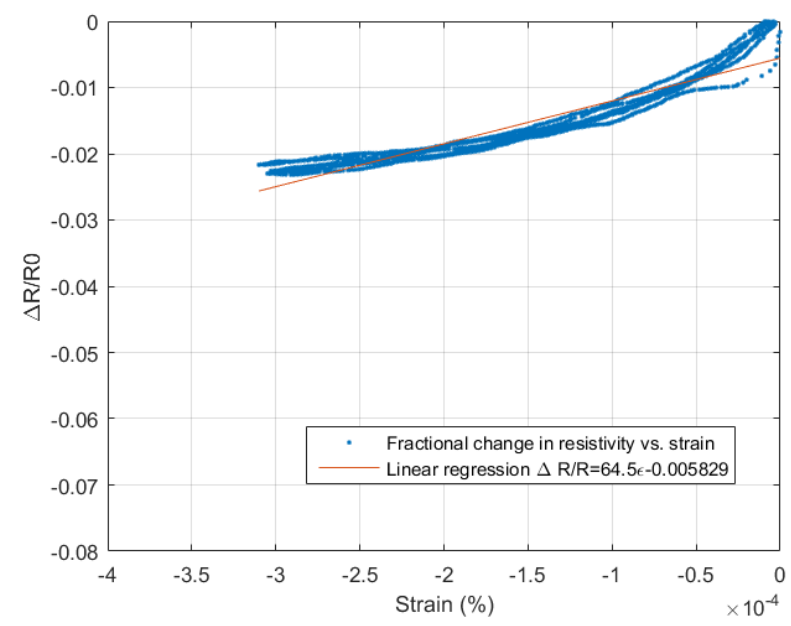

(a)

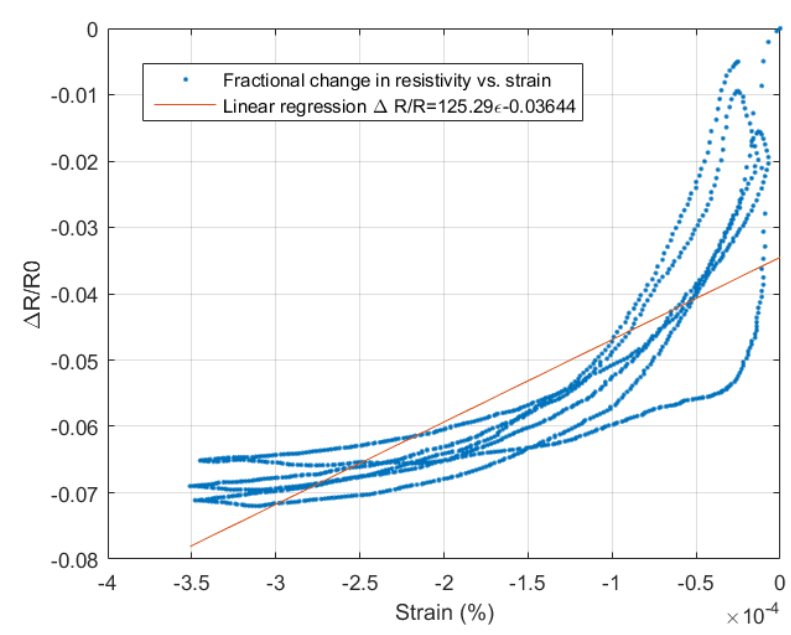

(c)

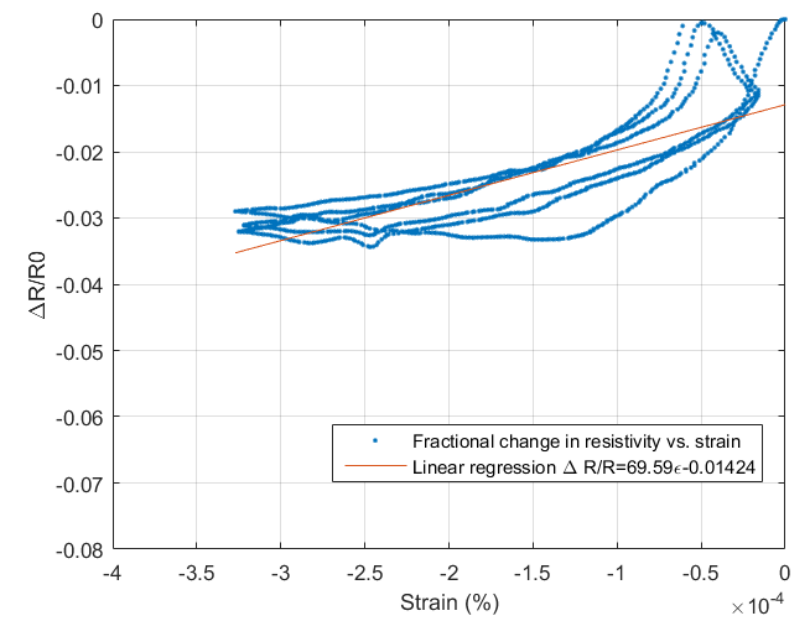

(b)

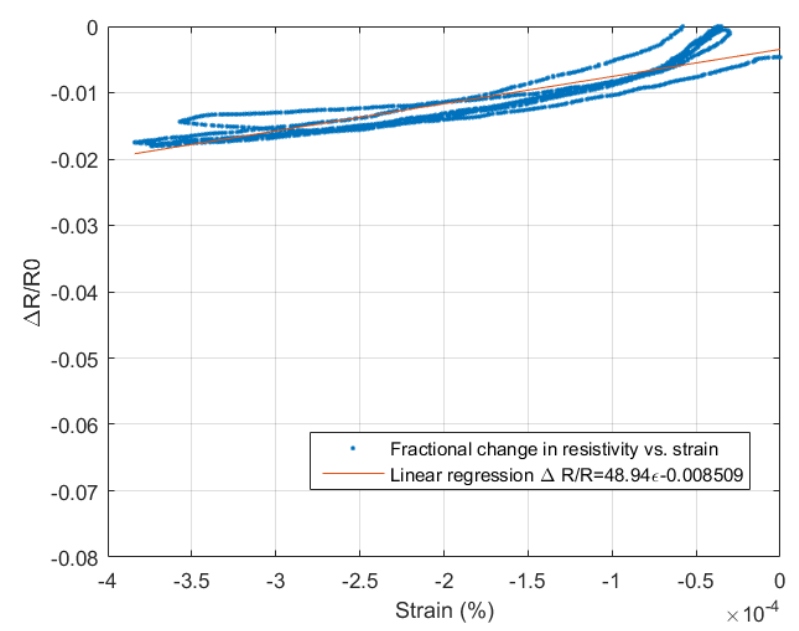

(d)

Figure 32. Fractional change in resistivity vs. strain of the specimens with $7.5 \%$ GNPs cast using (a) Method I; (b) Method II; (c) Method III; (d) Method III with fly ash.

Figure 33 shows the variation of the strain and the fractional change in resistivity with the time for specimens with 10\% GNPs cast using all methods, while Figure 34 illustrates the fractional change in resistivity versus strain and the linear regression of this relationship. The gage factor of specimens cast by Method III was again the larger than those measured for the other specimens, which indicates that it was more sensitive to strain changes.

Table 7 summarizes the gage factor of specimens with different GNP concentrations. It can be seen that the gage factor of specimens with $10 \%$ GNPs were smaller than the one with 
7.5\% GNPs, which indicates that the specimen with 7.5\% were more sensitive to strain changes. This might be due to large amount of superplasticizer used in specimens with $10 \%$ GNPs and not effective dispersion of GNPs at $10 \%$ concentration ratio.

In addition, comparing Figure 32 and Figure 34, it can be said that linear regression is not very suitable to relate the strain and change in resistivity for the specimen cast using Method III. Other type of regression or two separate linear regressions can be applied to more accurately calculate gage factor.

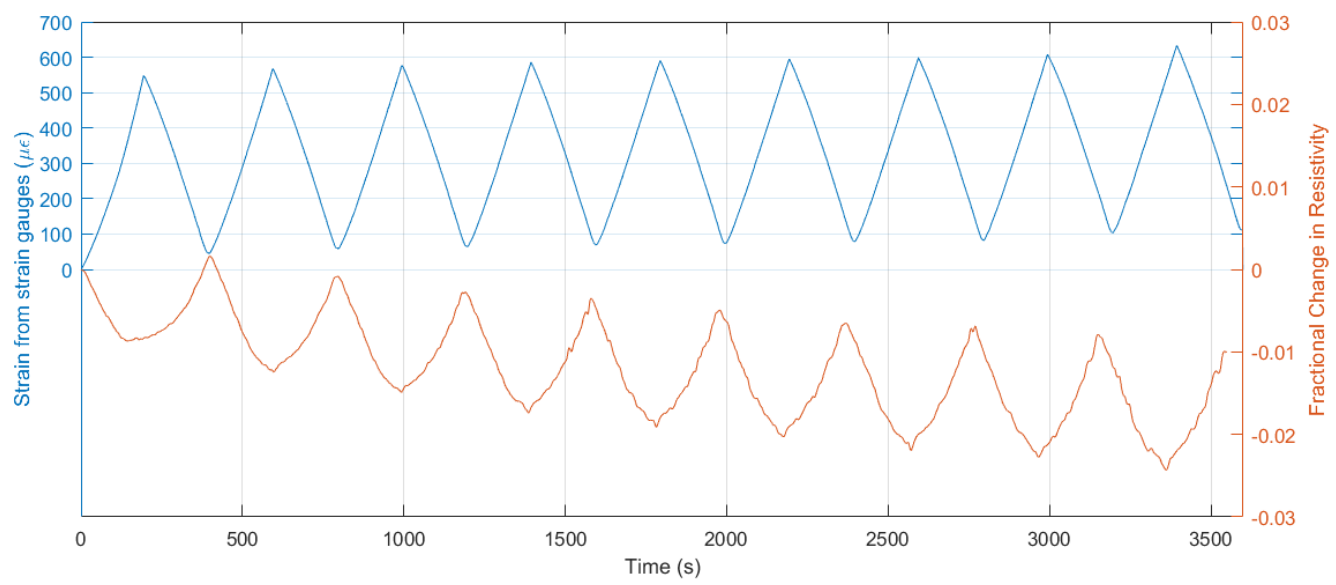

(a)

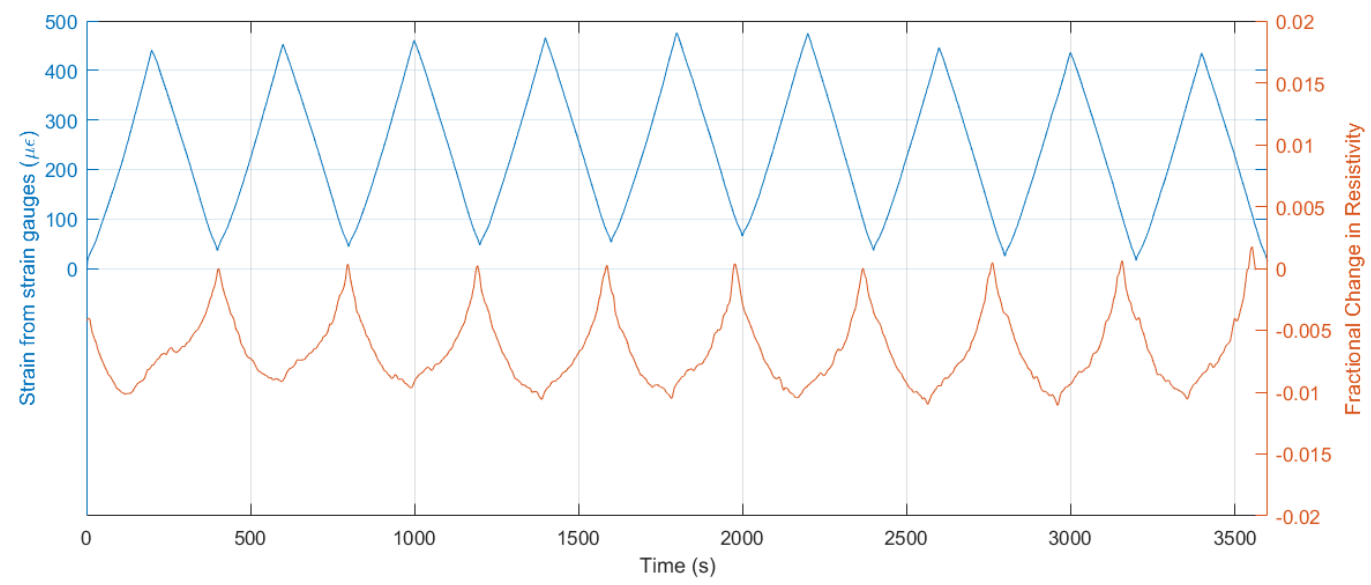

(b) 


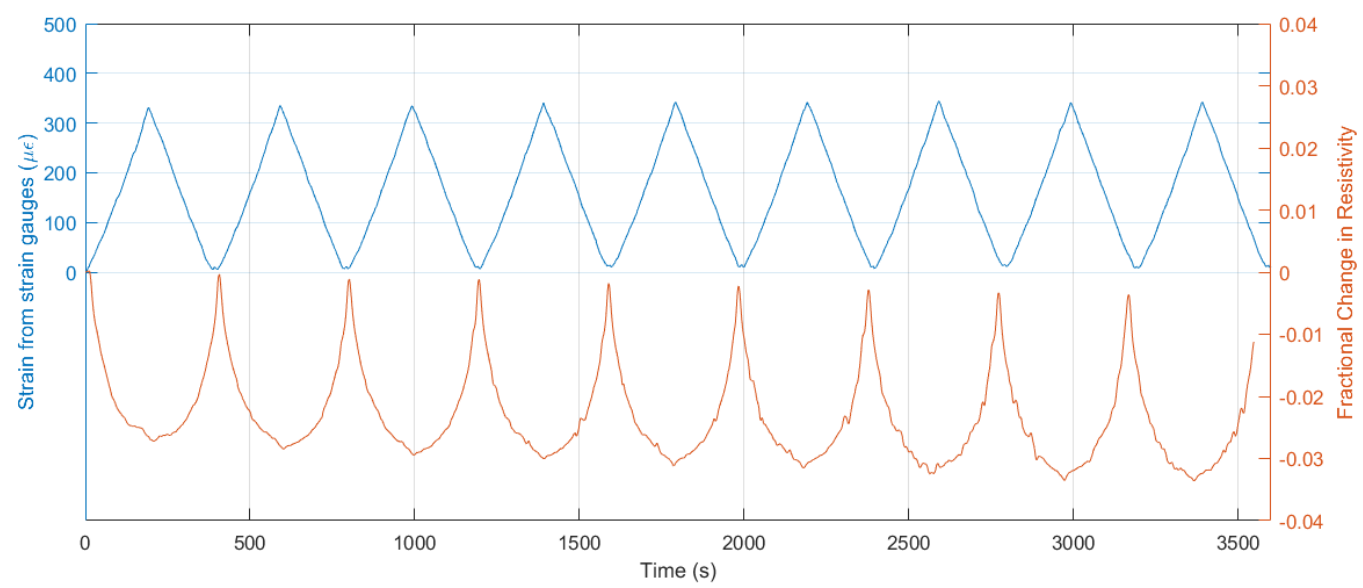

(c)

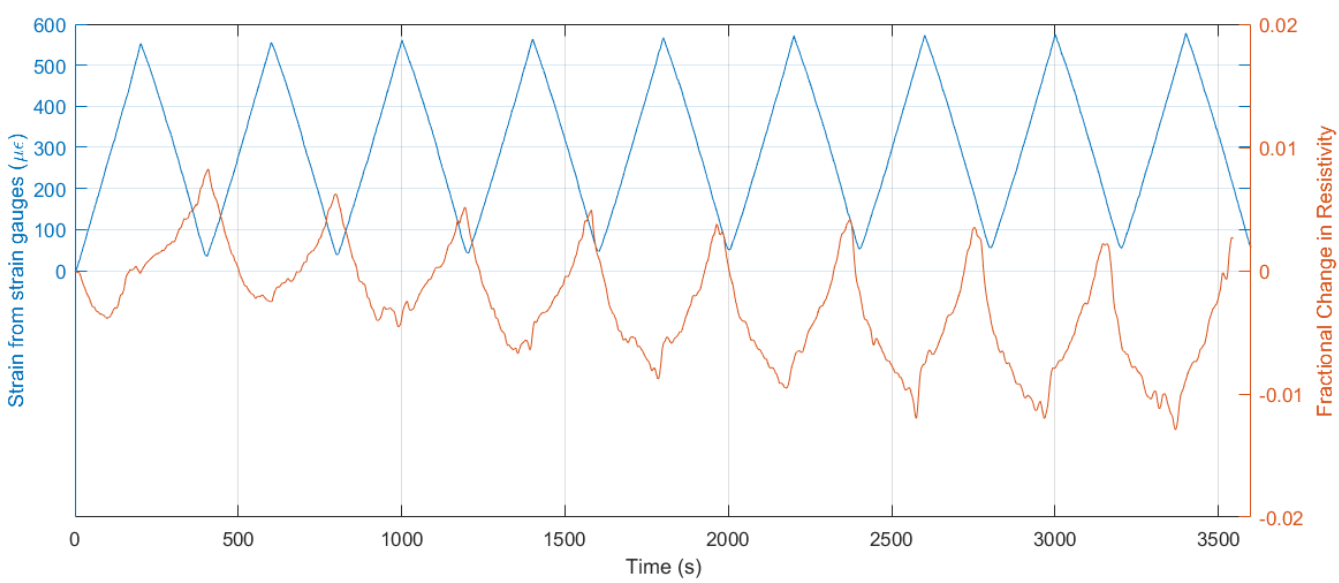

(d)

Figure 33. Strain and fractional change in resistivity of specimens with $10 \%$ GNPs cast using (a) Method I; (b) Method II; (c) Method III; (d) Method III with fly ash. 


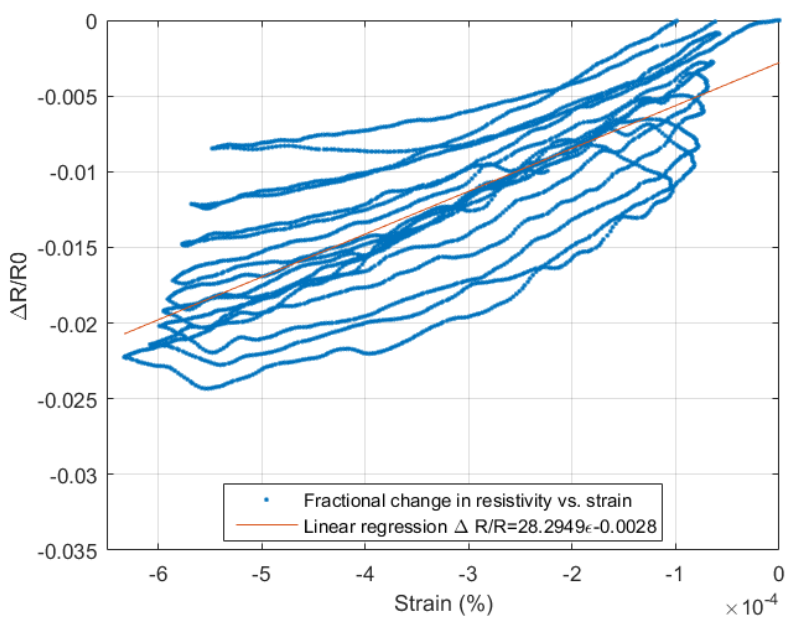

(a)

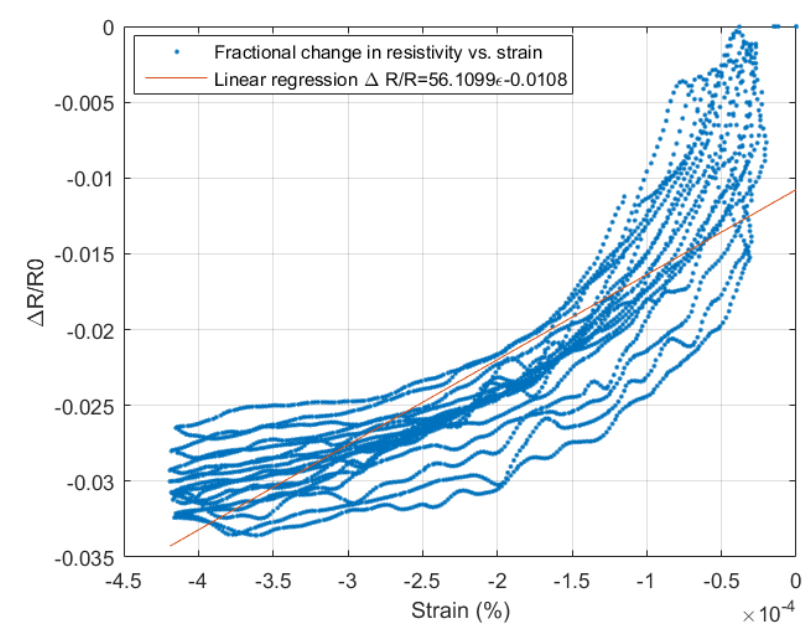

(c)

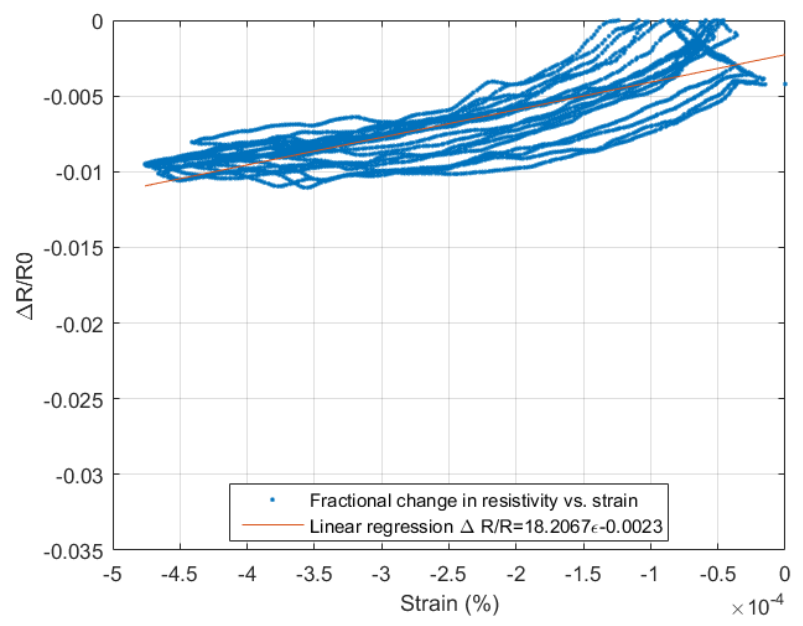

(b)

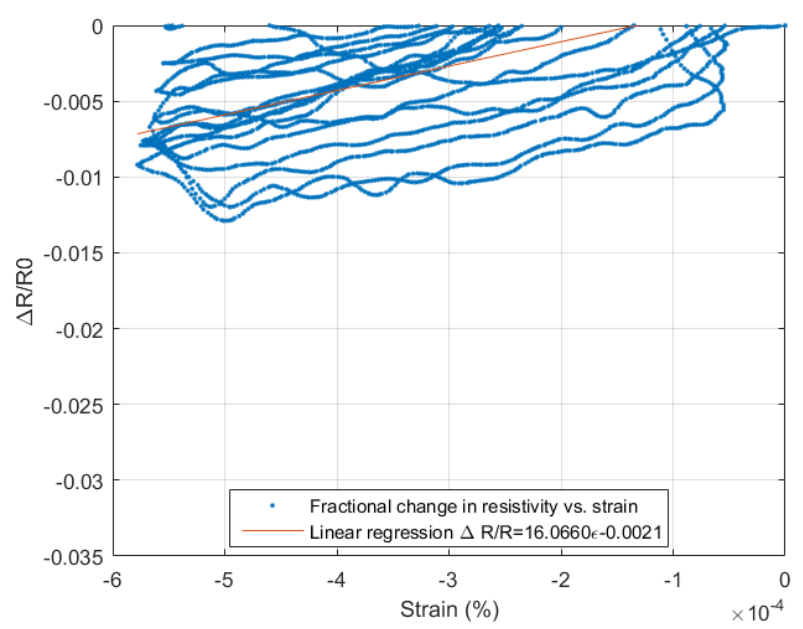

(d)

Figure 34. Fractional change in resistivity vs. strain of the specimens with $10 \%$ GNPs cast using (a) Method I; (b) Method II; (c) Method III; (d) Method III with fly ash.

Table 7. Gage factor of specimens with different concentrations prepared by different mixing methods

\begin{tabular}{ccc}
\hline Mixing method & GNP\% & Gage factor \\
\hline Method I & 7.5 & 64.5 \\
Method II & 10 & 28.29 \\
& 7.5 & 69.59 \\
Method III & 10 & 18.21 \\
& 7.5 & 125.29 \\
Method III with Fly Ash & 10 & 56.11 \\
& 7.5 & 48.94 \\
\hline
\end{tabular}




\section{8. Nonlinear Regression for Analysis}

A nonlinear regression model was also used for the analysis of the relationship between fractional change in resistivity and strain. Figure 35 and Figure 36 show the variation of the strain and the fractional change in resistivity with time for specimens with $7.5 \%$ and $10 \%$ GNPs cast using all methods. The correlation between the FCR and strain obtained from nonlinear regression was also shown in each figure. As can be seen from the figures, the nonlinear regression model fits the data much better. Using the equations obtained from the nonlinear regression, the measured FCR can be used to calculate the strain response.

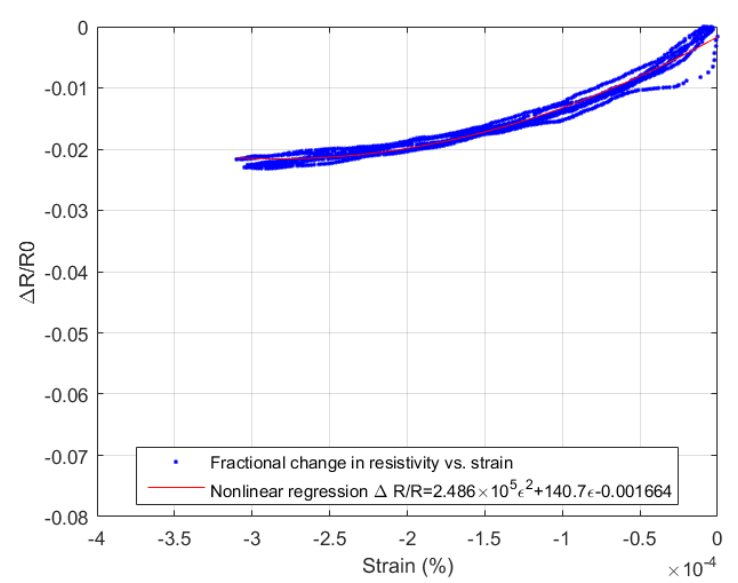

(a)

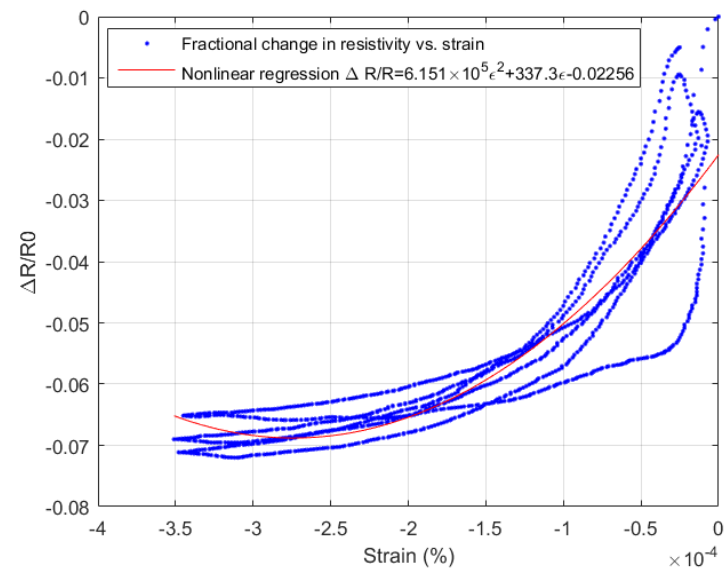

(c)

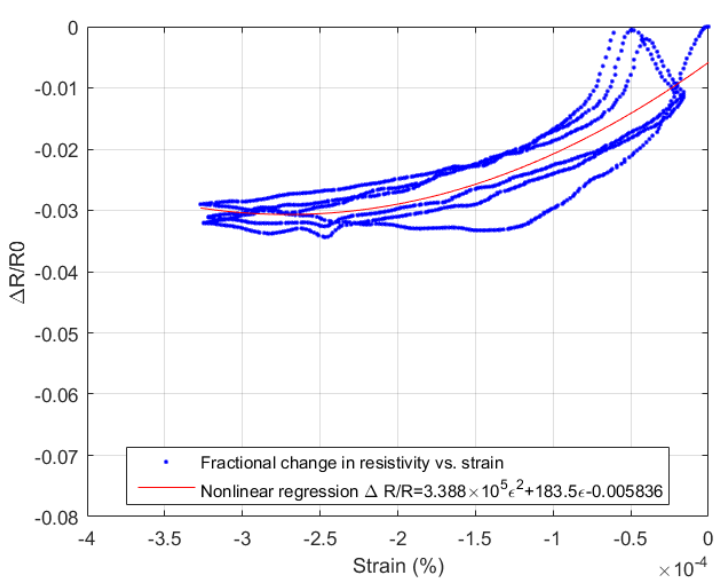

(b)

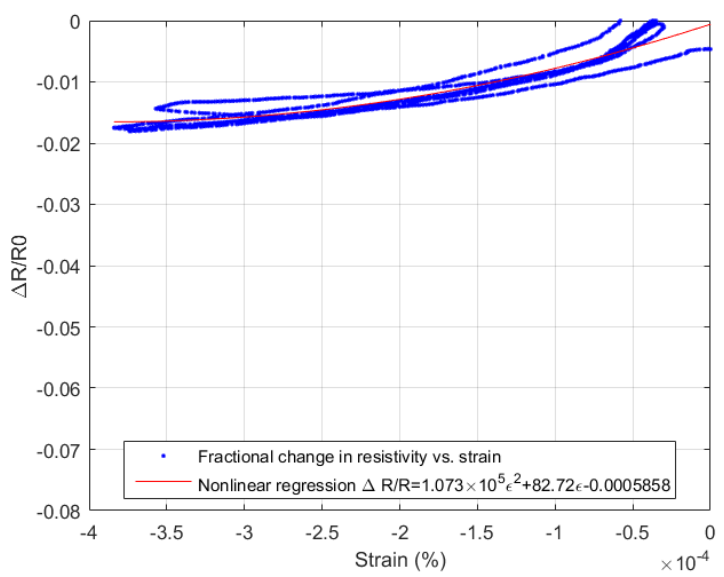

(d)

Figure 35. Fractional change in resistivity vs. strain and FCR-strain correlation of the specimens with 7.5\% GNPs cast using (a) Method I; (b) Method II; (c) Method III; (d) Method III with fly ash. 


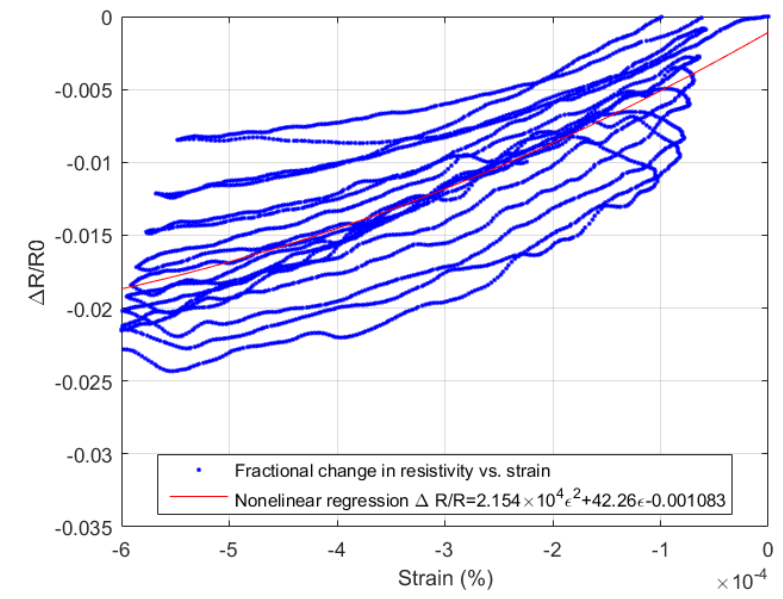

(a)

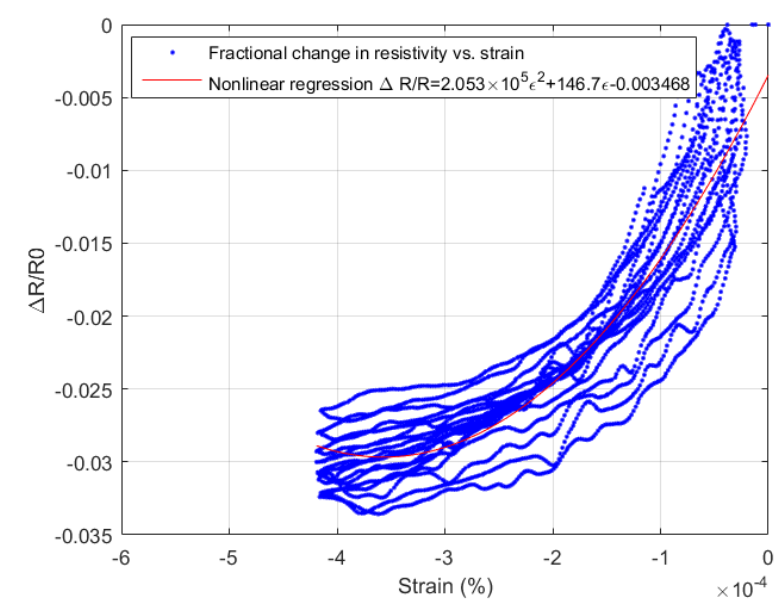

(c)

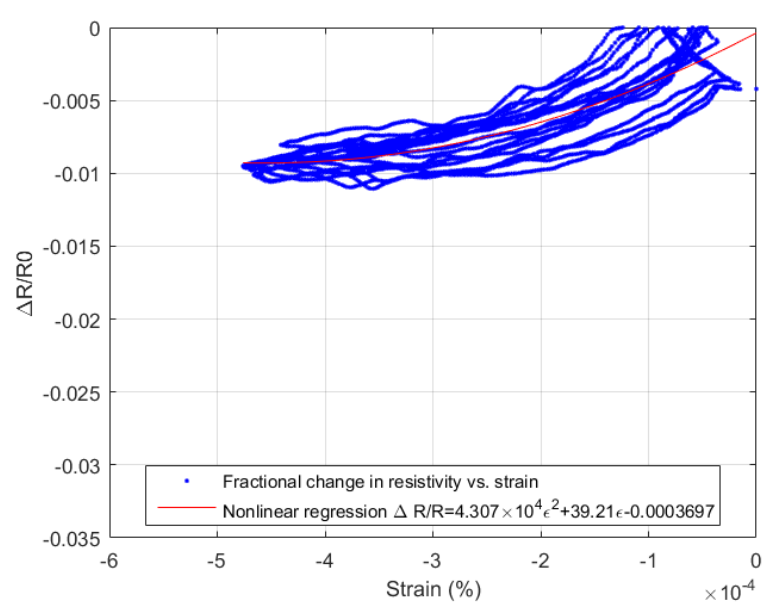

(b)

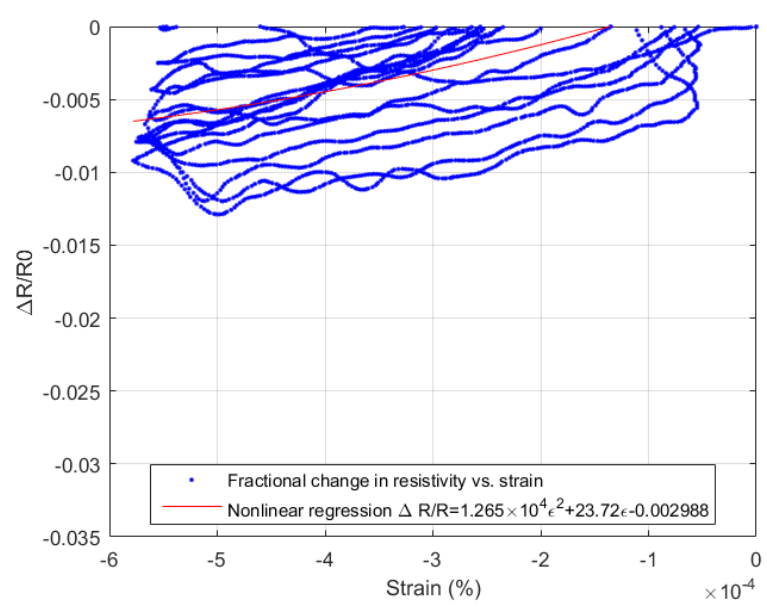

(d)

Figure 36. Fractional change in resistivity vs. strain and FCR-strain correlation of the specimens with 10\% GNPs cast using (a) Method I; (b) Method II; (c) Method III; (d) Method III with fly ash. 


\section{Conclusions}

In this study, the development of self-sensing GNP-reinforced cement composites using a simple fabrication method that does not require special treating procedures such as ultrasonication and chemical (covalent) treatments for the dispersion of GNPs was investigated. The effects of GNP concentration, mixing method, different dispersant and measurement method on the electrical resistivity of GNP reinforced cementitious composites were investigated. In addition, the influence of fly ash on the electrical properties of the GNP-reinforced mortar specimens was assessed. The GNPs used in this study had an average thickness of 8 nanometers and a diameter of 25 microns. Standard prismatic mortar specimens were prepared using three different mixing procedures. The bulk resistivity of the specimens was measured using a fourpoint probe method. The piezoresistive response of GNP-reinforced cement composites was evaluated under cyclic compressive loads. The effect of GNP concentration on the compressive strength of mortar specimens was also studied.

The findings of this study can be summarized as follows:

- The resistivity of specimens increased with the increasing curing age although the rate of increase for each batch was different. A marked decrease in the resistivity was observed at $7.5 \%$ GNP concentration for all the specimens, which implies that the percolation threshold might be around that concentration ratio. Note that $7.5 \%$ by weight of cement equals to $1.1 \%$ by volume of cementitious materials. This ratio is larger than the volume fraction predicted by an analytical expression, which indicates that the prediction equation underestimates the percolation threshold of GNPs.

- Although the resistivity measurements for the specimens prepared with each of three mixing methods were highly affected by the amount of GNPs and the curing age, all 
mixing methods were effective in producing a conductive mixture at $7.5 \%$ GNP concentration ratio, including the specimens with fly ash. The resistivity values of specimens cast using three different mixing methods were very similar when the GNP concentration exceeded the percolation threshold.

- The specimens prepared by Method III produced similar response as the specimens cast using Method I, which involves ultrasonication. The GNP-reinforced mortar specimens exhibited good piezoresistive behavior under cyclic compressive loads when the GNP ratios exceed 5\%.

- Though different resistance measurement would obtain different values of resistance, the trend of resistivity changes at different concentrations of GNPs were the same. Especially for copper tapes and copper meshes to serve as probes, the values were similar.

- The resistivity of most of the specimens containing 5\% and 7.5\% GNPs decreased after every compression cycle completed might be due to the more connections of conductive areas that formed inside the specimens. The results of cyclic compression test of specimens with $10 \%$ GNPs showed the similar results as the specimens with $5 \%$ and $7.5 \%$. GNPs.

- The DC power supply used in this study for the resistivity measurements led to an electrical polarization effect. This effect can be minimized by charging the specimens for four hours, especially in Method III and Method III with fly ash. However, more study should be conducted to find the most appropriate time. 
- The specimens cast using Method III had the largest strain gage factor which indicated this specimen was more sensitive to strain changes. But the linear regression was not suitable for specimens in Method III.

- The compressive strength of specimens with GNPs decreased significantly. This might be due to the large dosage of superplasticizer used in the specimens and large quantities of tiny voids.

The results of this study suggest that the GNPs can serve as an efficient nanofiller to provide self-sensing capability to cementitious composites. The combination of shear-type mixing and use of polycarboxylate-based superplasticizer can help the GNP dispersion. However, more studies are needed to explore the optimum amount and type of superplasticizer to be used in these GNP-based self-sensing composites. The use of very high dosages of superplasticizer might affect the comprehensive strength of the mortars. 


\section{Future Work}

The use of GNPs in mortar composites can provide self-sensing ability to these materials. However, further studies are needed in the following areas to explore the performance of GNPbased mortar composites:

- The use of other types of polycarboxylate-based superplasticizer in the dispersion of GNPs should be investigated. The molecular structure of polycarboxylatebased superplasticizer consists of an adsorbing anionic backbone and non-ionic side chains and looks like a comb [32]. It has been shown that anionic surfactants can effectively disperse graphene in water [33], while non-inoic surfactant can successfully stabilize and disperse graphene in aqueous solutions [34]. Since the polycarboxylate-based superplasticizers have both anionic and non-inoic components, they can be an effective dispersant agent for GNPs. Typical components of polycarboxylate-based superplasticizers such as backbone chemistry, backbone length, number of side chains, and length of side chains can be designed to achieve specific goals. Further research is needed to determine the effectiveness of different polycarboxylate-based superplasticizers.

- The interfacial interaction between GNPs and the hydration products of cement such as calcium-silicate-hydrates (C-S-H) should be studied and improved. Even a homogenous dispersion is achieved using a non-covalent surface treatment with superplasticizers, a weak interfacial strength between the matrix and GNPs can limit the improvements in mechanical properties of composite.

- The compressive strength of specimens with $7.5 \%$ and 10\% GNPs was much lower than those of plain specimens. The use of too high dosage of superplasticizer might be the main reason for this decrease in the compressive strength. Further studies are needed to determine optimum amount of superplasticizer that can achieve both good dispersion of GNPs while preserving the mechanical strength.

- Since the DC electrical field leads to an electrical polarization which make the resistance measurement less accurate, the AC power supply should be used in the future. 
- The effect of GNPs with different surface area, thickness and diameter on the selfsensing properties of the mortar composites needs to be experimentally assessed. 


\section{REFERENCES}

[1] Chung D. D. L. (2002). "Electrical conduction behavior of cement-matrix composites." Journal of Materials Engineering and Performance, 11(2), 194-204.

[2] Chacko R. M., Banthia N., and Mufti A. A. (2007). "Carbon-fiber-reinforced cement-based sensors.” Canadian Journal of Civil Engineering, 34(3), 284-290.

[3] Han B., Ding S., and Yu X. (2015). "Intrinsic self-sensing concrete and structures: A review." Measurement, 59, 110-128.

[4] Galao O., Baeza F. J., Zornoza E., Garcés P. (2014). "Strain and damage sensing properties on multifunctional cement composites with CNF admixture." Cement and Concrete Composites, 46, 90-98.

[5] Wen S., and Chung D. D. L. (2001). "Carbon fiber-reinforced cement as a strain-sensing coating." Cement and Concrete Research, 31(4), 665-667.

[6] Chen B., and Liu J. (2008). "Damage in carbon fiber-reinforced concrete, monitored by both electrical resistance measurement and acoustic emission analysis." Construction and Building Materials, 22(11), 2196-2201.

[7] Xiao H., Li H., and Ou J. (2011). "Self-monitoring properties of concrete columns with embedded cement-based strain sensors." Journal of Intelligent Material Systems and Structures, 22(2), 191-200.

[8] Saafi M. (2009). "Wireless and embedded carbon nanotube networks for damage detection in concrete structures." Nanotechnology, 20(39), 395502.

[9] Azhari F., and Banthia N. (2012). "Cement-based sensors with carbon fibers and carbon nanotubes for piezoresistive sensing." Cement and Concrete Composites, 34(7), 866-873.

[10] D'Alessandro A., Rallini M., Ubertini F., Materazzi A. L., Kenny J. M., and Laflamme S. (2015). "A comparative study between carbon nanotubes and carbon nanofibers as nanoinclusions in self-sensing concrete." In Nanotechnology (IEEE-NANO), 2015 IEEE 15th International Conference on. IEEE, 698-701.

[11] Dusza J., Morgiel J., Duszová A., Kvetková L., Nosko M., Kun P., and Balázsi C. (2012). "Microstructure and fracture toughness of $\mathrm{Si}_{3} \mathrm{~N}_{4}+$ graphene platelet composites." Journal of the European Ceramic Society, 32(12), 3389-3397.

[12] Zohhadi N., Aich N., Matta F., Saleh N. B., and Ziehl P. (2015). "Graphene Nanoreinforcement for Cement Composites." In Nanotechnology in Construction. Springer International Publishing, 265-270. 
[13] Wotring E., Mondal P., and Marsh C. (2015). "Characterizing the Dispersion of Graphene Nanoplatelets in Water with Water Reducing Admixture." In Nanotechnology in Construction. Springer International Publishing, 141-148.

[14] Le J. L., Du H., and Dai Pang S. (2014). "Use of 2D Graphene Nanoplatelets (GNP) in cement composites for structural health evaluation." Composites Part B: Engineering, 67, $555-563$.

[15] Kenneth J. L., and Gonzalez J. (2015). "Cementitious Composites Engineered with Embedded Carbon Nanotube Thin Film for Enhanced Sensing Performance." $11^{\text {th }}$ International Conference on Damage Assessment of Structures, conference series $628(2015) 012042$.

[16] Dalla, P. T., Dassios, K. G., Tragazikis, I. K., Exarchos, D. A., \& Matikas, T. E. (2016). "Carbon nanotubes and nanofibers as strain and damage sensors for smart cement.” Materials Today Communications, 8, 196-204.

[17] Konsta-Gdoutos M. S., and Aza C. A. (2014). "Self sensing carbon nanotube (CNT) and nanofiber (CNF) cementitious composites for real time damage assessment in smart structures." Cementitious \& Concrete Composites. 53, 162-169.

[18] Alkhateb H., Al-Ostaz A., Cheng A. H. D., and Li X. (2013). "Materials genome for graphene-cement nanocomposites." Journal of Nanomechanics and Micromechanics, 3(3), $67-77$.

[19] Du H., and Dai Pang S. (2015). "Enhancement of barrier properties of cement mortar with graphene nanoplatelet." Cement and Concrete Research, 76, 10-19.

[20] Tong T., Fan Z., Liu Q., Wang S., and Yu Q. (2015). "Investigation of the Effects of Graphene on the Micro-and Macro-Properties of Cementitious Materials." In Structures Congress 2015. ASCE, 1314-1325.

[21] Fan, Z. (2014). "Investigation on properties of cementitious materials Reinforced by Graphene” (Doctoral dissertation, University of Pittsburgh).

[22] Khushnood, R. A. (2015). "High Performance Self-Compacting Cementitious Materials Using Nano/Micro Carbonaceous Inerts”(Doctoral dissertation, Politecnico di Torino).

[23] Huang, S. (2012). "Multifunctional graphite nanoplatelets (GNP) reinforced cementitious composites." National University of Singapore, Singapore (Dissertation for the Degree of Master of Engineering).

[24] Du, H., Quek, S. T., \& Pang, S. D. (2013, April). "Smart multifunctional cement mortar containing graphite nanoplatelet.” In Proc. SPIE (Vol. 8692, p. 869238).

[25] Abu Al-Rub R. K., Tyson B. M., Yazdanbakhsh A., and Grasley Z. (2011). "Mechanical properties of nanocomposite cement incorporating surface-treated and untreated carbon 
nanotubes and carbon nanofibers." Journal of Nanomechanics and Micromechanics, 2(1), 16

[26] Li G. Y., Wang P. M., Zhao X. (2007). "Pressure-sensitive properties and microstructure of carbon nanotube reinforced cement composite." Cement \& Concrete Composites, 29, 377382

[27] Han, B., Yu, X., \& Ou, J. (2014). "Self-sensing concrete in smart structures." Butterworth-Heinemann.

[28] XG Science http://xgsciences.com/products/graphene-nanoplatelets/

[29] Li, J., \& Kim, J. K. (2007). "Percolation threshold of conducting polymer composites containing 3D randomly distributed graphite nanoplatelets." Composites Science and Technology, 67(10), 2114-2120.

[30] Du H., and Dai Pang S. (2015). "Enhancement of barrier properties of cement mortar with graphene nanoplatelet." Cement and Concrete Research, 76, 10-19.

[31] Al-Dahawi, A., Öztürk, O., Emami, F., Yıldırım, G., \& Şahmaran, M. (2016). "Effect of mixing methods on the electrical properties of cementitious composites incorporating different carbon-based materials." Construction and Building Materials, 104, 160-168.

[32] Felekoğlu B. and Sarkkahya H. (2008). "Effect of chemical structure of polycarboxylatebased superplasticizers on workability retention of self-compacting concrete." Construction and Building Materials, 22(9), 1972-1980.

[33] Guardia L., Fernández-Merino M. J., Paredes J. I., Solis-Fernandez P., Villar-Rodil S., Martinez-Alonso A., and Tascón J. M. D. (2011). "High-throughput production of pristine graphene in an aqueous dispersion assisted by non-ionic surfactants." Carbon, 49(5), 16531662.

[34] Liu L., Gao B., Wu L., Sun Y., and Zhou Z. (2015). "Effects of surfactant type and concentration on graphene retention and transport in saturated porous media." Chemical Engineering Journal, 262, 1187-1191. 